University of Louisville

ThinkIR: The University of Louisville's Institutional Repository

Electronic Theses and Dissertations

$5-2018$

\title{
Inflammasome independent leukotriene-b4 production drives crystalline silica induced sterile inflammation.
}

Bindu Hegde

University of Louisville

Follow this and additional works at: https://ir.library.louisville.edu/etd

Part of the Medical Immunology Commons, and the Medical Microbiology Commons

\section{Recommended Citation}

Hegde, Bindu, "Inflammasome independent leukotriene-b4 production drives crystalline silica induced sterile inflammation." (2018). Electronic Theses and Dissertations. Paper 2946.

https://doi.org/10.18297/etd/2946

This Doctoral Dissertation is brought to you for free and open access by ThinkIR: The University of Louisville's Institutional Repository. It has been accepted for inclusion in Electronic Theses and Dissertations by an authorized administrator of ThinkIR: The University of Louisville's Institutional Repository. This title appears here courtesy of the author, who has retained all other copyrights. For more information, please contact thinkir@louisville.edu. 


\title{
INFLAMMASOME INDEPENDENT LEUKOTRIENE-B4 PRODUCTION DRIVES CRYSTALLINE SILICA-INDUCED STERILE INFLAMMATION
}

\author{
By \\ Bindu Hegde \\ A Dissertation Submitted to the Faculty of the School of Medicine of the University of \\ Louisville \\ in Partial Fulfillment of the Requirements \\ for the Degree of \\ Doctor of Philosophy in Microbiology and Immunology \\ Department of Microbiology and Immunology \\ University of Louisville \\ Louisville, Kentucky
}

May, 2018 
Copyright 2018 by Bindu Hegde

CAll rights reserved 



\title{
INFLAMMASOME INDEPENDENT LEUKOTRIENE-B4 PRODUCTION DRIVES CRYSTALLINE SILICA-INDUCED STERILE INFLAMMATION
}

By

\author{
Bindu Hegde \\ M.S. University of Louisville, 2014 \\ M.Sc. Manipal University, 2008
}

\begin{abstract}
A Dissertation Approved
on MaLFKM , 2018
\end{abstract}

by the following Dissertation Committee

Haribabu Bodduluri, Ph.D. (Dissertation Director)

Venkatakrishna Jala, Ph.D.

Matthew Lawrenz, Ph.D.

Jun Yan, M.D., Ph.D.

Huang-Ge Zhang, Ph.D. 


\section{ACKNOWLEDGEMENTS}

First and foremost, I would like to thank my mentor Dr. Haribabu Bodduluri for his mentorship and support during the course of my study. I am particularly grateful for his advice and useful criticisms that helped me become a better scientist.

I would like to thank Dr. Venkatakrishna Jala for his generous help and guidance throughout the study. I would also like to express my sincere gratitude to Dr. Matthew

Lawrenz, Dr. Jun Yan and Dr. Huang- Ge Zhang for their valuable suggestions and inputs. Your time and effort during the course of this dissertation is much appreciated. I also wish to thank Dr. Siliva Uriarte and her lab members for their assistance.

I would like to thank all the past and present members of the Bodduluri lab for making these five years memorable. Thank you for all your help and encouragement throughout the study. Special thanks to Dr. Shuchismita Satpathy for her assistance, and for paving the way for this study.

I am thankful for all my wonderful friends in Louisville who have been there for me through every struggle and success. I cannot imagine going through this journey without you people in my life. Finally, I would like to thank my family for their love and support, and for always motivating me to do my best. 


\title{
ABSTRACT \\ INFLAMMASOME INDEPENDENT LTB 4 PRODUCTION DRIVES CRYSTALLINE SILICA-INDUCED STERILE INFLAMMATION
}

\author{
Bindu Hegde
}

MaUFKप] 2018

Silicosis is an irreversible lung inflammatory disease caused by chronic exposure to crystalline silica (CS) and is one of the most prevalent occupational diseases worldwide. Lipid chemoattractant Leukotriene $B_{4}\left(L_{T B}\right)$ plays an important role in neutrophilic inflammation that drives silicosis and promotes lung cancer. Previous studies in our laboratory have demonstrated that CS-induced neutrophilic inflammation and lung tumor burden in K-ras ${ }^{\mathrm{LA} 1}$ mice is abrogated in the $\mathrm{LTB}_{4}$-receptor deficient mice. Another pathway whose importance is well studied in the progression of silicosis is the Nalp3 inflammasome pathway. Studies have shown inflammasome- dependent IL-1 $\beta$ to be important for the development of CS-induced pulmonary fibrosis.

In this study, we examined the cellular mechanisms involved in CS-induced inflammatory pathways. We demonstrate that phagocytosis of CS particles is essential for the production of $\mathrm{LTB}_{4}$ and IL-1 $\beta$ in macrophages, mast cells and neutrophils. CS uptake induced rapid formation of lipid bodies in the cytoplasm independent of inflammasome activation. The appearance of these lipid bodies correlated with $\mathrm{LTB}_{4}$ production in mouse bone marrow-derived macrophages. $\mathrm{LTB}_{4}$ synthesis enzymes 5- 
LO, FLAP and $\mathrm{LTA}_{4} \mathrm{H}$, co-localized within the lipid bodies suggesting that they are not merely storage vesicles but the sites of CS-induced $\mathrm{LTB}_{4}$ production. We coined the term "lipidosome" to define the functional unit of $\mathrm{LTB}_{4}$ synthesis in these lipid bodies. Our studies with bafilomycin-A1 and NLRP3 deficient mice, confirmed that $\mathrm{LTB}_{4}$ synthesis in the lipidosome is independent of inflammasome activation. siRNA knockdown and confocal microscopy studies revealed that lipidosome is closely associated with phagosome and their formation appeared to be seamlessly linked to the phagosome maturation pathway. GTPases Rab5c, Rab40c along with JNK1 are essential for lipidosome formation and $\mathrm{LTB}_{4}$ production. Additionally, activation of JNK pathway is necessary for both $\mathrm{LTB}_{4}$ and IL-1 $\beta$ production. BI-78D3, a JNK inhibitor, completely abrogated CS-induced neutrophilic inflammation in an in-vivo air pouch model. In conclusion, these results highlight an inflammasome independent and JNK activation dependent lipidosome pathway as a major regulator of $\mathrm{LTB}_{4}$ synthesis and CS-induced sterile inflammation. 
TABLE OF CONTENTS

CONTENTS

PAGE

ACKNOWLEDGEMENTS ............................................... iii

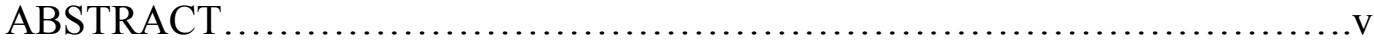

LIST OF TABLES...................................................

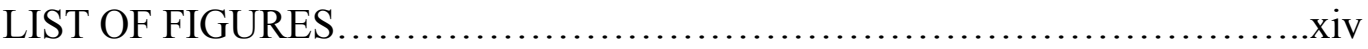

\section{CHAPTER I}

\section{BACKGROUND}

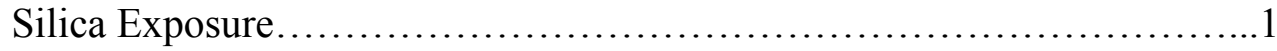

Pathophysiology of the development of silicosis....................... 3

Sterile Inflammation.........................................6

Cellular mediators of Silicosis...................................8

Macrophages............................................9

Mast Cells..................................................12

Neutrophils...........................................14

Leukotriene $\mathrm{B}_{4}$-synthesis and role in inflammatory diseases............15

Site of LT synthesis.......................................... 17

Eicosanoids in inflammatory diseases and cancer..................... 18

Current treatment for silicosis.................................... 19 
Silicosis and Lung Cancer.

Role of $\mathrm{LTB}_{4}$-dependent neutrophilic inflammation in silica-induced

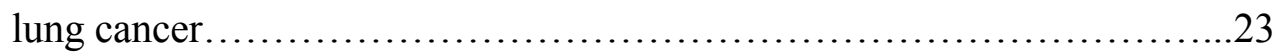

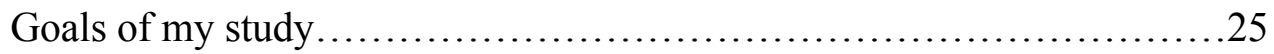

\section{CHAPTER II}

\section{MATERIALS AND METHODS}

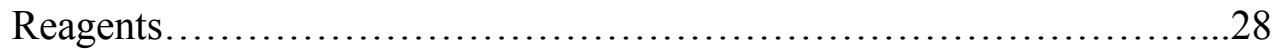

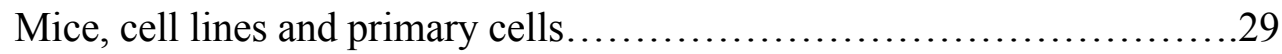

In-vitro stimulation assays........................................... 31

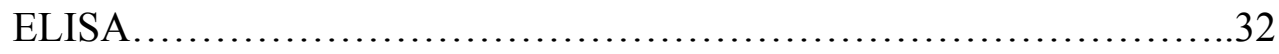

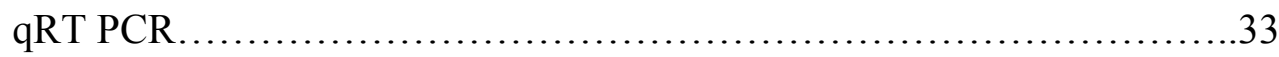

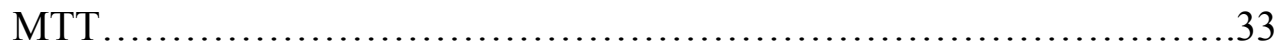

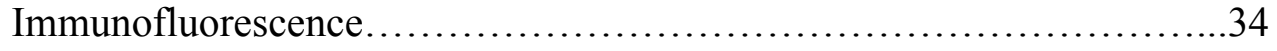

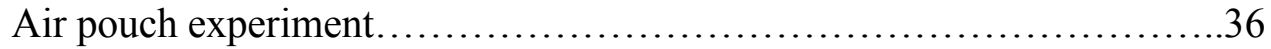

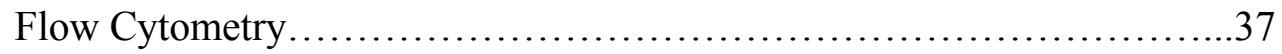

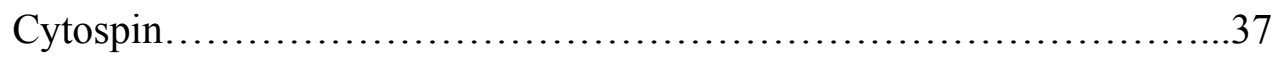

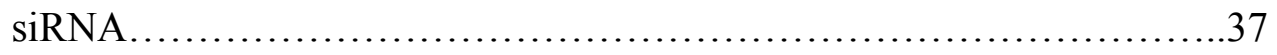

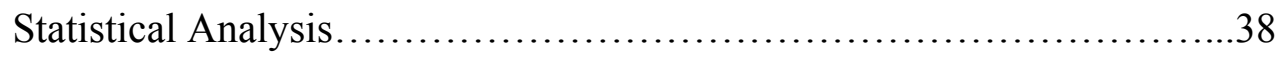

\section{CHAPTER III}

LTB $_{4}$ PRODUCTION IS INDEPENDENT OF INFLAMMASOME ACTIVATION

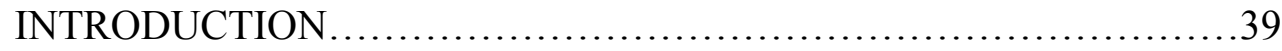

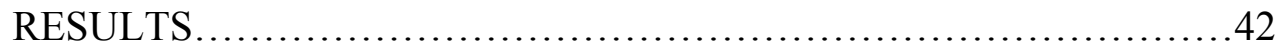

Phagocytosis is required for CS-induced $\mathrm{LTB}_{4}$ and IL- $1 \beta$ production......42 
Inhibition of phagolysosome formation enhances $\mathrm{LTB}_{4}$ production

$\mathrm{LTB}_{4}$ production is independent of inflammasome activation and IL-1 $\beta$ production............................................. 43

CS-induced lipid body formation is inflammasome independent..........44

Kinetics of lipid body and inflammasome activation....................45

A23187 induces $\mathrm{LTB}_{4}$ but not lipid body formation ...................45

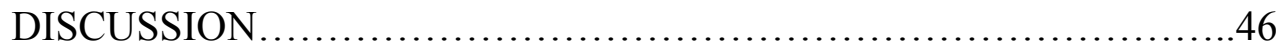

\section{CHAPTER IV}

CHARACTERIZATION OF LIPIDOSOME

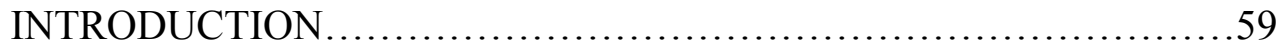

RESULTS ......................................................63

Lipid body is the primary site for CS-induced $\mathrm{LTB}_{4}$ production..........63

Lipid body is closely associated with phagosomes....................63

$\mathrm{LTB}_{4}$ production and lipid body formation with other

phagocytic particles.........................................63

Molecular mediators of CS-induced lipidosome formation

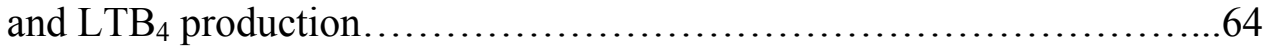

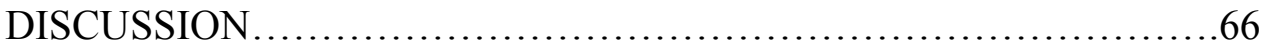

\section{CHAPTER V}

JNK ACTIVATION IS ESSENTIAL FOR CS-INDUCED LTB 4 AND IL-1 $\beta$ PRODUCTION

INTRODUCTION................................................. 79

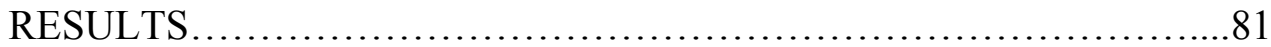


Activation of JNK pathway is essential for CS-induced $\mathrm{LTB}_{4}$ production..81 Activation of JNK pathway is essential for lipidosome formation........81 JNK signaling is required for CS-induced neutrophilic inflammation......82

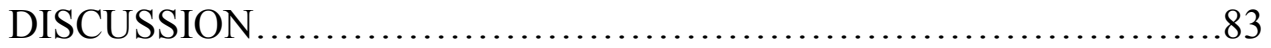

\section{CHAPTER VI}

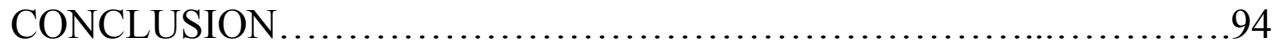

FUTURE DIRECTIONS........................................... 98

REFERENCES................................................... 101

APPENDIX ...................................................... 114

CURRICULUM VITAE ............................................117 


\section{LIST OF TABLES}

TABLE

PAGE

1. Inflammatory conditions cause by sterile particles.........................

2. Select siRNAs tested for their effects on lipidosome formation and $\mathrm{LTB}_{4}$

production....................................................... 75 


\section{LIST OF FIGURES}

FIGURES

PAGE

1. Prevalence of progressive massive fibrosis among underground-working coal miners from 1974-2015 in Kentucky, Virginia, and West Virginia.................................... .3

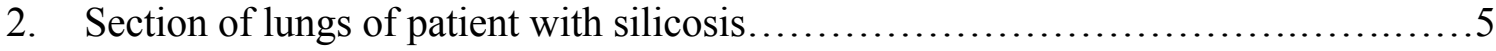

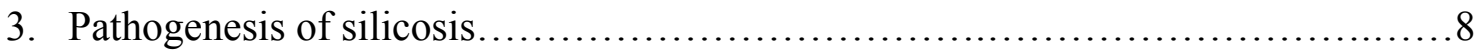

4. A schematic of inflammasome pathway...................................11

5. A schematic of Leukotriene $\mathrm{B}_{4}$ biosynthesis.............................. 16

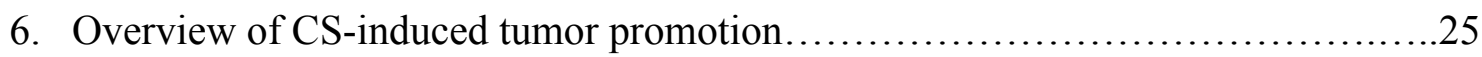

7. Phagocytosis is required for the production of CS-induced $\mathrm{LTB}_{4}$ and IL-1 $\beta$

production............................................................48

8. Inhibition of phagolysosome formation enhances $\mathrm{LTB}_{4}$ production..............50

9. $\mathrm{LTB}_{4}$ production is independent of inflammasome activation and IL-1 $\beta$

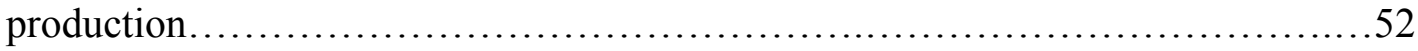

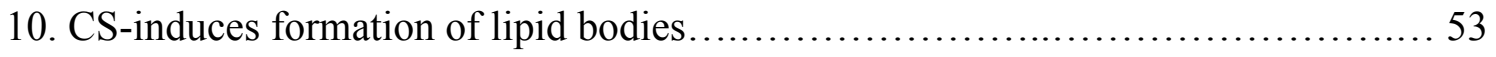

11. Kinetics of lipidosome and inflammasome activation.........................55

12. A23187 induces $\mathrm{LTB}_{4}$ production but not lipidosome activation.................. 57

13. CS-induced lipidosome formation is inflammasome independent.................58

14. CS-induced $\mathrm{LTB}_{4}$ production occurs in lipidosome............................69

15. Lipidosomes are closely associated with phagosomes........................... 71 
16. $\mathrm{LTB}_{4}$ production and lipidosome formation with other phagocytic particles.

17. Molecular mediators of CS-induced $\mathrm{LTB}_{4}$ production...........................74

18. Molecular mediators of CS-induced lipidosome formation.......................76

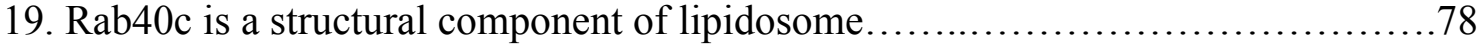

20. Activation of JNK pathway is essential for CS-induced $\mathrm{LTB}_{4}$ production...........86

21. Effect of BI-78D3 on CXC chemokine expression and cytotoxicity...............88

22. Activation of JNK pathway is essential for lipidosome formation.................90

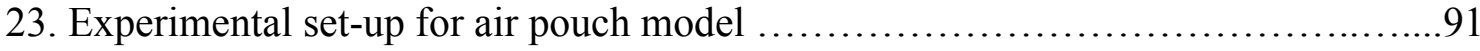

24. JNK signaling is required for CS-induced neutrophilic inflammation...............92

25. Graphical summary................................................. 97 


\section{CHAPTER I}

\section{BACKGROUND}

\section{Silica Exposure}

Silica or silicon dioxide is one of the most abundant elements on earth. Silica, also known as quartz or cristobalite exists in both crystalline and amorphous forms [1]. Occupational exposure to silica is a serious public health concern with millions of laborers working in mining, drilling, quarrying industries and construction sites continuously exposed to breathable silica particles [2-4].

Reports suggest that nearly 33 million workers in China and India, and around 2 million people in the U.S are occupationally exposed to crystalline silica (CS) $[5,6]$. In developing countries like China, India and Brazil, it remains a major problem especially in the low and middle-income groups. With the growth in industry and the lack of effective measures to control the dust, silicosis cases continue to rise in China [7]. 
Pneumoconiosis $^{1}$ is the most prevalent occupational disease in China and accounts for $90 \%$ of all work related illnesses. In 2013 alone, 23,152 new cases of pneumoconiosis were diagnosed, $35 \%$ of those were confirmed to be silicosis $(8,095$ cases) [8].

In developed countries like the United States, silicosis was a major problem during the depression era. There have been several reports of silica epidemics in the past. The most significant one occurred in 1930-31 during the construction of Gauley Bridge tunnel in West Virginia, where more than 400 of the estimated 2000 workers died of silicosis and almost all the survivors developed silicosis [9]. More recently, in 1996, 60 of the 1072 workers in an automotive factory developed silicosis. In the last few decades, deaths due to silicosis appear to have declined due to awareness on the adverse effects of silica and improved workplace protection. Recently, the Occupational Safety and Health Administration (OSHA) revised the permissible limits of silica exposure at construction sites from $250 \mu \mathrm{g} / \mathrm{cc}$ to $50 \mu \mathrm{g} / \mathrm{cc}$ over an $8 \mathrm{~h}$ period $[10,11]$. These new guidelines can have a huge impact on the 2.3 million workers employed in construction industries. When in effect, this policy could save 600 lives and prevent 900 new cases of silicosis every year $[10,11]$.

Pneumoconiosis in coal miners is known as the "black lung" disease. The Coal Act of 1969 created the National Institute for Occupational Safety and Health (NIOSH)

\footnotetext{
${ }^{1}$ Pneumoconiosis- Inflammation of the lungs caused by inhalation of coal dust, asbestos and
} 
for surveillance of coal dust exposure. The incidence of pneumoconiosis and progressive massive fibrosis (PMF) dropped to a historic low during 1990-99 with only of 31 cases reported. Although the overall incidence may appear to have decreased, this could be due a cluster of incidents undetected in the surveillance program, which was recently brought to attention by NIOSH. A higher number of miners are now seeking radiographs to obtain more information about their health, which has led to resurgence in the PMF cases (Fig. $1)$.

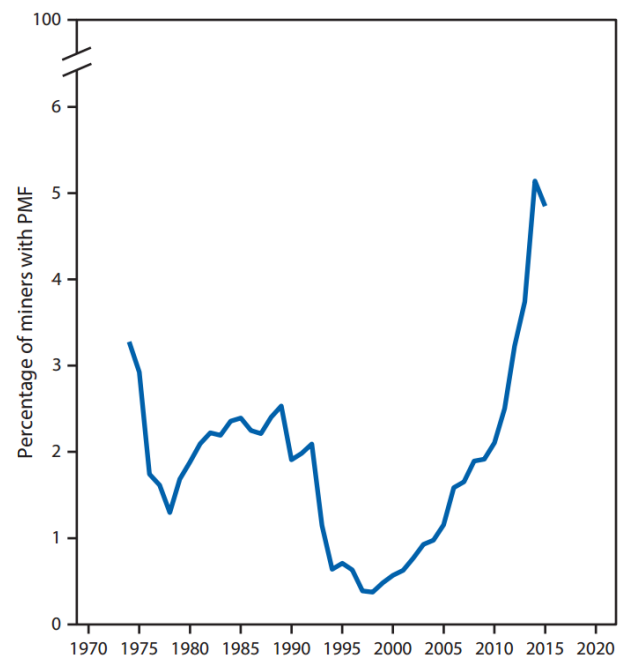

Figure 1. Prevalence of progressive massive fibrosis among underground-working coal miners from 1974-2015 in Kentucky, Virginia, and West Virginia [12].

\section{Pathophysiology of development of silicosis}

Silicosis is a chronic and irreversible inflammatory disease of the lungs caused due to silica exposure [13]. Silica particles less than $10 \mu \mathrm{m}$ in size are highly pathogenic 
as they can escape the mucociliary defense mechanism and reach the distal parts of the lungs $[2,14]$. Silicosis is a progressive, debilitating and often fatal lung disease. Exposure to silica can lead to other diseases such as lung fibrosis[15], chronic bronchitis[16], emphysema, increased susceptibility to tuberculosis [17], renal disorders[17] scleroderma [18], autoimmune diseases[18], and lung cancer [19-21].

Silicosis can be classified as chronic, accelerated, or acute based on the onset and rapidity of disease progression [22]. Chronic silicosis usually develops after 10-30 years of exposure to low concentrations of silica. This is the most common type. Acute and accelerated silicosis can take a few weeks to less than 10 years to develop and is caused by high doses of silica exposure. Silicosis is diagnosed with a combination of history of silica exposure, radiography, and CT scan [22, 23]. Pathologically, small round opacities (non-fibrogenic) are classified are simple silicosis whereas large opacities $>1 \mathrm{~cm}$ size are classified as pneumoconiosis. Simple silicosis may be mostly asymptomatic, except for the presence of cough, and shows minor decrease in lung vital capacity. Pneumoconiosis is associated with chronic cough, dyspnea, pulmonary edema and progressive massive fibrosis. In severe cases, upper lobules of the lungs show dense nodules with central collagenous deposition or lipoproteinaceous material filling the alveolar spaces (silicoproteinosis) [13, 14, 22-24]. Fig 2 shows the histopathology of lungs of chronic silicosis patient. 


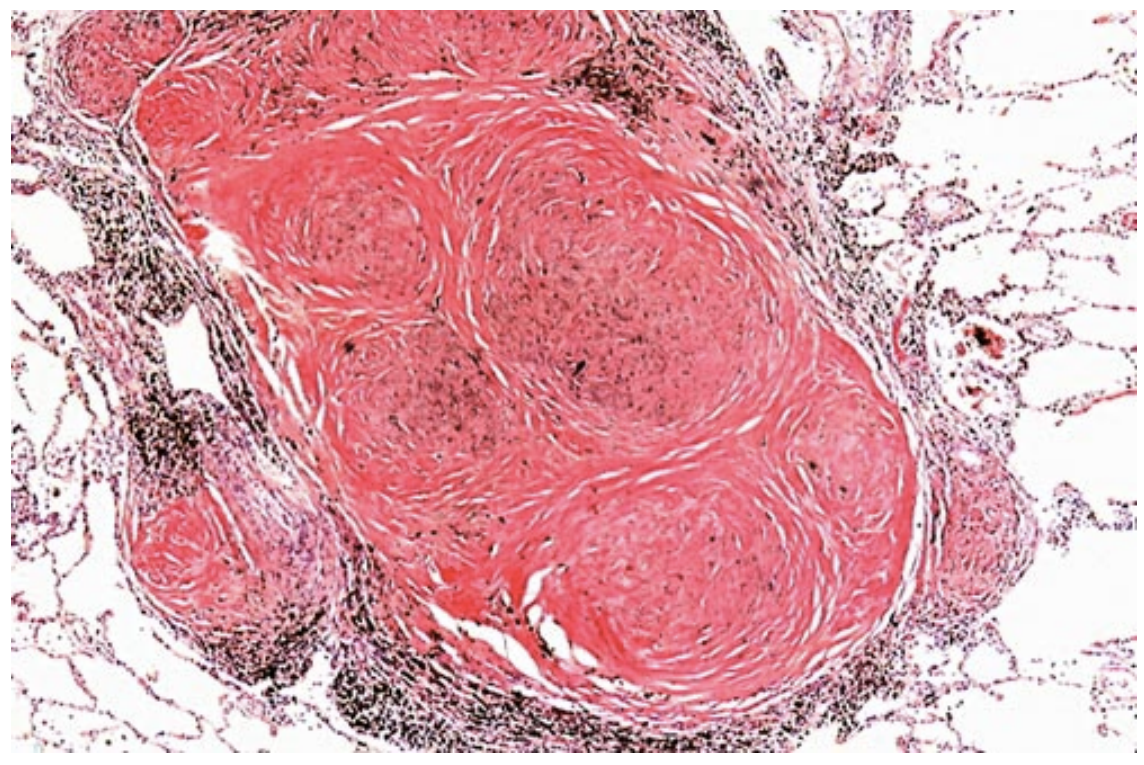

Figure 2. Section of lungs of a chronic silicosis patient, showing central dense nodule with concentric whorls collagen fibers surrounded by a peripheral zone of silica dustladen macrophages [25].

Evidence suggests that uncontrolled inflammation triggered by crystalline silica is responsible for the development of silicosis. Lung epithelial cells, fibroblasts, mast cells, and alveolar macrophages release an array of inflammatory mediators such as cytokines, neutrophil chemokines and reactive oxygen species (ROS) that contribute to the pathogenesis of the disease [26]. The mechanisms involved in the initiation of inflammation and its potential role in the pathogenesis of the disease are described here. 


\section{Sterile inflammation}

Inflammatory cells like neutrophils and macrophages are the first line of defense against invasive pathogens. These phagocytes engulf the pathogens and release proinflammatory mediators that are responsible for the recruitment and activation of the adaptive immune system. Other than the pathogens, a myriad of substances like crystals, minerals, toxins, chemicals, antigens and mechanical trauma can trigger inflammation [27, 28]. Inflammation triggered by non-infectious agents is known as "sterile inflammation". Both infectious and sterile inflammation have similar responses including the recruitment of neutrophils and macrophages, the production of inflammatory mediators and the induction of adaptive immune responses. The effector mechanisms adopted by these phagocytes to get rid of the pathogens are production of ROS, and degradation by proteases and acidic enzymes in the lysosomes [28]. The immune system is effective in clearing the infection rapidly; therefore, the tissue damage caused by these effector mechanisms is minimal. While these mechanisms might be useful in dealing with pathogens, they have the potential to cause more harm than good in case of sterile particulates. In the case of sterile inflammation, this could lead to chronic inflammation and significant tissue damage if the particles are not cleared. Due to this, sterile inflammation is the underlying cause for many inflammatory diseases [28]. Table

1 shows a list of sterile particles that can trigger inflammation along with the associated inflammatory disease. 


\begin{tabular}{lll}
\hline Sterile particles & Condition & Affected area \\
\hline Endogenous particles & & \\
Monosodium urate crystals (MSU) & Gout & Joints \\
Calcium pyrophosphate crystals & Acute arthritis & Joints \\
$\beta$-amyloid & Alzheimer's disease & Brain \\
Cholesterol crystals & Atherosclerosis & Arteries
\end{tabular}

\section{Exogenous particles}

Asbestos

Asbestosis

Lung

Silica

Silicosis

Lung

Table1. Inflammatory conditions caused by sterile particles

Once inhaled, silica particles persist in the system for a lifetime. Immune cells ingest the particles in an attempt to "digest" them. However, even the acid enzymes in the lysosomes are unable break it down. Eventually the phagocytes undergo apoptosis and the silica particles are released back into the system triggering a continuous cycle of phagocytosis and inflammation [29-31]. Unlike pathogen-induced cell death, which is helpful in containing the inflammation, sterile particle-induced cell death can induce an acute inflammatory response. Therefore, apoptotic cells and their debris themselves can play an important part in promoting the pathogenesis of the disease [32, 33]. Chronic 
inflammation is followed by a reparative phase marked by increased proliferation of mesenchymal cells and neovascularization [26]. In order to repair the injured tissue, collagens, fibronectins, and growth factors are released. Certain cytokines released by the inflammatory cells, such as IL-1 $\beta$, TGF $\beta$ and TNF- $\alpha$ are also fibrinogenic [34-36]. All these factors perpetuated by chronic inflammatory and reparative phases contribute to the formation of dense nodules that is responsible for respiratory failure in the lungs (Fig. 3).
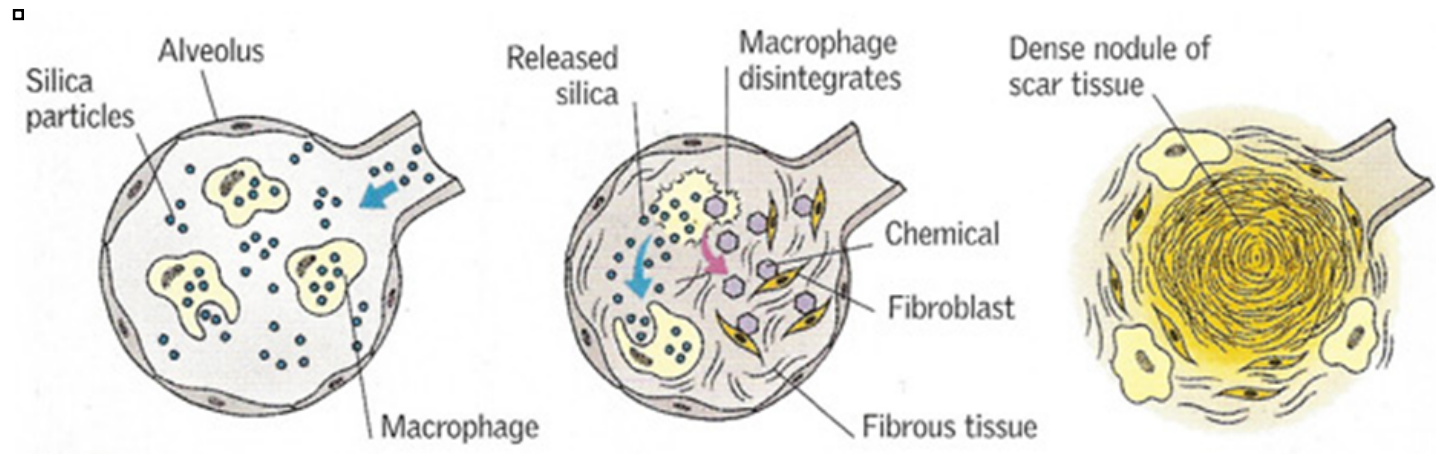

Figure 3. Pathogenesis of silicosis: phagocytes ingest inhaled silica dust, deposited in the alveoli. Phagocytes undergo apoptosis releasing silica particles, several pro-inflammatory and fibrogenic factors that result in fibrous tissue formation. The process repeats resulting in formation of dense nodules and scarring of lung tissue [37].

\section{Cellular mediators of silicosis}

Alveolar macrophages, mast cells, and lung epithelial cells orchestrate the initial responses to silica in lung tissue. Production of neutrophil chemokines by these cells result in an acute neutrophilic inflammatory response, which is a hallmark of silica induced sterile inflammation [38]. Activation of the NLRP3 inflammasome and 
inflammation triggered by necrotic cells contribute to a sustained neutrophilic inflammation in the lungs. The contribution of different cell types to the pathogenesis of the disease are discussed below.

\section{Macrophages}

Macrophages are one of the "first responders" at the site of silica deposition in lungs. Macrophages have specialized receptors known as scavenger receptors (SR) that recognize ligands, including bacteria and opsonized particles [1, 39]. SRs that are mainly associated with binding Crystalline Silica (CS) are SR-AI, SR-AII and MARCO [40-43]. Alveolar macrophages are present in large number and they amplify the signal by secreting several mediators. IL- $1 \beta$ is one of the key mediators of sterile inflammation and several studies have demonstrated that persistent production of IL-1 $\beta$ is a driving factor for silicosis [44-47]. IL-1 $\beta$ is responsible for the upregulation of adhesion molecules necessary for recruitment of neutrophils and monocytes $[48,49]$, and is required for the production of several pro-inflammatory mediators [50]. 


\section{IL-1 $\beta$ and inflammasome pathway}

A plethora of endogenous and exogenous agents is capable of activating the NLRP3 inflammasome pathway ${ }^{2}$ [51]. Particulates such as low-density lipoprotein (LDL) cholesterol, MSU, amyloid- $\beta$ peptides and crystalline silica capable of activating the inflammasome complex [52]. Inflammasome sensors can also detect various intracellular bacteria, viruses and intracellular protozoa $[53,54]$.

IL-1 $\beta$ production is regulated by two separate mechanisms. First, activation of toll-like receptors (TLR) triggers the signaling cascade to increase the production of proIL-1 $\beta$ via the transcription factor NFK-B. The second step involves the activation of the pattern recognition receptor (PRR) NALP3, which results in the production of active IL$1 \beta$ from pro-IL-1 $\beta$ [27]. NALP3 is a multi-ligand sensing receptor that can recognize a variety of "danger signals". These danger signals can be pathogen-associated molecular patterns (PAMPs) present on pathogens (eg. LPS on the bacterial cell wall) or damageassociated molecular patterns (DAMPs) present on nuclear proteins or endogenous substances. Uptake of crystalline silica leads to phagolysosomal destabilization and activation of NALP3 [55]. NALP3 binds to the adaptor protein ASC and pro-caspase-1 to form the inflammasome complex. The assembly of inflammasome complex leads to the spontaneous activation of caspase-1, which cleaves the pre-formed pro-IL1 $\beta$ to its active

\footnotetext{
${ }^{2}$ Inflammasome activation is not exclusive to macrophages. It can occur in various myeloid and epithelial cells.
} 
form (Fig. 4). Similarly, inflammasome pathway can lead to the production of active IL18 from its inactive form $[27,56,57]$.

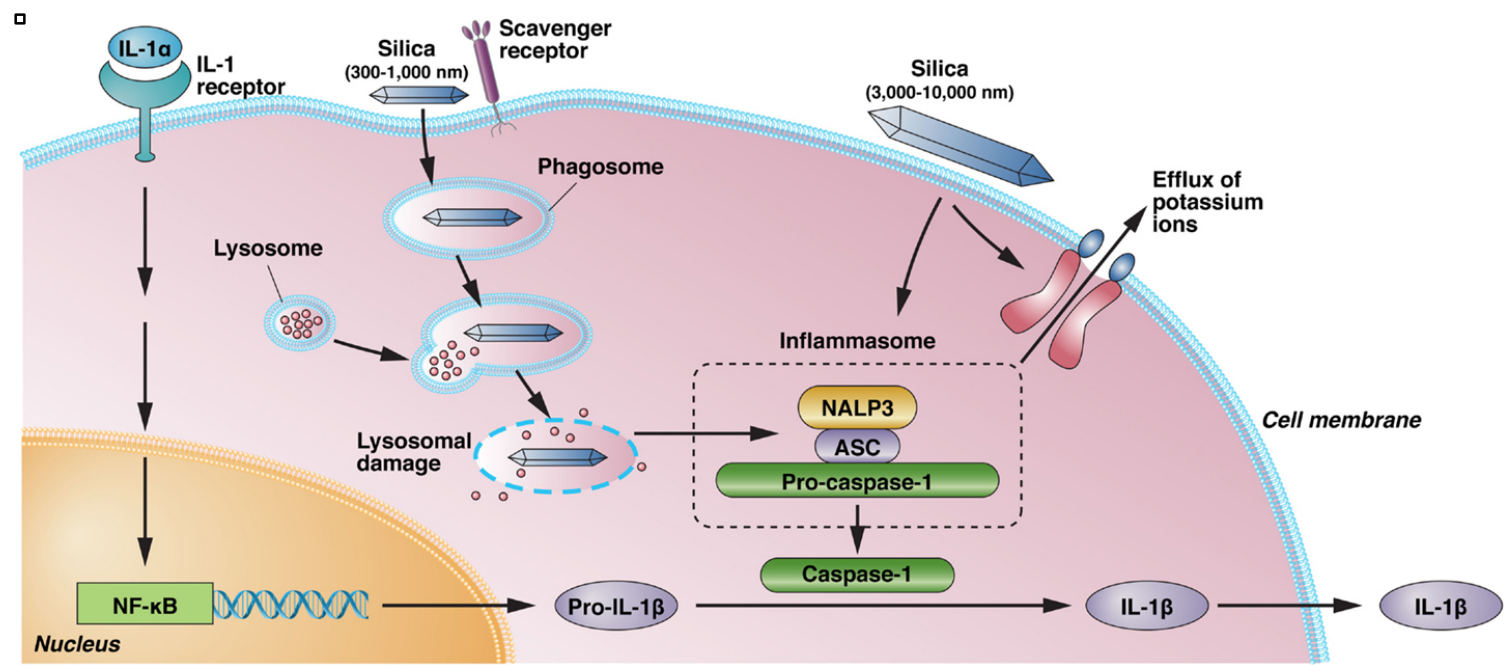

Figure 4. A schematic of inflammasome pathway. Priming of macrophages with low levels of IL-1 $\beta$ following CS exposure results in activation of NF- $\kappa$ B and production of pro-IL-1 $\beta$. CS uptake leads to destabilization of phagolysosomal membrane and leakage of its contents. This results in assembly of a multi-protein inflammasome complex consisting of NALP3, ASC and caspase-1. Active caspase-1 in the complex can cleave preformed pro-IL-1 $\beta$ to its active IL-1 $\beta$ [57].

Activation of the NALP3 inflammasome/IL-1 $\beta$ driven inflammation plays an important role in the pathogenesis of other crystal-mediated diseases namely, MSU induced gout and cholesterol crystal induced atherosclerosis [58]. Additionally, macrophages can also produce IL-1 $\alpha$, IL-33, and neutrophil chemokines, such as Leukotriene B4 ( $\left.\mathrm{LTB}_{4}\right)$ and CXC chemokines, in response to sterile inflammation [59]. IL-33 is produced at high levels by endothelial cells in response to silica [60]. Both IL-1 $\alpha$ 
and IL-33 are active cytokines that initiate necrosis and are important for recruitment of neutrophils $[61,62]$.

\section{M1/M2 macrophages and fibrosis}

Macrophages display characteristics of heterogeneity and plasticity. In response to different stimuli, they can differentiate into pro-inflammatory, cytotoxic M1 or antiinflammatory, cell proliferation and tissue repair-promoting M2 phenotypes. Differentiation of macrophages into the M2 phenotype promotes a microenvironment that supports fibrosis in several disease conditions $[63,64]$. However, in the case of silicosis, the role of M2 macrophages is controversial. Several studies have shown that alveolar macrophages express M2 markers such as YM1, FIZZ1, Arginase 1 (Arg1), Nitric Oxide Synthase 2 (NOS2) and SOCS3 in response to silica [65, 66] [67]. Although, Mission et.al. have shown that M2 markers are expressed in the early stages (at day3), they are not persistently in silica- treated mice [65]. Some argue that M2 macrophages help in uptake of extracellular matrix components and resolution of fibrosis [68]. Cruz et. al. showed that treatment with Dasatinib reduces lung inflammation and fibrosis by inducing macrophage polarization towards M2 phenotype [69].

\section{Mast cells}

Mast cells are a specific subset derived from hematopoietic progenitor cells present in all organs and abundant in skin and mucosal tissues [70]. Mast cells are 
known for mediating allergic reactions by crosslinking their surface receptors to $\operatorname{IgE}$ leading to degranulation and release of histamines, cytokines, arachidonic acid metabolites, and proteolytic enzymes causing inflammatory reactions [70]. Mast cells have been long known to play a role in the onset and progression of various inflammatory diseases such as asthma, allergic diseases, neuroinflammatory diseases (Alzheimer's disease, Parkinson's disease, and multiple sclerosis), and also arthritis [71].

Histological examination of lungs with silicosis has revealed an increase in the number of mast cells in silicosis patients [72]. Mast cells produce inflammatory mediators and cytokines such as mast cell tryptase, fibroblast growth factor (bFGF), interferon -gamma (IFN- $\gamma$ ), and transforming growth factor -beta (TGF- $\beta$ ), which play an important role in fibrinogenisis. The presence of mast cell produced bFGF in silicotic nodules in lung sections of patients suffering from silicosis has been demonstrated [73]. Mast cell deficient mice B6.Cg-Kit ${ }^{\mathrm{W}-s h}$ do not develop silica-induced inflammation or fibrosis $[74,75]$. These evidences suggest that mast cells are crucial for the development for silicosis. However, the exact mechanism through which mast cells mediate this effect is not clear. Previous studies in our laboratory showed that mast cells are a major source of $\mathrm{LTB}_{4}$ in in-vitro experiments with CS [76]. Although small in numbers, because of their ability to produce massive amounts of $\mathrm{LTB}_{4}$ in response to silica $(10 \mathrm{x}$ more than macrophages), they appear to be critical for neutrophil recruitment and promotion of CSinduced inflammation. 


\section{Neutrophils}

Neutrophils are the most abundant leukocyte sub-population in the circulation. Neutrophils are short-lived cells and produced at a rate of $10^{11}$ cells per day in the bone marrow [77]. Neutrophils play a fundamental role in the acute phase of inflammation, and are capable of activating the adaptive immune system [78]. Neutrophils are not only powerful phagocytes, they can release large amounts of superoxide and reactive oxygen species [79]. They also have another unique mechanism of killing microbes by releasing a web of chromatin loaded with proteases, known as neutrophil extracellular traps (NETs), to trap and kill the microbes [80-82]. When the inflammatory response fails to return to a homeostasis, it could lead to chronic inflammation.

Due to the possible damaging side effects of their effector mechanisms, neutrophils are the driving factor of several inflammatory diseases. Neutrophils and NETs are found in the atherosclerotic plaques at all stages of the disease [83]. In fact, neutrophil count can predict cardiovascular events in both mice and humans [84]. Neutrophil infiltration is also observed in mouse models of Alzheimer's in the $\beta$-amyloid plaques [85]. $\mathrm{Ng}$ 's group described neutrophil recruitment and migration pattern to the site of injury in the case of sterile inflammation using a laser injury model [86]. Similarly, neutrophils have been found to play an important role in the pathogenesis of other sterile inflammatory diseases such gout caused by MSU, arthritis, and silicosis. Several reports, including the studies done in our laboratory, have indicated an increase 
in neutrophil influx in silicosis $[69,87-89]$. Neutrophil chemokines, leukotriene $\mathrm{B}_{4}$ $\left(\mathrm{LTB}_{4}\right)$ and IL-1 $\beta$ are critical for the development for silicosis [76] .

\section{Leukotriene B4- synthesis and role in inflammatory diseases}

Arachidonic acid (AA) derivatives or eicosanoids are synthesized de novo in the cells in response to bacterial agents, inflammatory mediators, allergens and various stress factors. Eicosanoids are one of the first mediators released in response to silica. Three different pathways can metabolize AA: cyclooxygenase (COX), lipoxygenase (LOX) and epoxygenase (EPOX) pathways. Cyclooxygenase pathway results in the production of prostaglandins, procyclins and thromboxanes [90]. Prostaglandins are powerful vasodialators and regulate smooth muscle contraction, whereas thromboxanes are vasoconstrictors [90].

$\mathrm{AA}$, a precursor for eicosanoid synthesis, is not freely available in the cell. $\mathrm{Ca}^{+}$ is important for activation and translocation of the enzymes to intracellular membranes [91]. Upon activation, cytosolic phospholipase $2\left(\mathrm{c}-\mathrm{PLA}_{2}\right)$ translocates to the Golgi apparatus, the endoplasmic reticulum, and the nuclear envelope. Active c-pLA $\mathrm{A}_{2}$ catalyzes the release AA from the membrane. AA is metabolized by 5-lipoxygenase (5-LO) and 5lipoxygenase activating protein (FLAP) to biologically active Leukotrienes (LTs). Cysteinyl leukotrienes $\left(\mathrm{LTC}_{4}, \mathrm{LTD}_{4}\right.$ and $\left.\mathrm{LTE}_{4}\right)$ and $\mathrm{LTB}_{4}$ are the end products of lipoxygenase pathway (Fig. 5). Cysteinyl leukotrienes (CysLT) mediate contraction of smooth muscle and immediate hypersensitivity reactions [92]. $\mathrm{LTB}_{4}$ has been implicated 
as a major mediator of inflammation through induction of leukocyte and lymphocyte activation. $\mathrm{LTB}_{4}$ is a potent neutrophil chemoattractant and exerts its effects by acting on G-protein coupled receptors BLT1 and BLT2 [93]. BLT1 is the high affinity receptor and is expressed on immune cells namely neutrophils, macrophages, eosinophils and $\mathrm{T}$ cells $[94,95]$. BLT2 is the low affinity receptor and is more ubiquitously expressed [94, 95].

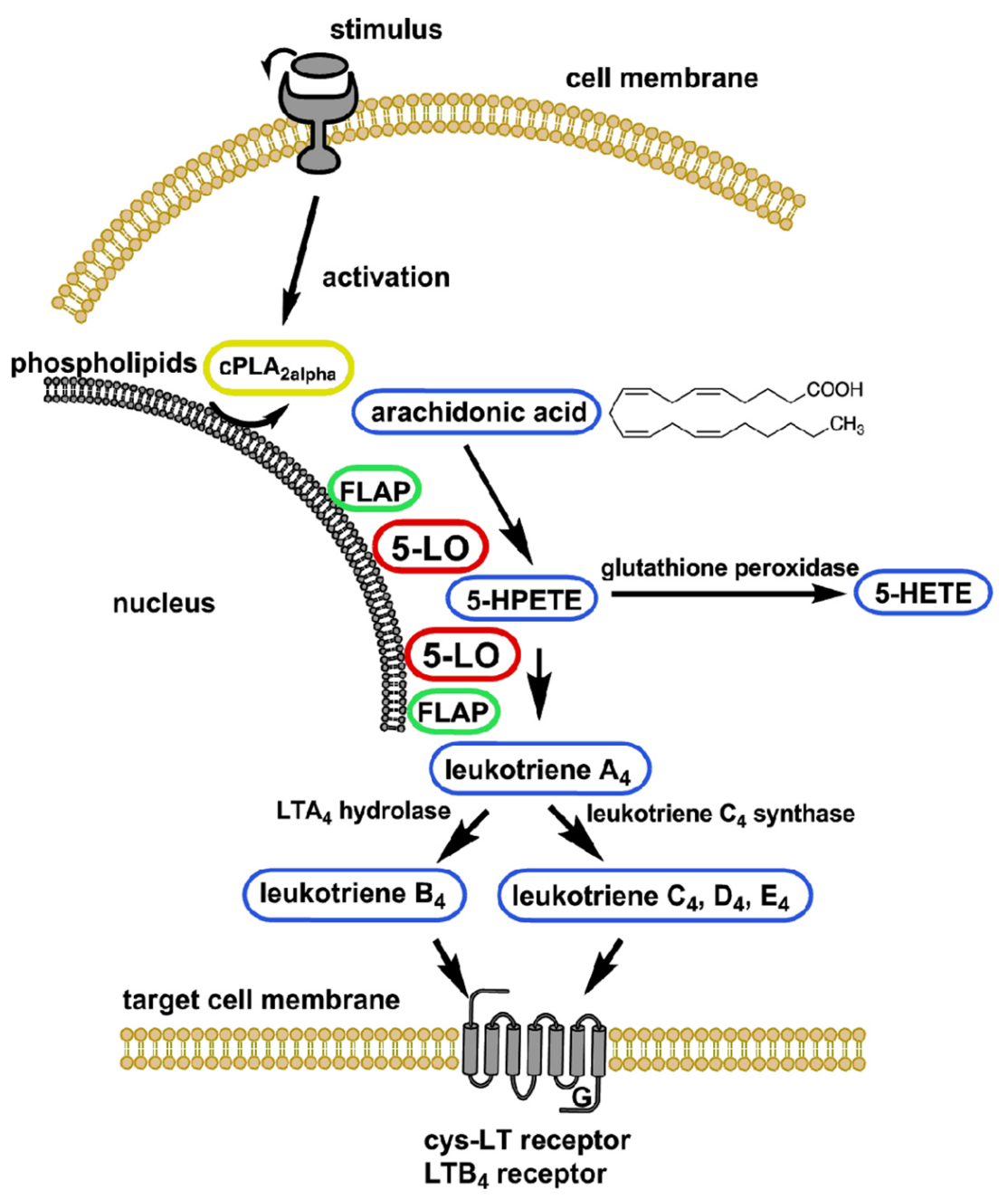


Figure 5. A schematic of Leukotriene $\mathrm{B}_{4}$ biosynthesis. $\mathrm{LTB}_{4}$ is synthesized on the nuclear membrane by the sequential action of cPLA2, 5LO-FLAP and $\mathrm{LTA}_{4} \mathrm{H}$ enzymes in the lipoxygase pathway [96].

\section{Site of LT synthesis}

Synthesis of LTs is a highly regulated process and requires interaction of at least four proteins on the phospholipid membrane. Nuclear membrane and endoplasmic reticulum is widely considerend as the site of LT synthesis [97-99]. However, there is now an evolving understanding of compartmentalization of enzymes required for LT synthesis in other locations. Patricia Bozza was the first to propose that depending on the stimulatory conditions, the enzymes required for LT synthesis could be localized to a cytoplasmic site. From the studies done in her laboratory and others, it is now wellestablished that LTs could be synthesized in cytoplasmic lipid bodies [100-102]. cPLA2 was found to localize within the lipid bodies [103, 104]. Additionally, elecron microscope studies with radiolabelled AA provided evidence for the presence of active cPLA2 in these organelles [104]. LT synthesis in lipid bodies was observed in different cell types under varying pathological condition. Eicosanoid containing lipid bodies were shown to be found in increased numbers in cancer [105], hypoxia [106], and infections $[107,108]$. Although the enzymatic pathway of LT synthesis is well known, knowledge on the mechanisms of LT synthesis in lipid bodies is very limited. 


\section{Eicosanoids in inflammatory diseases and cancer}

CysLTs and $\mathrm{LTB}_{4}$ play a central role in the pathophysiology of asthma. Elevated levels of CysLTs have been detected in the breath condensates, brochoalveolar lavage fluids, and sputum of asthma patients. CysLT receptor antagonists (e.g., montelukast, zafirlukast, pranlukastand) and 5-LO inhibitors (e.g., zileuton) have shown therapeutic efficacy in patients with asthma [109]. $\mathrm{LTB}_{4}$ plays a critical role in the pathogenesis of various other inflammatory diseases such as rheumatoid arthritis [110], atherosclerosis [111], and autoimmune uveitis [112]. The importance of $\mathrm{LTB}_{4}$ pathway in the development of arthritis is demonstrated in 5-LO, LTA 4 hydrolase, and BLT1 knockout mice that do not develop arthritis [113].

Eicosanoids are implicated not just in inflammatory diseases but also in cancer. Studies have shown an upregulation in both COX2 and 5-LOX in colon, esophagus, breast, and pancreatic cancer [114]. A few studies have also reported polymorphisms in the ALOX-5 gene to be associated with colorectal and ovarian cancer risk [115-117]. Further evidence in support of the role of eicosanoids in cancer comes from epidemiological studies showing reduced incidence of solid tumors with the use of nonsteroidal anti-inflammatory drugs (NSAID). The role of neutrophils and $\mathrm{LTB}_{4}$ in silicosis-associated lung cancer is discussed further in the next section. 


\section{Current treatment for silicosis}

Silicosis leads to decreased pulmonary function and increased susceptibility to various lung infections like tuberculosis. There is a lack of effective therapeutic interventions for silicosis. Most treatment options aim at alleviating pain and discomfort associated with the disease. Management of silicosis is similar to other chronic lung diseases, with the use of bronchodilators and corticosteroids to reduce the secondary symptoms like COPD, fibrosis, and inflammation [13, 118, 119]. However, there are no treatment options available to halt or reverse the progression of the disease. Lung transplantation is the only viable option in many cases [120].

Using protective measures remains the best way to avoid the disease. Respirable dust must be within legal limits at work places. Regular check-ups every 1-3 years is recommended for workers exposed to silica dust to diagnose the disease at an early stage. Once diagnosed, all exposure must be avoided to prevent the progression of the disease [23].

IL-1 $\beta$ has been a potential target for sterile inflammatory disorders including silicosis. IL-R antagonist anakinra, was highly effective in patients with gout who failed to respond to previous therapies. However, blockade of IL-1 $\beta$ only moderately reduced lung inflammation and fibrosis in mice and failed to show any promising therapeutic benefit in human clinical trials [35]. 
Another relatively recent approach for the treatment of silicosis is cell-based therapies. Local infusion of bone marrow derived mononuclear cells resulted in reduced inflammation, fibrosis and apoptosis, and improved lung functions in an experimental silicosis model. However, the beneficial effects lasted only 60 days [121]. Phase I clinical trials with autologous transplantation of bone marrow derived mononuclear and mesenchymal cells in silicosis patients showed improved lung function and no adverse effects after one year $[122,123]$. Despite these efforts, there is a lack of effective therapeutic strategy for silicosis. Therefore, understanding the mechanisms of silica induced inflammation to identify new therapeutic approaches becomes vital.

\section{Silicosis and Lung Cancer}

Lung cancer is a major cause of cancer related deaths worldwide. It is the second most common type of cancer in men and women (prostate and breast cancer being the most common type in men and women, respectively). More people die of lung cancer each year than prostate, breast, and colon cancer combined [124, 125]. Cigarette smoking is by far the leading cause for lung cancer. Exposure to radon, asbestos, and silica are some of the other causes for lung cancer. Exposure to asbestos leads to a type of cancer known as mesothelioma. Asbestos was widely used for insulation purpose in homes and industries. The use of asbestos has now been greatly restricted by the government after 
recognizing the serious ill effects of asbestos [14]. Although the relative risk of lung cancer due to silica exposure is lower than smoking or asbestos exposure, it is significant nevertheless. According to OSHA, there is a $6 \%$ risk of getting lung cancer in workers exposed to a working lifetime (45 years) of silica [3]. Connection between CS exposure and lung cancer has been controversial. There are studies linking CS exposure to lung cancer, but they have been inconsistent. Long latent periods for cancer development, exposure to other carcinogens like cigarette smoke, genetic susceptibility, and poor nutrition have made it difficult to establish a cause-effect relationship [126]. Nevertheless, a 2016 meta-analysis supported the carcinogenic role of silica at higher exposures [127]. Another report suggested that silica exposure is at a higher risk of lung cancer among smokers. After careful assessment of studies with low confounding factors, the International Agency for Research on Cancer (IARC) classified CS as a Group I human carcinogen in 1997 [14, 124].

Inflammation is a promoter of various cancers including colorectal cancer, ovarian, pancreatic, and lung cancer. Several types of cancer arise at the site of inflammation or infection. In fact, inflammation is now considered a hallmark of cancer and a key component of the tumor microenvironment [128-130]. A tumor microenvironment consisting of immune cells, stromal cells and fibroblasts foster cancer survival and are indispensable players in tumorigenesis. The innate immune system is an integral part of the tumor microenvironment as well as the invasion, migration and 
metastasis processes [131]. Cytokines, chemokines, transcription factors and infiltrating leukocytes can all contribute to the progression of cancer [131]. Although it is clear that inflammation alone does not cause cancer, sustained cell proliferation in an environment rich in inflammatory cells, mediators and growth factors can promote cancer growth. Inflammation being key player in cancer development is also demonstrated by regression of tumors or a reduced risk of colon cancer development by COX2 inhibitors, NF- $\mathrm{KB}$ inhibitors, aspirin, and other NSAIDs.

The main function of neutrophils is to defend the host from organisms and aid in wound healing. Once the neutrophils encounter the microorganisms they release a variety of cytotoxic substances, including proteases, that can damage the surrounding host tissue [132]. The role of neutrophils in cancer biology is increasingly becoming clear. Neutrophils make up a significant number of immune cells infiltrating the tumor microenvironment. High neutrophil numbers do not always correlate with increase in host defense. Tumor-associated neutrophils (TAN) have a distinct phenotype compared to blood neutrophils. They can be either anti-tumorigenic (N1) or pro-tumorigenic (N2) [132-136]. A high neutrophil count has been associated with a favorable prognosis in gastric tumors. On the contrary, neutrophilia has been considered a poor prognosis in many cancers, including colorectal cancer, non-small cell lung cancer, bronchoalveolar and renal carcinoma $[135,136]$. In the case of mesothelioma, a higher neutrophillymphocyte ratio (NLR) is considered a poor prognosis and is now used as a predictive 
marker for malignant mesothelioma [137-139]. Several studies have noted an increase in neutrophil population in silicosis $[69,87-89]$. However, there is a lack of experimental mouse models studying silica-induced lung carcinogenesis. Satpathy et. al. from our laboratory developed a mouse model for examining the role of CS in promoting lung tumorigenesis [76]. While the neutrophilic inflammation was found be predominant at the tumor sites, the precise role of neutrophils in accelerating tumor growth in these models remains to be determined

\section{Role of $\mathrm{LTB}_{4}$-dependent neutrophilic inflammation in silica-induced lung cancer}

The role of $\mathrm{LTB}_{4}$ in several sterile inflammatory diseases is well established as discussed previously. Additionally, elevated levels of $\mathrm{LTB}_{4}$ was detected in plasma, urine, and breath condensates of patients with silicosis [140]. Although, inflammatory conditions in selected organs are known to increase the risk of cancer, the role of $\mathrm{LTB}_{4}$ in silica-induced lung cancer was not clearly understood. In our laboratory, we investigated that role of $\mathrm{LTB}_{4}-\mathrm{BLT} 1$ pathway in CS-promoted lung tumor growth [76]. In K-ras ${ }^{\mathrm{LA} 1}$ mice that spontaneously develop lung cancer, CS exposure led to an increase in lung tumor burden. In $\mathrm{BLT}^{-/-} \mathrm{K}^{-r a s}{ }^{\mathrm{LA} 1}$ mice that were exposed to $\mathrm{CS}$, there was a significant attenuation of lung tumor burden in these mice. Histological examinations of lung 
sections of $\mathrm{BLT}^{+/+}$K-ras ${ }^{\mathrm{LA} 1}$ mice exposed to CS showed neutrophil aggregates. CSexposed $\mathrm{BLT}^{-/-} \mathrm{K}^{-r a s}{ }^{\mathrm{LA} 1}$ showed reduced overall inflammation. Further analysis of bronchoalveolar lavage fluid (BALFs) and immunohistochemical sections revealed that CS-exposed $\mathrm{BLT}^{-/}{ }^{-}$K-ras ${ }^{\mathrm{LA} 1}$ had significantly lower neutrophil numbers compared to

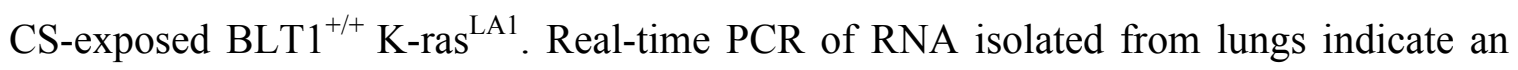
elevated level of neutrophil active chemokines and cytokines. Ex-vivo studies in primary macrophages, mast cells, and neutrophils derived from mice produced large amounts of $\mathrm{LTB}_{4}$ on stimulation with CS. Mouse macrophages also secreted IL-1 $\beta$ and CXC CC neutrophil active chemokines. The importance of $\mathrm{LTB}_{4}-\mathrm{BLT} 1$ axis in promoting was confirmed using two other murine models: an air pouch model- a simple inflammation model to investigate sterile inflammation -and an orthotopic tumor model.

Collectively the data suggests that neutrophil inflammation drives CS-induced lung cancer. More importantly, the $\mathrm{LTB}_{4}$-BLT1 pathway is crucial for promotion of CSinduced lung cancer. Absence of $\mathrm{LTB}_{4}-\mathrm{BLT} 1$ pathway led to a significant abrogation of CS-induced lung tumor promotion, further confirming the importance of $\mathrm{LTB}_{4}$ in the pathogenesis of silicosis. This knowledge opens up various therapeutic possibilities for the treatment of silicosis and silicosis-associated lung cancer. 


\section{Goals of my study}

Our previous studies have established $\mathrm{LTB}_{4}$ as an important mediator in CSinduced sterile inflammation and lung tumor promotion (Fig. 6). CS-exposure results in the production of IL- $1 \beta$ through the activation of inflammasome pathway, and $\mathrm{LTB}_{4}$. While the inflammasome pathway is well studied, the key events leading up to $\mathrm{LTB}_{4}$ synthesis is not clearly understood. In this dissertation, I set out to understand the mechanisms involved in CS-induced $\mathrm{LTB}_{4}$ production. The goal of this study is to delineate the signaling pathways leading to $\mathrm{LTB}_{4}$ and IL-1 $\beta$ production. In addition, I wanted to understand how these pathways are integrated to mediate an overall inflammatory response. Lastly, I wanted to test the efficacy of select inhibitors of $\mathrm{LTB}_{4}$ pathway in in-vivo models of CS-induced sterile inflammation.

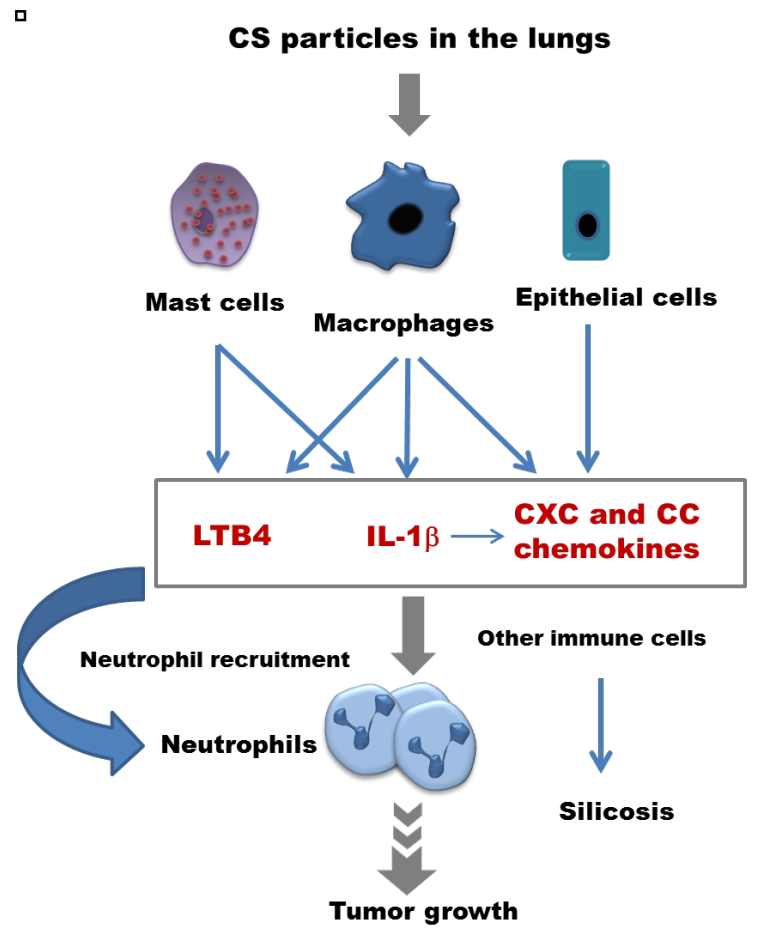


Figure 6. Overview of CS-induced tumor promotion: Activation of resident macrophages, mast cells, and lung epithelial cells in response to CS, results in the production of $\mathrm{LTB}_{4}, \mathrm{IL}-1 \beta$ and $\mathrm{CXC}$ and $\mathrm{CC}$ chemokines. This results in the recruitment of neutrophils to the lungs. Neutrophils themselves can secrete $\mathrm{LTB}_{4}$, resulting in an amplification of the loop. Neutrophil inflammation is responsible for CS-induced promotion of lung tumor.

AIM I: To investigate whether CS-induced $\mathrm{LTB}_{4}$ production is dependent on inflammasome pathway or IL-1 $\beta$ production. I used specific phagocytosis inhibitors to determine whether uptake of CS is necessary for $\mathrm{LTB}_{4}$ synthesis. I also used inflammasome inhibitors, BMDMs from inflammasome, and 5LO KO mice to determine how the two pathways are regulated. I used bone marrow-derived macrophages to study the interaction between $\mathrm{LTB}_{4}$ and IL-1 $\beta$ pathway. To address cell type-specificity, I performed experiments in primary mast cells, bone marrow-derived neutrophils and human neutrophils.

AIM II: To identify the source of $\mathrm{LTB}_{4}$ production. Using confocal microscopy, various staining techniques, and siRNA knockdowns, I examined the molecular mediators required for lipid body formation and activation. I used bone marrow-derived macrophages for labeling cellular compartments and proteins. I used RAW264.7 cells in siRNA knockdown studies.

AIM III: To evaluate the role of JNK pathway in CS-induced sterile inflammation. Using in-vitro CS stimulations assays and an in-vivo airpouch model, I evaluated the role 
of JNK activation in lipidosome activation and $\mathrm{LTB}_{4}$ production. In-vitro experiments were performed in bone marrow-derived macrophages, mast cells, and neutrophils and human neutrophils. 


\section{CHAPTER II}

\section{MATERIALS AND METHODS}

\section{Reagents}

Crystalline Silica (MIN-U-SIL-5; average particle diameter $1.7 \mathrm{~mm}$ ) was obtained from US Silica Co., WV, and was baked at $200^{\circ} \mathrm{C}$ overnight to make it endotoxin free. Zinc Oxide ( $\mathrm{ZnO}$ ) nanoparticles $10-30 \mathrm{~nm}$ in size (US Research Nanomaterials, Inc., Houston,TX). Monosodium urate (MSU) crystals (tlrl-msu; Invivogen, San Diego, CA), mCherry expressing E.Coli was described earlier in (16) and fluorescent red latex beads (L3280; Sigma-Aldrich, St.Louis, Missouri) were used as controls in phagocytosis experiments. Calcium ionophone A23187 was purchased from Sigma- Aldrich. The following pharmacological inhibitors were used in the study: Zileuton, Cytocholasin D, SB202190, and BI-78D3 (all from Sigma-Aldrich), Bafilomycin-A1 (Santa Cruz, Dallas,TX) and AG-126 (Cayman Chemicals, Ann Arbor, MI). 


\section{Mice, cell lines and primary cells}

C57BL/6, 5-LO-deficient Alox $5^{-/-}$and NALP3-deficient $\mathrm{Nlrp}^{-/-}$mice were purchased from Jackson laboratories and bred at the University of Louisville. 6-8 weeks age old mice were used in ex-vivo and in-vivo experiments. All mice were cared for in accordance with the institutional and National Institutes of Health $(\mathrm{NIH})$ guidelines. The University of Louisville Institutional Animal Care and Use Committee (IACUC) approved all the procedures.

\section{Bone marrow derived macrophages}

Mice (6-8-week-old) of indicated genotypes were euthanized by cervical dislocation. The hind legs were dissected and the bone marrow cells were flushed out. The bone marrow cells were cultured in Dulbeco's Modified Eagle Medium (DMEM) containing 10\% FBS, 100 units $/ \mathrm{ml}$ penicillin, $100 \mathrm{mg} / \mathrm{ml}$ streptomycin, $2 \mathrm{mM}$ L-glutamine and $50 \mathrm{mM} \beta$ mercaptoethanol supplemented with $50 \mathrm{ng} / \mathrm{ml}$ recombinant mouse macrophage colonystimulating factor (BioLegend; San Diego, CA). The cells were plated at a density of 1 million cells per $100-\mathrm{mm}$ tissue culture dishes containing $10 \mathrm{ml}$ of medium. After 3 days, the medium was replaced by $10 \mathrm{ml}$ of fresh growth medium. The culture were maintained for another 3 days before the experiments. The purity of the cells $(>99 \%)$ was confirmed using flow cytometry by surface staining for F4/80 and CD11b. 


\section{Bone marrow derived mast cells}

6-8-week-old mice of indicated genotypes were euthanized by cervical dislocation. The hind legs were dissected and the bone marrow cells were flushed out. The bone marrow cells were plated at density of 1 million cells in T-75-cm2 flask containing $15 \mathrm{ml}$ of DMEM medium containing 10\% FBS, 100 units $/ \mathrm{ml}$ penicillin, $100 \mathrm{mg} / \mathrm{ml}$ streptomycin, $2 \mathrm{mM}$ L-glutamine, $50 \mathrm{mM} \quad \beta$-mercaptoethanol supplemented with $12.5 \mathrm{ng} / \mathrm{ml}$ recombinant mouse stem cell factor $(\mathrm{R} \& \mathrm{D}, 455 \mathrm{MC})$ and $10 \mathrm{ng} / \mathrm{ml}$ recombinant mouse IL-3 (R\&D, 403-ML). The non-adherent cells were transferred after $48 \mathrm{~h}$ into fresh flasks. The cells were transferred into a new flask weekly with media containing freshly supplemented cytokines. The homogenous population of mast cells was visible after 4 weeks of culture and propagated further for 4 weeks. The purity of primary mast cells was confirmed to by flow cytometry using CD117 and FceR1 cell surface markers [76].

\section{RAW 264.7 macrophages}

RAW 264.7 cells (ATCC, TIB-71) were maintained in DMEM containing 10\% FBS, 100 units/ml Penicillin, $100 \mu \mathrm{g} / \mathrm{ml}$ Streptomycin, 2mM L-Glutamine and $50 \mu \mathrm{M} \beta$ mercaptoethanol. 


\section{Neutrophils}

Human neutrophils were isolated from healthy donors using the plasma-Percoll gradient as previously described (15). The recruitment of healthy donors and all the procedures involved in blood draws were in accordance with the guidelines approved by the University of Louisville Institutional Review Board. Microscopy evaluation of isolated cells determined to be $90-95 \%$ neutrophils and $>97 \%$ of cells were viable by Trypan blue exclusion. Following Percoll gradient, a second purification step was performed to obtain 99.9\% purity using EasySep Neutrophil Enrichment Kit (StemCell Technologies; Vancouver, Canada).

\section{In-vitro CS stimulation assays}

BMDMs were plated at a density of 0.3 million cells per well in a 12 well culture dish in $1 \mathrm{ml}$ or 0.1 million cells per well in a 96 well culture dish in $200 \mu \mathrm{l}$ of DMEM containing $10 \% \mathrm{FBS}$ and allowed to attach overnight. BMDMs were primed with $10 \mathrm{ng} / \mathrm{ml}$ of LPS (LPS-EK; InvivoGen, San Diego, CA) for 3 hours. The media was changed to $1 \%$ FBS containing media to achieve a final volume of $400 \mu 1$ in 12 well plate or $200 \mu 1$ in a 96 well plate. The cells were then pre-treated with the pharmacological inhibitors at the indicated concentrations for 1 hour prior to stimulation with $100 \mu \mathrm{g} / \mathrm{cm}^{2}$ of CS for 3-6 hours. 
RAW 264.7 cells were plated at a density of 0.1 million cells in $100 \mu$ in a 96 well plate in $10 \%$ FBS containing media. They were primed for 3 hours with $10 \mathrm{ng} / \mathrm{ml}$ LPS. The media was changed to $1 \%$ FBS containing media. The cells were pre-treated with the compounds for an hour before stimulation with $100 \mu \mathrm{g} / \mathrm{cm} 2 \mathrm{CS}$ for 3 hours.

Mast cells were plated at a density of 0.1 million cells per well in a 12 well culture dish in $400 \mu 1$ of serum-free media. Mast cells required no LPS priming. The cells were pretreated with the inhibitors for an hour before stimulation with $100 \mu \mathrm{g} / \mathrm{cm}^{2} \mathrm{CS}$ for 3 hours.

Neutrophils plated at 0.1 million cells per well in a 96 well plate with $100 \mu 1$ of serum free media, were primed with $50 \mathrm{ng} / \mathrm{ml}$ LPS and stimulated with $100 \mu \mathrm{g} / \mathrm{cm}^{2}$ CS for 3 hours after pre-treatment with the inhibitors for an hour.

\section{ELISA}

$\mathrm{LTB}_{4}$ and IL-1 $\beta$ in the supernatants of cell culture and air pouch lavage fluid were measured using $\mathrm{LTB}_{4}$ EIA Kit (Cayman Chemicals) and Mouse IL-1 $\beta$ ELISA MAX Standard Kit (Biolegend) respectively, using manufacturer's instructions. Absorbance was measured using a BioTek (Winooski, VT) microplate reader at $405 \mathrm{~nm}$ and $450 \mathrm{~nm}$ for $\mathrm{LTB}_{4}$ and IL-1 $\beta$ respectively. 
qRT-PCR

Cells were lysed using TRIzol reagent and total RNA was isolated using an RNeasy Mini Kit (Qiagen) using manufacturer's protocol. RNA samples were treated with DNase (Qiagen) to remove any trace of DNA from the samples before reverse transcription with TaqMan reverse transcription reagents (Applied Biosystems) using random hexamer primers. Quantitative PCR was performed using 'power SYBR-green master mix' (Applied Biosystems). Expression of the target genes was normalized to GAPDH and the relative fold changes relative to the PBS (vehicle)-treated were calculated using the delta CT method. Data were representative of triplicate cell cultures. GAPDH, CXCL1, CXCL2, CXCL3, CXCL5, CCL2, CCL3, CCL4 and CCL5 primers obtained from Real Time Primers.

\section{MTT assay}

RAW264.7 macrophages were pre-treated with the pharmacological inhibitors for an hour, followed by CS treatment. 3-[4,5-dimethyltiazol-2-yl] 2,5-diphenyl-tetrazolium bromide (MTT) was added to the cells post CS-treatment. After 2h, absorbance was measured at $562 \mathrm{~nm}$ using a BioTek reader. 


\section{Immunofluorescence}

$1 \times 10^{6}$ BMDMs or RAW 264.7 cells were plated in a $35 \mathrm{~mm}$ cover-glass bottom dish (World precision Instruments, Sarasota, FL) in DMEM with 10\% FBS for attachment overnight. The media was changed to DMEM with $1 \%$ FBS and the cells were primed with LPS as described above. The cells were stimulated with $35 \mu \mathrm{g} / \mathrm{cm} 2 \mathrm{CS}$ and processed for different staining protocols for microscopy as described below. The confocal images were captured using Nikon A1R confocal microscope at $60 \mathrm{x}$ magnification with appropriate lasers as indicated. A minimum of five fields were captured for each sample. Confocal reflection microscopy combined with florescence microscopy was used to visualize internalized CS particles. Reflection was captured by allowing the laser light to directly pass to the detector channel.

\section{BODIPY staining}

After 3 hours of treatment with $35 \mu \mathrm{g} / \mathrm{cm} 2 \mathrm{CS}$, cells were washed with Hanks-buffered salt solution without calcium chloride and magnesium chloride $\left(\mathrm{HBSS}^{-/}\right)$and incubated with $1 \mu \mathrm{M}$ BODIPY: 4,4-difluoro-1,3,5,7,8-pentamethyl-4-bora- 3a,4a-diaza-sindacene (ThermoFisher Scientific, Waltham, MA) for 1 hour at $37{ }^{\circ} \mathrm{C}$ to stain the lipid bodies. Cells were washed again with $\mathrm{HBSS}^{-/}$and fixed with 4\% paraformaldehyde for 15 min. Subsequently, cells were permeabilized with $0.1 \%$ saponin and stained 
with nuclear stain DAPI (4',6-Diamidino-2-Phenylindole, Dihydrochloride; ThermoFisher Scientific) (17).

\section{Acridine orange staining}

BMDMs were loaded with $5 \mu \mathrm{g} / \mathrm{ml}$ acridine orange (Sigma- Aldrich) for $30 \mathrm{~min}$ post CS treatment and washed with HBSS-/- before imaging.

\section{Phagosome staining}

BMDMs were loaded with $40 \mu \mathrm{g} / \mathrm{ml}$ pHrodo Red Dextran (ThermoFisher Scientific) together with $1 \mu \mathrm{M}$ BODIPY and DAPI for 1 hour at 370C, after 3 hours of CS treatment. The cells were washed thoroughly with $\mathrm{HBSS}^{-/-}$before analyzing by confocal microscopy.

\section{Antibody staining}

The cells were fixed with $4 \%$ paraformaldehyde for 15 min post CS treatment. The cells were permeabilized with $0.1 \%$ saponin and blocked with $5 \%$ BSA for 1 hour. Subsequently, the cells were incubated with either anti-Caspase-1, anti-Rab-40c, antiFLAP (sc-56036, sc-514826, sc-28815; Santa Cruz), anti-5-LO (160402;Cayman Chemicals) or anti-LTA $4 \mathrm{H}(\mathrm{ab196607)}$ antibodies at 1:500 dilution overnight at 40C. The cells were washed three times with 1x PBS and incubated with the appropriate secondary antibody (Alexa Fluor 594 goat anti-mouse IgG A-11032 or Alexa Fluor 594 
goat anti-rabbit IgG A-11012; ThermoFisher Scientific) at 1:500 dilution for 1 hour. The cells were washed and stained with DAPI. Additionally, for phagocytosis experiments, Alexa Fluor 488 or 594-Cholera toxin Subunit B (ThermoFisher Scientific) was used at the last step along with DAPI. The cells were washed again before analyzing by confocal microscopy.

For time-lapse studies, LPS-primed BMDMs were loaded with $1 \mu \mathrm{M}$ BODIPY or Active Caspase-1 stain (ab219935; abcam) along with nuclear stain Hoechst. After an hour, cells were stimulated with $35 \mu \mathrm{g} / \mathrm{cm}^{2} \mathrm{CS}$ for different times, as indicated. The cells were washed with $\mathrm{HBSS}^{-/-}$before analyzing by confocal microscopy.

\section{Air pouch experiment}

$5 \mathrm{ml}$ of sterile air was injected subcutaneously into the back of 6-8 weeks old mice to generate an air pouch. An additional $3 \mathrm{~mL}$ was injected into the pouch 3 days later to maintain the air pouch. 3 days later, the animals were either injected with $25 \mathrm{mg} / \mathrm{kg} \mathrm{BI-}$ 78D3 or vehicle into the air pouch. After an hour, $1 \mathrm{mg}$ of CS in $1 \mathrm{ml}$ PBS was injected into the air pouch. The control animals received PBS. After 6 hours, the air pouch was rinsed by injecting $3 \mathrm{ml}$ of cold PBS and the lavage fluid was collected. 


\section{Flow Cytometry}

Cells from the air pouch lavage were stained with CD45, CD11b-APC, Ly6G-FITC, F480-PerCP, SiglecF-PE fluorochrome labeled antibodies purchased from BD Biosciences or Biolegend, following standard protocols. Cells labeled with isotype matched antibodies were used as controls. Flow cytometry data were acquired on FACS Calibur or FACS Canto (BD Biosciences) and analyzed using Flowjo software (Tree Star).

\section{Cytospin}

The air pouch lavage fluid cells were spun down Shandon Cytospin centrifuge (Shandon Lipshaw) followed by staining with Hema-3 reagents (ThermoFisher Scientific) according to the manufacturer's recommendations.

$\operatorname{siRNA}$

For siRNA transfection, $20 \mu \mathrm{l}$ of $168 \mathrm{nM}$ Silencer siRNA (Life Technologies) diluted in Opti-MEM (Life Technologies) was mixed with $10 \mu \mathrm{l}$ of $0.03 \%$ (v/v) Lipofectamine RNAiMax/Opti-MEM (Life Technologies) as described by the manufacturer. $30 \mu$ of the siRNA-lipofectamine mixture was added to each well of a white flat-bottom 96-well plate

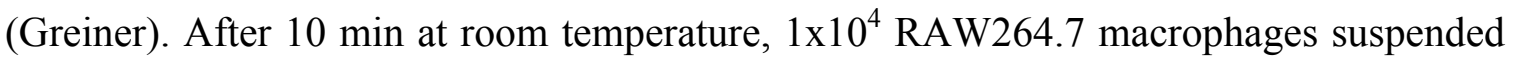
in $80 \mu \mathrm{l}$ of DMEM+10\% FBS were added. Cells were incubated for $48 \mathrm{~h}$ at $37^{\circ} \mathrm{C}$ with $5 \%$ 
CO2. $48 \mathrm{~h}$ later, the cells were re-suspendend in DMEM $+1 \%$ FBS medium, primed with $10 \mathrm{ng} / \mathrm{ml}$ of LPS for $3 \mathrm{~h}$ and stimulated with $100 \mu \mathrm{g} / \mathrm{cm} 2 \mathrm{CS}$. After $6 \mathrm{~h}$, the supernatant was analyzed for $\mathrm{LTB}_{4}$ production. A total of 110 genes were screened using three distinct siRNAs for each gene. 5-LO siRNA and scrambled siRNAs served as positive and negative controls, respectively.

\section{Statistical Analysis}

All in-vitro experiments were repeated at least three times. Represented data are a mean \pm S.E of triplicate cultures. All data were analyzed with GraphPad Prism4 Software (San Diego, CA). Statistical significance was determined using unpaired Student's $t$-test. 


\section{CHAPTER III}

\section{$\mathrm{LTB}_{4} \mathrm{PRODUCTION} \mathrm{IS} \mathrm{INDEPENDENT} \mathrm{OF}$ INFLAMMASOME ACTIVATION}

\section{Introduction:}

Uptake of CS is essential for the production of various pro-inflammatory mediators including IL-1 $\beta[45,55,56]$. Internalized particles go through distinct intracellular compartments before they are degraded in the lysosomes (or attempted to be degraded, in the case of silica). The contents in the early endocytic vesicles are delivered to Early Endosomes (EE) in the peripheral cytoplasm. EEs receive cargo from both Clathrin and Caveolin-mediated pathways [141]. The components to be recycled are sorted out and transported back to the surface via recycling endosomes. Endocytosed materials are then delivered to Late Endosomes (LE), which are large vesicles found in the perinuclear region. $\mathrm{pH}$ is an important factor for the maturation of the endosomes. Vacuolar proton pumps (V-ATPases) are responsible for progressively reducing the $\mathrm{pH}$ : 6.2 in the early endosomes, 5.5 in the late endosomes and 4.5 in the lysosomes. Finally, 
LEs fuse with the lysosomes where its contents are digested by the lysosomal hydrolases [141].

Uptake of crystals and particulates like alum and silica go through the phagosomal maturation pathway in the same way a pathogen would. The production of ROS and lysosomal proteases in response to the surface ligands result in degradation of pathogens, whereas in case of silica, it results in phagosomal membrane destabilization and release of cathepsin proteases into the cytosol. This in turn triggers NLRP3 inflammasome and caspase-1 activation. Uptake of silica induces a caspase -1 dependent cell death known as Pyroptosis ${ }^{3}$ [142-144]. David Knecht's group studied the timeline of events after silica uptake demonstrated that phagosomal leakage occurs 30-120 min after silica uptake and cell death is triggered 3-6 hours post-uptake [29]. The production of several CS-induced pro-inflammatory mediators including IL-1 $\beta$, bFGF, HMGB1, CXCL1,2,3,5 are directly linked to the activation of inflammasome pathway [50]. However, the sequence of events leading to the synthesis of $\mathrm{LTB}_{4}$ in response to CS and its relationship to the inflammasome pathway is not clearly understood.

Here, I sequentially evaluated the requirement of each step leading to the inflammasome activation in the synthesis of $\mathrm{LTB}_{4}$. First, I evaluated the requirement of phagocytosis for $\mathrm{LTB}_{4}$ production by using several pharmacological inhibitors that

\footnotetext{
${ }^{3}$ Pyroptosis does not require apoptotic caspases 3, 6 or 8. Moreover, loss of mitochondrial integrity and cytochrome c release is not seen in pyroptosis.
} 
inhibit phagocytosis: Cytocholasin D (Cyt D) - an F-actin polymerase inhibitor; Chlorpromazine (CPZ) - a clathrin-dependent endocytosis inhibitor; and Genistein - a caveolin mediated endocytosis inhibitor. Next, I used Bafilomycin-A1 (Baf-A1), a macrolide antibiotic isolated from Streptomyces species that inhibits the vacuolar $\mathrm{H}+$ ATPase (V-ATPase), to evaluate the requirement of phagolysosome fusion for $\mathrm{LTB}_{4}$ production. Baf-A1 prevents fusion of phagosome and lysosome by inhibiting the acidification of phagosomes [141, 145]. Finally, I used macrophages derived from 5LO and NLRP3 KO mice to determine whether inflammasome activation or IL-1 $\beta$ is required for $\mathrm{LTB}_{4}$ production. 


\section{Results:}

Phagocytosis is required for CS-induced $\mathrm{LTB}_{4}$ and IL-1 $\beta$ production. To examine the requirement of phagocytosis for CS-induced $\mathrm{LTB}_{4}$ production, LPS-primed BMDMs were stimulated with $\mathrm{CS}$ in the presence of phagocytosis inhibitors. CytD $(10 \mu \mathrm{M}), \mathrm{CPZ}$ $(10 \mu \mathrm{g} / \mathrm{mL})$ and Genistein $(100 \mu \mathrm{M})$, all blocked the production of IL-1 $\beta$ and $\mathrm{LTB}_{4}$ in BMDM (Fig. 7a-b). To determine whether uptake was necessary in other cell types that produce $\mathrm{LTB}_{4}$ in response to CS, mouse mast cells, mouse neutrophils and human neutrophils were stimulated with $\mathrm{CS}$ in the presence of phagocytosis inhibitors. Phagocytosis inhibitors completely blocked CS-induced $\mathrm{LTB}_{4}$ production in all these cell types (Fig. 7c). Mast cells and neutrophils did not make any detectable levels of IL-1 $\beta$.

Reflective microscopy in combination with fluorescence staining techniques was used to visualize CS particles inside the cell. In the presence of CytD, the cells did not take-up CS particles (Fig.7d). Together, these results indicate that phagocytosis of CS particles is necessary for $\mathrm{LTB}_{4}$ production.

Inhibition of phagolysosome formation enhances $\mathbf{L T B}_{4}$ production: The production of several CS-induced pro-inflammatory mediators including IL-1 $\beta$, bFGF, and HMGB1 are directly linked to the activation of inflammasome pathway. Bafilomycin-A1 (BafA1), an ATPase inhibitor prevents fusion of phagosome and lysosome by inhibiting vacuolar acidification. To investigate whether phagolysosome formation is necessary for 
$\mathrm{LTB}_{4}$ production, LPS-primed BMDMs were treated with varying doses of Baf-A1 prior to CS stimulation. Baf-A1 had opposite effects on $\mathrm{LTB}_{4}$ and IL-1 $\beta$ production. As expected, Baf-A1 blocked IL-1 $\beta$ production (Fig. 8a) [55]. In contrast, Baf-A1 enhanced CS-induced $\mathrm{LTB}_{4}$ production in BMDM (Fig. 8b). It is important to note that Baf-A1 alone did not cause $\mathrm{LTB}_{4}$ production. A similar trend in RAW 264.7 cells, mouse mast cells, mouse neutrophils and human neutrophils was observed (Fig. 8c). Approximately three-fold increase in $\mathrm{LTB}_{4}$ production over CS control was observed at $5 \mu \mathrm{M}, 0.5 \mu \mathrm{M}$ and $1 \mu \mathrm{M}$ in BMDM, RAW 264.7 cells and human neutrophils, respectively.

The effect of Baf-A1 on lysosomal acidification was measured using acridine orange staining. Acridine orange emits green fluorescence in nuclear and cytoplasmic compartments, whereas acidic lysosomes or phagolysosomes are stained orange-red. CStreated cells show enlarged lysosomal compartments. Acridine orange staining in the lysosomal compartments was completely lost in Baf-A1 treated cells, in the presence of CS (Fig. 8d). Together, these results indicate that phagolysomal fusion is not required for $\mathrm{LTB}_{4}$ production.

\section{$\mathrm{LTB}_{4}$ production is independent of inflammasome activation and IL-1 $\beta$ production:}

To evaluate whether $\mathrm{LTB}_{4}$ production is independent of inflammasome activation, I used BMDMs from $5 \mathrm{LO}^{-/}$and $\mathrm{NLRP}^{-/}$mice. LPS-primed BMDMs derived from the knockouts were stimulated with CS for $6 \mathrm{~h}$ and the supernatants were assayed for $\mathrm{LTB}_{4}$ 
and IL-1 $\beta$ production using ELISA. BMDMs from $5 \mathrm{LO}^{-/-}$mice were deficient in CSinduced $\mathrm{LTB}_{4}$ production but produced IL-1 $\beta$. Similarly, BMDMs derived from NLRP3 ${ }^{-/}$ mice made $\mathrm{LTB}_{4}$ in response to CS but did not make IL-1 $\beta$. Collectively, these results indicate that CS-induced $\mathrm{LTB}_{4}$ production is completely independent of inflammasome activation (Fig.9).

CS-induced lipid body formation is inflammasome independent: To visualize the divergence in CS-induced $\mathrm{LTB}_{4}$ and IL-1 $\beta$ pathways, I used BODIPY and caspase-1 staining. LPS-primed BMDMs with/without pre-treatment with pharmacological inhibitors were stimulated with CS for $3 \mathrm{~h}$, followed by staining with BODIPY, a yeast extract that stains lipid bodies in the cell. An increase in accumulation of lipid bodies was observed in the cytoplasm of CS- stimulated cells. In the presence of CytD, lipid bodies were absent, whereas in the presence of Baf-A1, there was a significant increase in the formation of lipid bodies in cells (Fig. 10a, upper panel). Confocal microscopy images are quantified in terms of fluorescence intensity of lipid bodies and the number of lipid bodies per cell. Inflammasome activation under similar conditions was measured by staining for active caspase-1 as described in Materials and Methods. CS-exposed cells showed caspase- 1 activation, whereas the cells that were pre-treated with CytD or BafA1 prior to CS-stimulation showed no caspase 1 staining (Fig. 10b). Formation of lipid bodies and inflammasome pathway are regulated independent of each other as observed in BODIPY and caspase-1 staining of CS-stimulated BMDMs from NLRP3 ${ }^{-/}$and 5-LO ${ }^{-/-}$ 
mice. (Fig. 13). Since the formation of lipid bodies correlated with $\mathrm{LTB}_{4}$ production, we speculated that these could be sites of CS-induced $\mathrm{LTB}_{4}$ synthesis.

Kinetics of lipid body formation and inflammasome activation: To examine the kinetics of lipid body formation and inflammasome activation, $\mathrm{LTB}_{4}$ and IL-1 $\beta$ production in the supernatants were measured at time points ranging from 1 hour to 6 hours (Fig. 11c). Cells loaded with BODIPY and active caspase-1 stain were stimulated with CS and live images were captured at various time points (Fig. 11b). Although the accumulation of both $\mathrm{LTB}_{4}$ and IL-1 $\beta$ in the supernatant appears to follows a similar time course, live staining data reveals that lipid body formation occurs as early as 5 min, whereas the earliest caspase -1 activation was observed at $30 \mathrm{~min}$ after CS exposure. These results indicate that lipid body formation precedes inflammasome activation.

\section{A23187 induced $\mathrm{LTB}_{4}$ but not lipid body formation}

To determine whether a calcium ionophore that induces $\mathrm{LTB}_{4}$ production activates lipid body formation, I stimulated LPS-primed BMDMs with A23187. Stimulation with A23187 resulted in huge amounts of $\mathrm{LTB}_{4}$ secretion within 5 min of exposure but did not show any lipid body formation (Fig. 12). These results indicate that phagocytosis of CS triggered a unique pathway that was different from the conventional $\mathrm{LTB}_{4}$ production. 


\section{Discussion:}

Silica can be internalized by receptor mediated phagocytosis and endocytosis depending on physical and chemical properties of the particles such as size, shape or surface charge. Several studies have highlighted the importance of scavenger receptors SR-AI, SR-AII and MARCO in internalization of silica [146]. However, scavenger receptor-knockout studies have revealed that they are important but not essential for CS uptake $[147,148]$. These studies suggest that there could be other mechanisms by which silica can be taken up, such as clathrin and caveolin mediated endocytosis. In this study, blocking uptake of CS using CytD, Genistein, and CPZ, abrogated IL-1 $\beta$ and $\mathrm{LTB}_{4}$ production (Fig 7). These results suggest that CS particles could possibly be taken up by more than one mechanism. Particles of size $<200 \mathrm{~nm}$ are internalized by clathrin-coated pits, whereas slightly larger particles up to $500 \mathrm{~nm}$ are taken up via caveolin mediated endocytosis [149, 150]. Phagocytosis typically involves uptake of larger particles $(>250 \mathrm{~nm})$. Since the CS particles size used in this study ranged from $500-5000 \mathrm{~nm}$ in diameter, it is likely to be taken up by more than one ways.

Inflammatory pathways triggered by phagocytosis of CS particles appears closely linked to the phagosome maturation pathway with different mediators such as $\mathrm{LTB}_{4}$, IL$1 \beta$ and CXC chemokines produced at different stages. Treatment of cells with bafilomycin-A1 prevents phagolysosome formation [151]. Although this is a key step in IL-1 $\beta$ production [55], based on the results presented here, it appears to be downstream 
of $\mathrm{LTB}_{4}$ synthesis (Fig 8). Dissociation of inflammasome activation that requires phagosome fusion with lysosome clearly places the lipid body formation upstream of this phagosome maturation event (Fig 10). Kinetics study showing lipid body formation as early as $5 \mathrm{~min}$ after CS exposure as opposed to $30 \mathrm{~min}$ for caspase-1 activation (Fig. 11) also supports the hypothesis that lipid body formation might precede inflammasome activation.

The complete independence of $\mathrm{LTB}_{4}$ and IL- $1 \beta$ pathways is further supported by the use of primary cells from NLRP3 ${ }^{-/-}$and $5-\mathrm{LO}^{-/-}$mice (Fig 9). BODIPY and caspase-1 staining in BMDMs from 5LO and NLRP3 KO mice showed that lipid bodies are formed independent of inflammasome activation (Fig 13). The appearance of the lipid bodies correlated with the $\mathrm{LTB}_{4}$ production under similar conditions allowing us to speculate that they may be a source of CS-induced $\mathrm{LTB}_{4}$ production. Interestingly, A23187, a calcium ionophore, induced $\mathrm{LTB}_{4}$ production instantly but did not show any appearance of lipid bodies, suggesting that CS-induced $\mathrm{LTB}_{4}$ synthesis in the lipid bodies could be a novel phagocytosis-dependent pathway. Together, these data provide evidence that inhibition of phagocytosis inhibits both $\mathrm{LTB}_{4}$ and IL-1 $\beta$ producing pathways, whereas Baf-A1 enhances $\mathrm{LTB}_{4}$ production while blocking the inflammasome pathway. Our preliminary data with lipid bodies suggest that they could be sites of $\mathrm{LTB}_{4}$ production. 
a

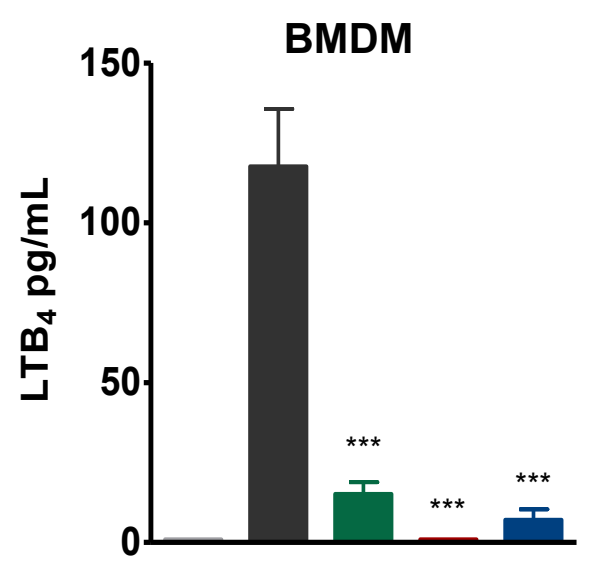

C
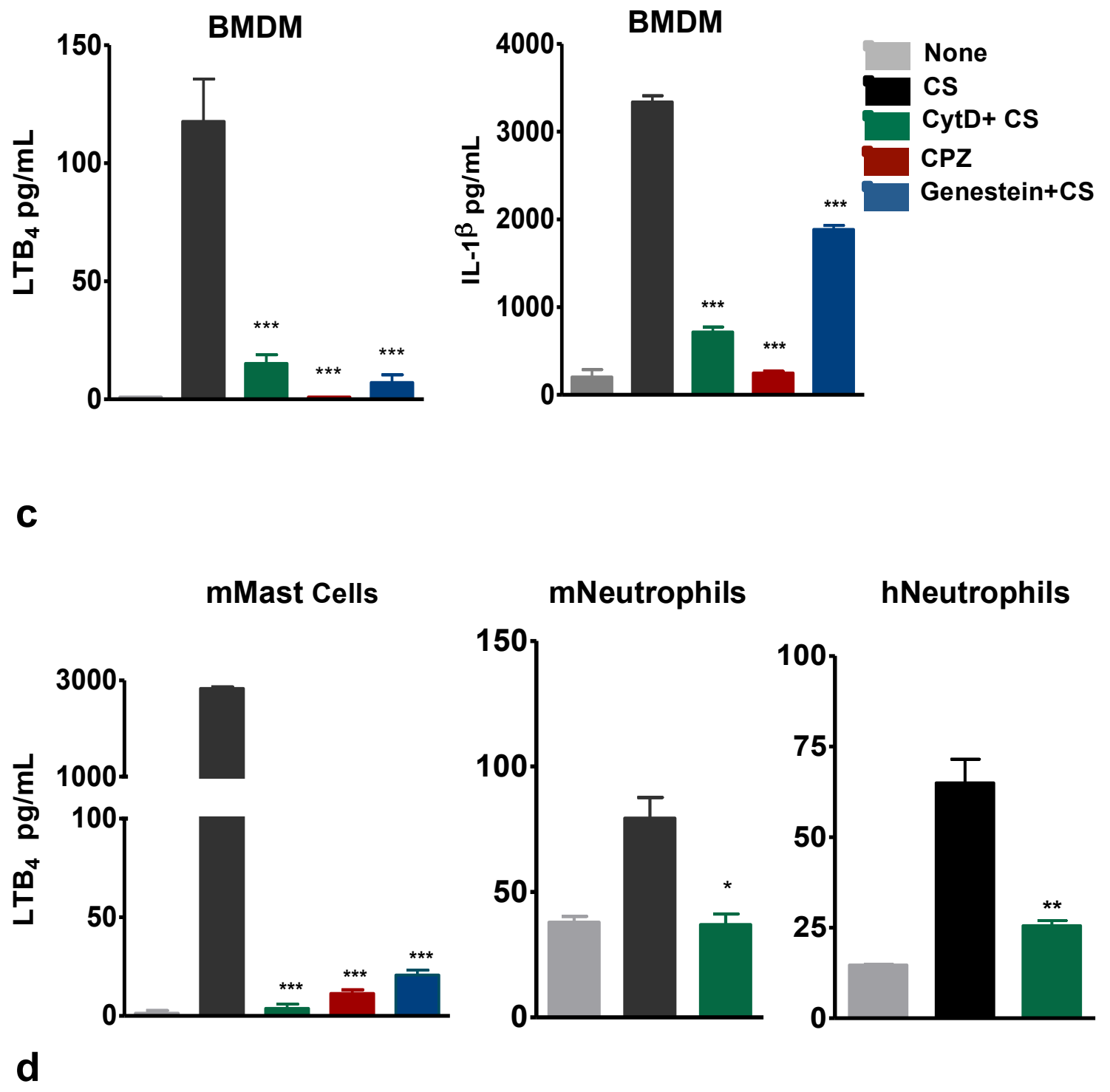

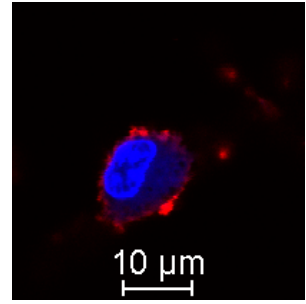

None

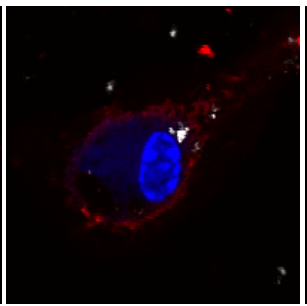

CS

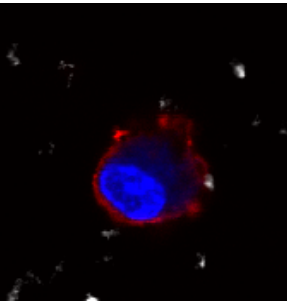

CytD+CS
DAPI (Nucleus)

Cholera toxin

(Membrane)

Reflection (CS) 
Figure 7. Phagocytosis is required for the production of CS-induced $\mathrm{LTB}_{4}$ and IL$1 \beta$ production. Bone marrow-derived macrophages (BMDM) from WT mice were LPSprimed and stimulated with $100 \mu \mathrm{g} / \mathrm{cm}^{2} \mathrm{CS}$ for $6 \mathrm{~h}$ in the presence or absence (control) of phagocytosis inhibitors Cytocholasin D, Chlorpramazine and Genestein. ELISA was done to asses (a) $\mathrm{LTB}_{4}$ levels (b) IL-1 $\beta$ levels in the cell culture supernatants. $\mathrm{LTB}_{4}$ production in (c) mouse bone marrow-derived mast cells, mouse bone marrow-derived neutrophils and human neutrophils upon stimulation with $100 \mu \mathrm{g} / \mathrm{cm}^{2} \mathrm{CS}$ in the presence phagocytosis inhibitors was measured using ELISA. Data represented is from one of the three experiments. Data are expressed as mean \pm SE. ${ }^{* *} \mathrm{p}<0.01, * * * \mathrm{p}<0.001$ nonparametric t-test. (d) CS uptake in the presence and absence of CytD was analyzed in LPS-primed BMDM, 2h post stimulation with $100 \mu \mathrm{g} / \mathrm{cm}^{2} \mathrm{C}^{\prime} \mathrm{S}$. Cell membrane was stained with fluorescent choler a toxin (red), nucleus with DAPI (blue) and CS particles were observed using reflective microscopy. 
a

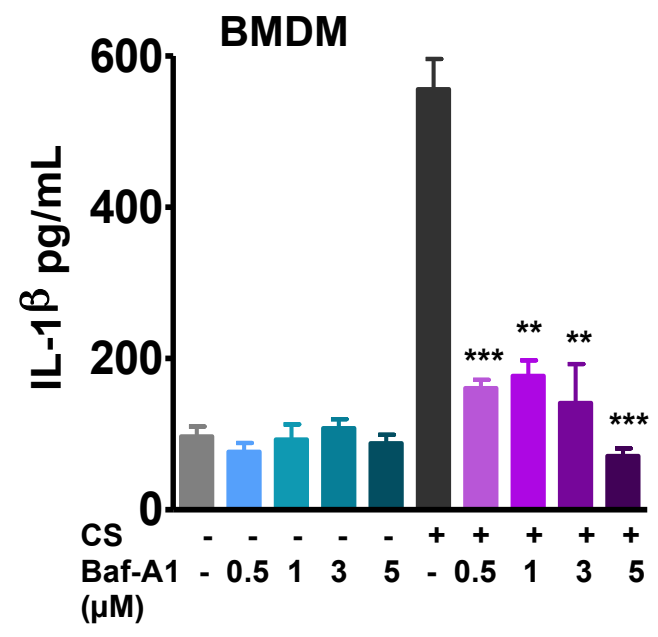

b

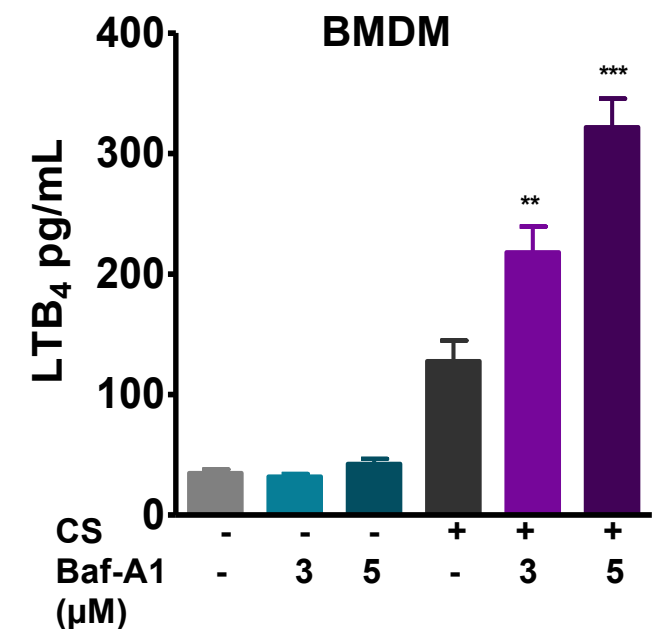

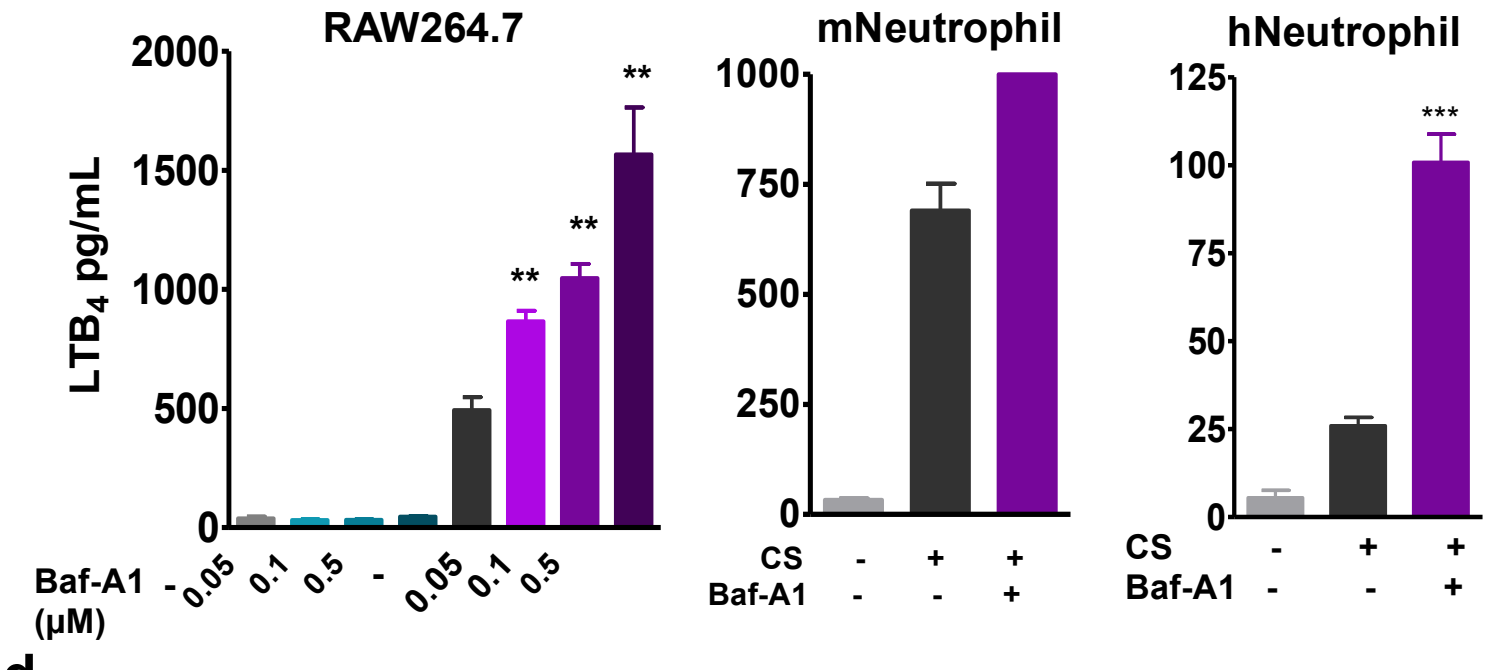
d

None

CS

Baf-A1+ CS
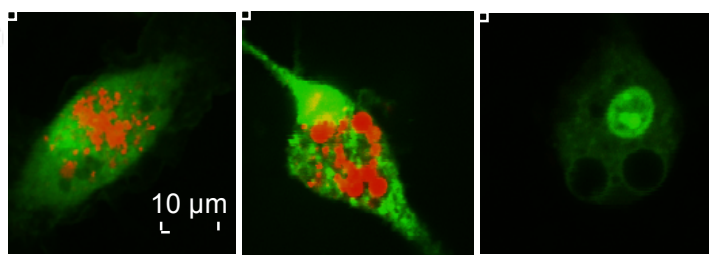

Acridine orange

(DNA/RNA, 
Figure 8. Inhibition of phagolysosome formation enhances $\mathrm{LTB}_{4}$ production. BMDMs derived from WT mice were LPS-primed and stimulated with $100 \mu \mathrm{g} / \mathrm{cm}^{2} \mathrm{CS}$ for $6 \mathrm{~h}$ in the presence or absence (control) of varying doses of Bafilomycin-A1. ELISA was done to assess (a) IL-1 $\beta$ and (b) LTB 4 levels in the cell culture supernatants. LTB $_{4}$ production in (c) LPS-primed RAW264.7 cells, mouse and human neutrophils upon stimulation with $100 \mu \mathrm{g} / \mathrm{cm}^{2} \mathrm{CS}$ in the presence of Baf-A1. 5-LO inhibitor Zileuton was used as a positive control in these experiments. Data represented is from one of the three experiments. Data are expressed as mean $\pm \mathrm{SE} . * * \mathrm{p}<0.01, * * * \mathrm{p}<0.001$ non-parametric $\mathrm{t}$ test. (e) LPS-primed BMDMs were stimulated with $35 \mu \mathrm{g} / \mathrm{cm}^{2} \mathrm{CS}$ for $3 \mathrm{~h}$ in the presence or absence of Baf-A1. Cells were stained with acridine orange (red) for 30 min after CS treatment and analyzed by confocal microscopy. 
a

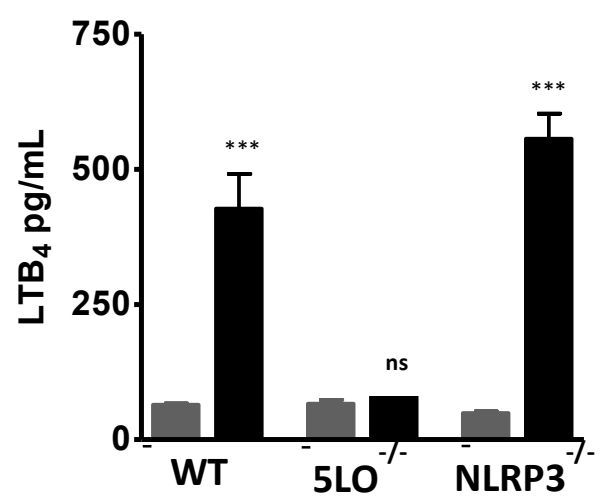

b

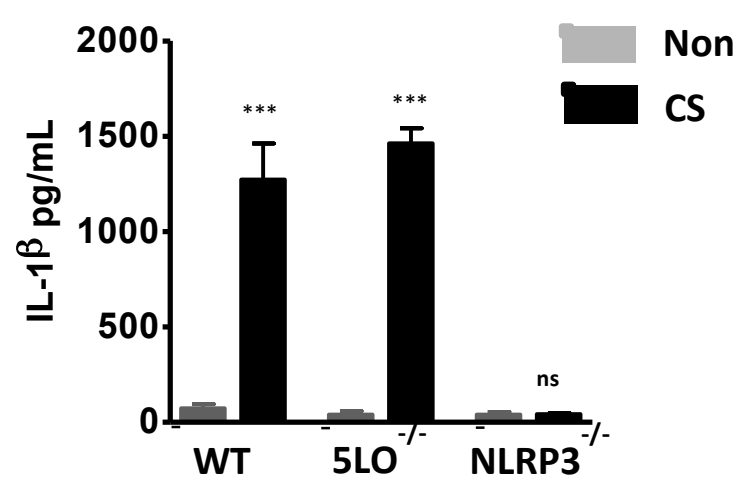

Figure 9: $\mathrm{LTB}_{4}$ production is independent of inflammasome activation and IL-1 $\beta$ production: LPS-primed BMDMs from WT, $5-\mathrm{LO}^{-/-}$and $\mathrm{NLRP}^{-/-}$were stimulated with $100 \mu \mathrm{g} / \mathrm{cm}^{2} \mathrm{CS}$ for $6 \mathrm{~h}$. ELISA was done to assess (a) $\mathrm{LTB}_{4}$ levels and (b) IL- $1 \beta$ levels in the cell culture supernatants. Data are expressed as mean $\pm \mathrm{SE} .{ }^{* *} \mathrm{p}<0.01,{ }^{* * *} \mathrm{p}<0.001$. $n s=$ not significant, non-parametric t-test. Representative experiment of $n=2$. 
DAPI (Nucleus), BODIPY (Lipid body)

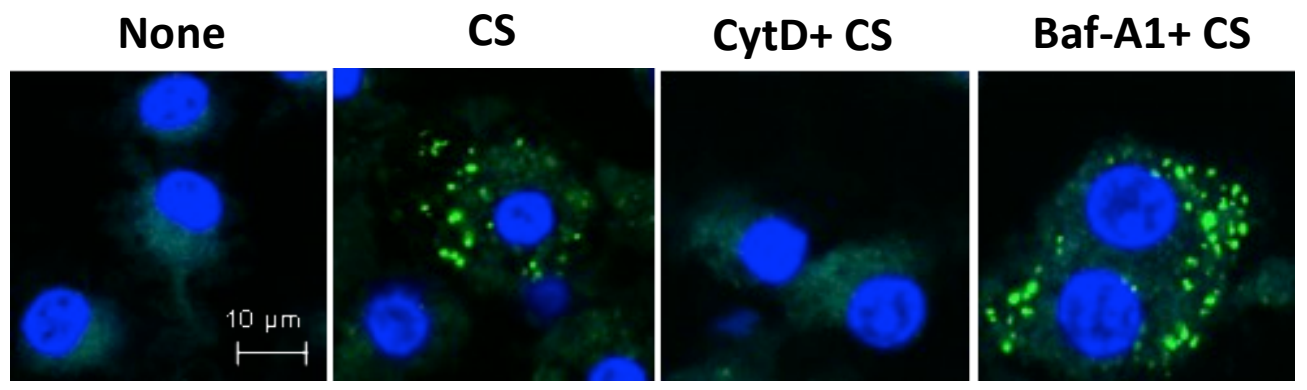

Intensity of lipid bodies

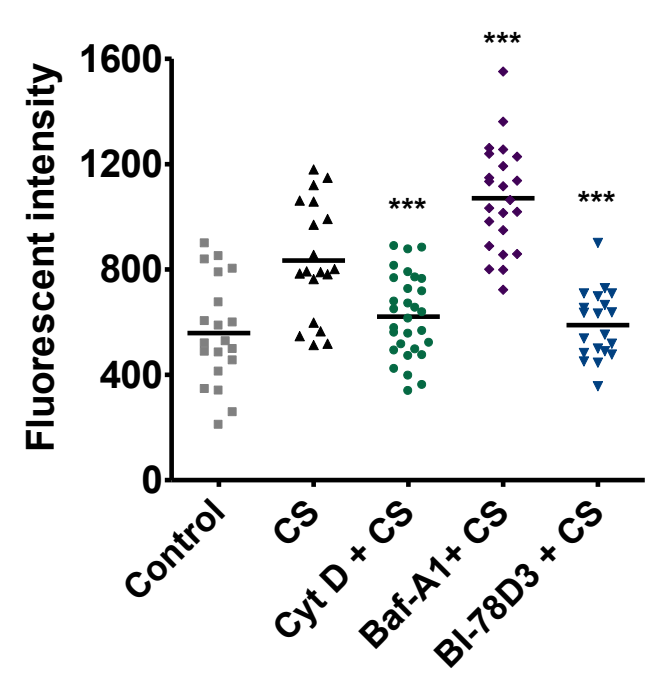

Lipid Bodies/ Cell

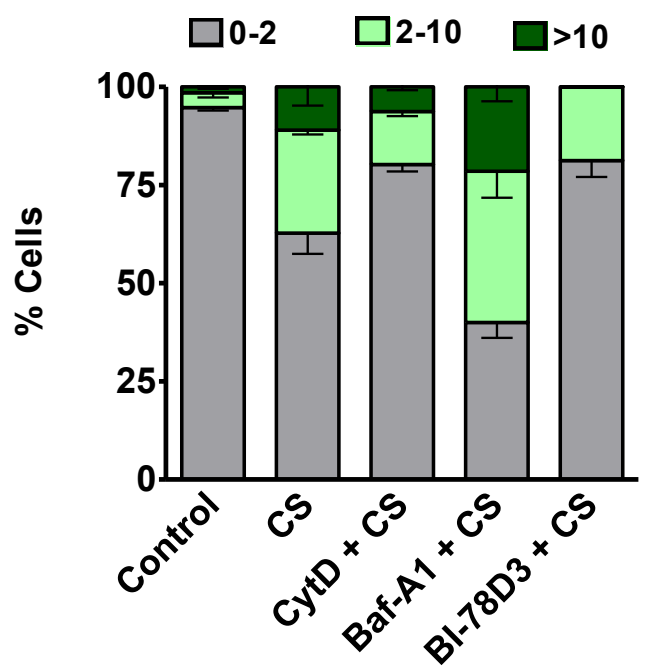

b

DAPI (Nucleus), Cholera Toxin (Membrane), Caspase-1 (Inflammasome)

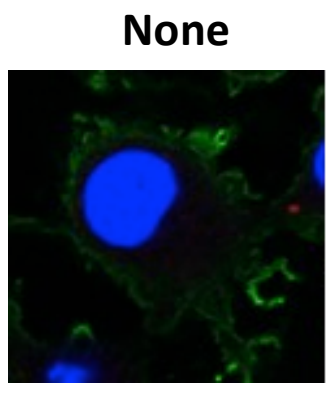

CS

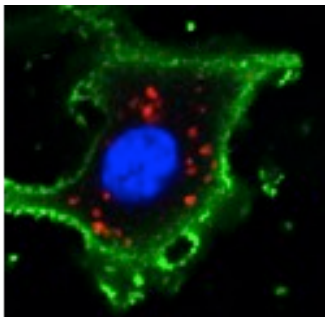

CytD+ CS

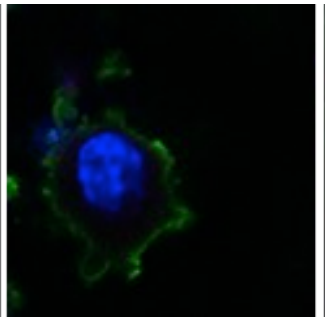

Baf-A1+ CS

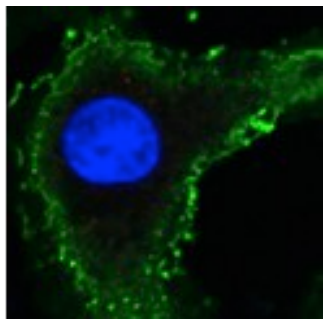


Figure 10. CS induces formation of lipid bodies. LPS-primed BMDMs were stimulated with $35 \mu \mathrm{g} / \mathrm{cm}^{2} \mathrm{CS}$ for $3 \mathrm{~h}$ in the presence or absence (control) of CytD or BafA1 (a) The cells were loaded with BODIPY (green) for 60 min. Subsequently, cells were fixed, permeabilized (saponin 0.01\%) and stained for nucleus using DAPI (blue) and analyzed by confocal microscopy to visualize lipid bodies (upper panel). Lipid bodies were quantified based on the intensity of BODIPY in cell (assessed in at least 20 cells/sample) and number of lipid bodies/cell (counted in at least 25 cells/sample). Representative experiment of $n=5$. (b) The cells were fixed, permeabilized and stained for: Caspase-1 (red), cell membrane using Cholera toxin (green) and nucleus using DAPI (blue), post CS-treatment to visualize inflammasome activation (lower panel). 


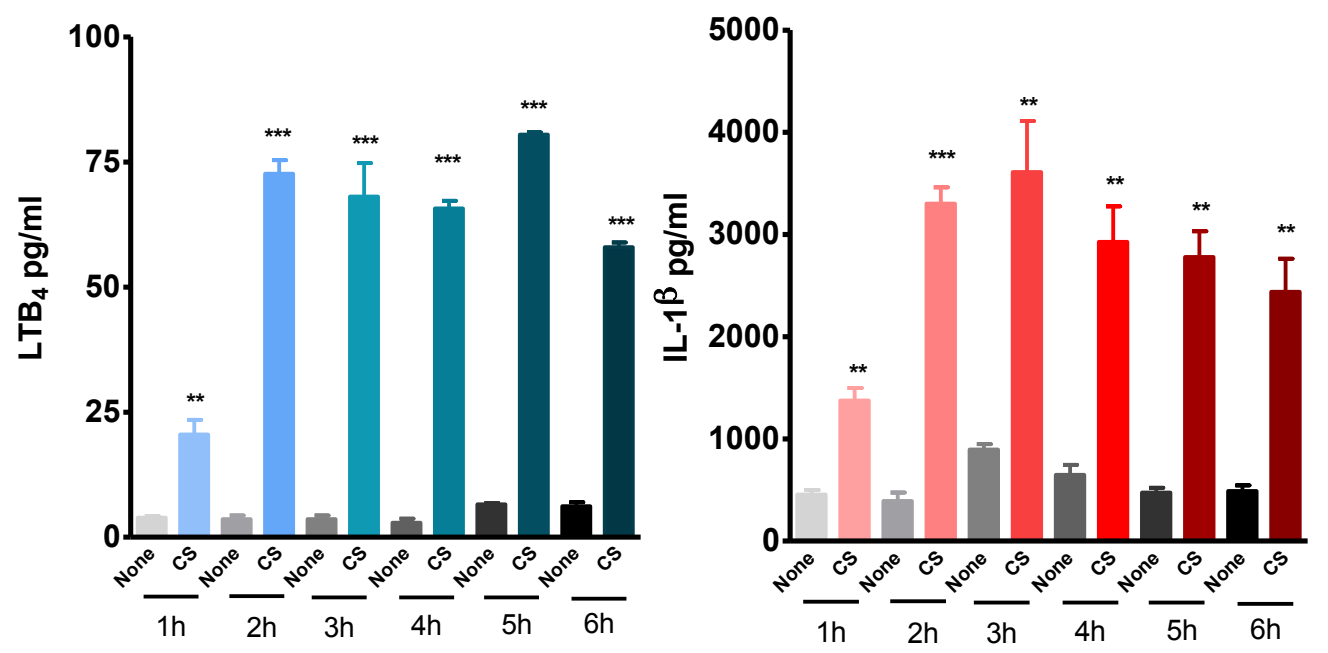

b

Hoechst Stain, BODIPY
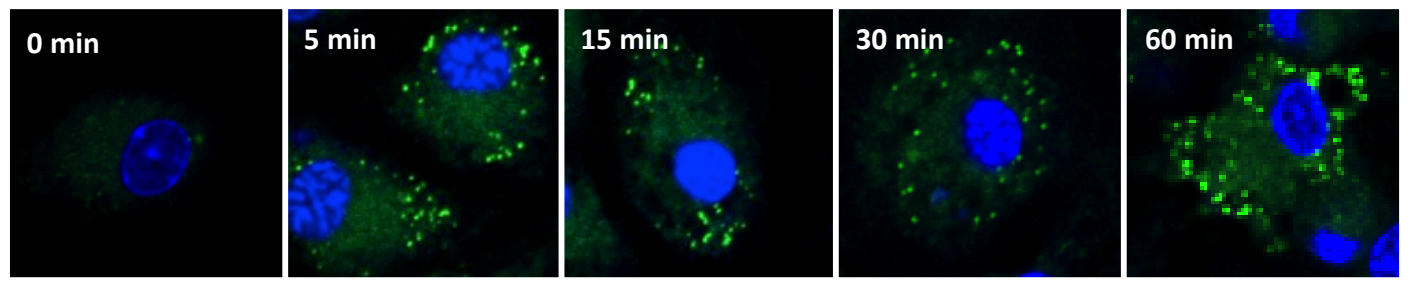

Hoechst Stain, Active Caspase-1
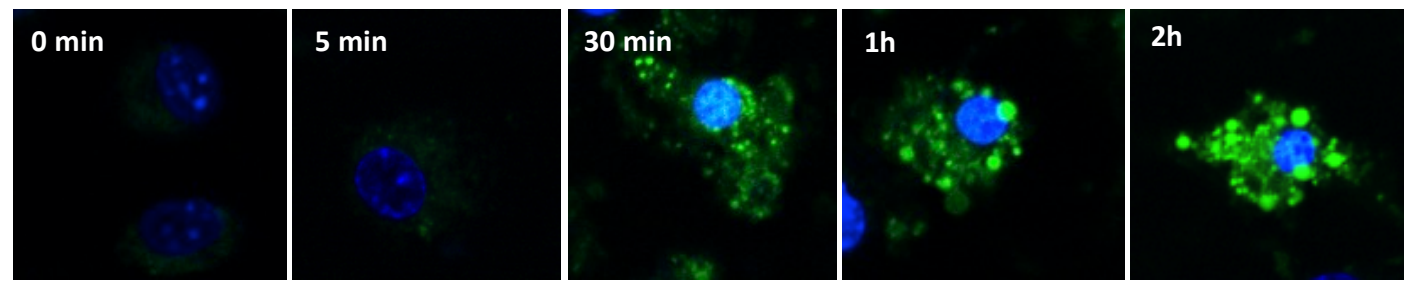
Figure 11. Kinetics of lipid body and inflammasome activation. LPS-primed BMDMs $\left(0.3 \times 10^{6}\right.$ cells in $400 \mu 1$ media) were stimulated with $100 \mu \mathrm{g} / \mathrm{cm}^{2} \mathrm{CS}$. (a) $\mathrm{LTB}_{4}$ and IL-1 $\beta$ levels were measured in the supernatants collected at the indicated time points from 1 hour through 6 hours. Data are expressed as mean \pm SE. $* * p<0.01, * * * p<0.001$ non-parametric t-test. (b) LPS-primed BMDMs were loaded with BODIPY or active caspase-1 stain along with nuclear Hoechst stain, stimulated with $35 \mu \mathrm{g} / \mathrm{cm}^{2} \mathrm{CS}$ and live cell images were captured at indicated time points to observe lipid body and inflammasome activation. Images shown are representative of one of the three experiments. 

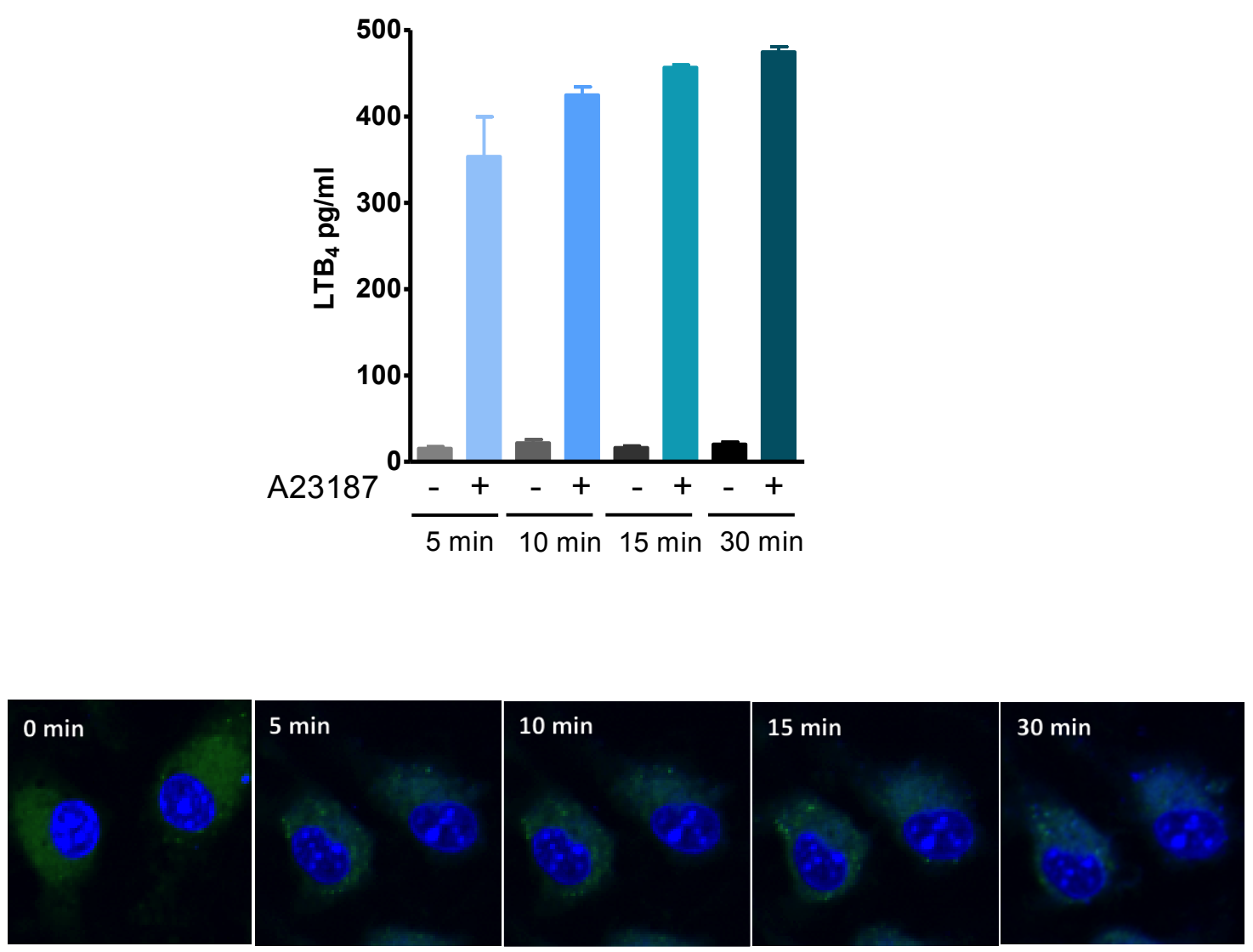

Figure 12. A23187 induces $\mathrm{LTB}_{4}$ production but not lipid body activation. LPSprimed BMDMs were stimulated with $\mathrm{A} 23187(10 \mu \mathrm{M})$ and $\mathrm{LTB}_{4}$ was measured in the supernatants. Representative experiment of $\mathrm{n}=3$. Data are expressed as mean \pm SE. $* * \mathrm{p}<$ $0.01, * * * p<0.001$ non-parametric t-test. In parallel cultures, the cells were stained with BODIPY at 5, 10, 15 and $30 \mathrm{~min}$ after A23187 $(10 \mu \mathrm{M})$ addition and confocal images 
were obtained. Representative Images from one of the three independent experiments are shown.

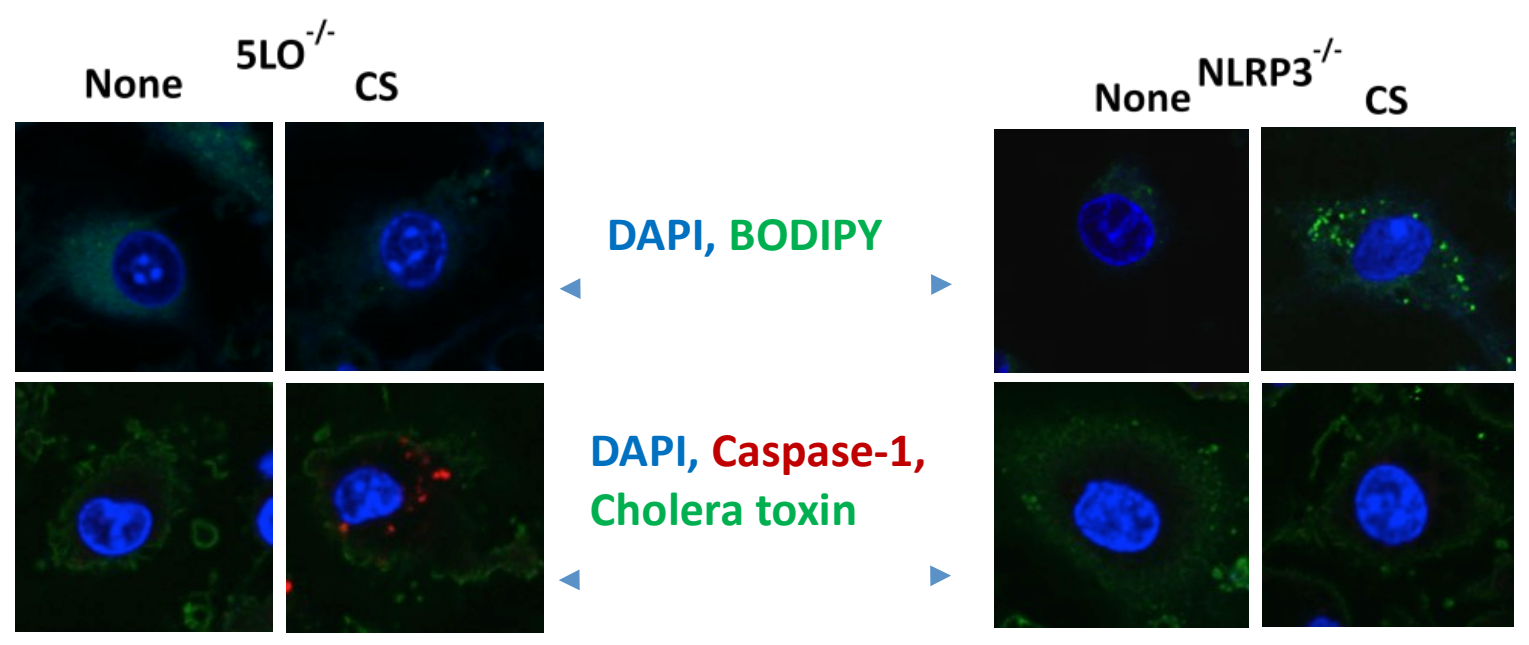

Figure 13. CS-induced lipid body formation is inflammasome independent. LPSprimed BMDMs from $5-\mathrm{LO}^{-/-}$and $\mathrm{NLRP}^{-/-}$were stimulated with $35 \mu \mathrm{g} / \mathrm{cm} 2 \mathrm{CS}$ for $3 \mathrm{~h}$. They were stained with: BODIPY (green) and DAPI (blue) to visualize lipid body formation (upper panels). The cells were also stained for Caspase-1 (red), cholera toxin (green) and DAPI (blue) to visualize inflammasome activation (lower panels). Images shown are representative from one of the three experiments. 


\section{CHAPTER IV}

\section{CHARACTERIZATION OF LIPIDOSOME}

\section{Introduction:}

Lipid bodies are highly regulated cytoplasmic organelles that are found in yeast, plant and eukaryotic cells [152]. They consist of a hydrophobic lipid core mostly consisting of triaclyglycerol and cholesterol lined by a single layer of phospholipid [153155]. They are called by various names such as adiposomes, oil bodies (plants), lipid droplets, etc. [156-158]. In mammalian cells, they are predominantly seen in adipocytes as fat storing organelles that release energy during starvation $[159,160]$. Recent studies have revealed that they are not just storage organelles but are induced in response to various stimuli. Leukocytes, including macrophages, neutrophils, mast cells, eosinophils, and basophils, can also induce cytoplasmic lipid bodies in response to various stimuli [161]. Naturally, their dysregulation is associated with various disease conditions like inflammation, cancer, diabetes, liver diseases and stress responses [162-166]. For example, macrophages that have densely packed lipid bodies, called foam cells, are associated with atherosclerosis $[102,167]$. 


\section{Biogenesis of lipid bodies}

Lipid body biogenesis involves formation of a monolayer bound organelle from a bilayer membrane [168]. Lipid bodies mostly arise from endoplasmic reticulum; however, they can also be derived from plasma membrane, endosomes, and mitochondria $[169,170]$. Several studies have shown lipid bodies to be closely associated with the phagosomes, although the physiological relevance of this is not known [171]. The mechanisms of budding of lipid droplets from the membrane is not well understood. Additionally, the proteins required for the formation of lipid bodies have also not been identified. In mammalian tissues, lipids are stored in lung, brain, and mammary glands in cytoplasmic lipid bodies. ADRP is highly expressed in all these tissues [172]. Adipocytes and steroidogenic cells in the adrenal cotex, ovarian follicles, and testis also store lipids in lipid bodies. The composition and formation of lipid bodies in the later is distinct from those present in mammary glands and brain. These possess perilipins in addition to ADRP [172]. Lipid bodies can be triggered in leukocytes in response to certain stimuli. Enzymes required for lipid synthesis, and proteins involved in membrane trafficking like specific Rabs and SNARES may be associated with lipid bodies, although the composition of lipid bodies may depend on its stimulatory conditions [173-175]. Lipid bodies are usually encompassed of three main proteins collectively known as the PAT proteins: Perilipins, ADRP (Adipose differentiation related protein) and TIP47 [102, 170, 176]. Proteomics, subcellular fractionation, and Western blotting techniques have 
revealed various other proteins to be localized within the lipid bodies. Two other proteins S3-12 and OXPAT are other coat proteins later discovered to be important $[177,178]$. Kimmel et. al described a new nomenclature for these coat proteins as follows: perilipin 1 for perilipin; perilipin 2 for ADRP; perilipin 3 for TIP47; perilipin 4 for S3-12, and perilipin 5 for OXPAT [179]. While perilipins 1 and 2 constitutively associated with lipid bodies, perilipins 3, 4, and 5 are exchangeable between cytosol and lipid body [180]. Skinner et. al have found perilipin 3 to be important the formation of lipid bodies from ER [181]. Attempts to characterize the signaling pathways required for biogenesis of lipid bodies have revealed that it is specific to the stimuli $[152,182,183]$. PAF induced lipid bodies involved increase in intracellular cAMP, which activates protein kinase A, which then activates perilipins which probably regulate lipid body formation $[152,182$, 183]. Nascent lipid bodies are of the size range 50-100 $\mathrm{nm}$ in diameter, whereas mature cytoplasmic lipid bodies have diameters in the range of 250-500 $\mathrm{nm}[184,185]$. Larger lipid bodies can arise from coalescence of smaller lipid bodies to form a single, larger lipid body [168].

Here, I characterize CS-induced lipid bodies that are activated upon phagocytosis of CS, independent of the inflammasome pathway. Using several staining techniques and RNAi approach, I sought to answer several important questions such as: 
Are lipid bodies merely a storage vesicle or site of $\mathrm{LTB}_{4}$ synthesis? Are the enzymes required for $\mathrm{LTB}_{4}$ synthesis such as 5-LO, FLAP, and $\mathrm{LTA}_{4} \mathrm{H}$ be localized to the lipid bodies?

Do other crystals similar to crystalline silica, inert particles, or infectious agents activate lipid bodies? Do they all correlate with $\mathrm{LTB}_{4}$ synthesis?

At what stage in the phagosome maturation pathway are lipid bodies formed? What are the molecules necessary for the formation of $\mathrm{LTB}_{4}$ associated lipid bodies? 


\section{Results:}

Lipid bodies are the primary site for CS-induced $\mathbf{L T B}_{4}$ production: To investigate whether the observed lipid bodies are in fact the source of CS-induced $\mathrm{LTB}_{4}$ production, LPS-primed BMDMs were stained for 5-LO, FLAP and $\mathrm{LTA}_{4} \mathrm{H}$, using specific antibodies, along with BODIPY, $3 \mathrm{~h}$ after CS stimulation. The enzymes required for LTB4 synthesis: 5-LO, FLAP, and $\mathrm{LTA}_{4} \mathrm{H}$ co-localized with the lipid bodies, confirming our hypothesis that they are not merely a storage vesicle but are the primary sites of CSinduced $\mathrm{LTB}_{4}$ production (Fig. 14).

Lipid bodies are closely associated with phagosomes: CS-induced $\mathrm{LTB}_{4}$ production in the lipid bodies appears to be seamlessly linked to the phagocytosis pathway. In order to spatially localize lipid bodies, the LPS-primed BMDMs were loaded with endosome stain pHrodo dextran along with BODIPY $3 \mathrm{~h}$ after CS treatment. A z-section and quantification using the intensity plot shows the close association of he two organelles (Fig. 15), providing a proof of connection between phagosome pathway and lipid bodies formation.

\section{LTB $_{4}$ production and lipid body formation with other phagocytic particles: Next, we} wanted to further explore the correlation between phagocytosis and lipid body formation. We used an array of phagocytic particles: Monosodium Urate (MSU) crystals, Zinc oxide nanoparticles, inert latex beads, and mCherry labeled E.Coli particles in this experiment. LPS-primed BMDMs stimulated with CS, MSU, E.Coli particles induced $\mathrm{LTB}_{4}$ 
production and lipid body formation (Fig. 16). Whereas, phagocytosis of $\mathrm{ZnO}$ nanoparticles or inert latex beads did not induce $\mathrm{LTB}_{4}$ production or lipid body formation. In agreement with previous studies, CS, MSU and latex beads were also capable of activating the inflammasome pathway and IL-1 $\beta$ production (Fig. 16).

\section{Molecular mediators of CS-induced lipidosome formation and $\mathrm{LTB}_{4}$ production:}

Since $\mathrm{LTB}_{4}$ production in response to CS occurs after phagocytosis and before the fusion of phagosome with the lysosome, we sought to identify specific components in the phagosome maturation pathway by siRNA knockdown experiments to identify the key molecules necessary for lipidosome formation. In previous studies, screening 18,000 murine genes for interference with Yersenia pestis persistence in macrophages led to identification of $\sim 300$ genes involved in the phagocytosis and autophagy pathway to be important for Y. pestis survival in macrophages. Of these, 110 genes were selected to investigate their role in CS-induced $\mathrm{LTB}_{4}$ production in RAW264.7 cells. RAW264.7 cells were incubated with the siRNA for $48 \mathrm{~h}$. The cells were then LPS-primed and stimulated with CS. After 6h, the $\mathrm{LTB}_{4}$ levels were measured in the supernatant using ELISA (Fig. 18a). Inhibition of these proteins led to more than $50 \%$ inhibition of $\mathrm{LTB}_{4}$ levels compared to the scrambled siRNA control. These included genes involved in phagocytosis such as clathrin, dynamin-2; GTPases Arf6, Rab1, Rab14, Rab40c; signaling kinases like PI3K, JNK1/2, PKA, PKC. In a second screen, we specifically examined proteins involved in lipid metabolism and adapters/ scaffold proteins and found 
that 5-LO, cPLA2- $\alpha$, Pld2 as well as Plin3, Hip1r, Akap1 were also critical in CSinduced $\mathrm{LTB}_{4}$ production. Almost sixty other genes in our screen such as Caveolin-1, Rab7, Rab8a, Rab20 and Seipin reduced the $\mathrm{LTB}_{4}$ levels by less than $50 \%$ relative to scrambled siRNA control (Fig. 17).

To further explore the contribution of some of these molecules in lipidosome formation, 7 genes (Table1) were selected. RAW264.7 cells were incubated with the siRNA for 48h. The cells were then LPS-primed and stimulated with CS. After $6 \mathrm{~h}$, the $\mathrm{LTB}_{4}$ levels were measured in the supernatant using ELISA (Fig. 18a). RAW264.7 cells plated in confocal dishes were transfected with siRNA for 48 hours. The cells were then LPS-primed, stimulated with CS for 3 hours and stained with BODIPY and nucleus stain DAPI to analyze lipidosome formation. $\mathrm{LTB}_{4}$ levels were measured in supernatants collected from cells plated in parallel after 6 hours of CS exposure. Knockdown of early endosome marker Rab5c, components of JNK pathway (JNK1, JIP1/2) and Rab40c inhibited $\mathrm{LTB}_{4}$ production whereas knockdown of ASC and Rab18 did not. Complete abrogation of lipid body formation was observed in the presence of Rab5c, JNK1 and Rab40c siRNAs (Fig 18). In concurrence with previous results, knockdown of inflammasome activation with LAMP1 and ASC enhanced lipidosome formation. To further validate whether Rab40c is an integral part of the lipidosome structure, LPS-primed BMDMs were stained with Rab40c along with BODIPY 3h after CS stimulation. Fig. 19 shows co-localization of Rab40c with lipidosome. 


\section{Discussion:}

Leukotriene biosynthesis was suggested to occur exclusively on the nuclear membrane after the translocation of 5-lipoxygenase (5-LO) into the nucleus [99, 186, 187]. However, recent studies have demonstrated that leukotriene synthesis can also take place in cytosolic lipid bodies [100,161, 188, 189]. Diverse physiological functions including lipid homeostasis, testosterone production and eicosanoid generation were attributed to lipid bodies that are variably named as lipid droplets, adiposomes, lipid bodies etc. [171, 190, 191]. However, not all of these are associated with $\mathrm{LTB}_{4}$ synthesis. Localization of eicosonoid synthesis enzymes within lipid bodies have confirmed that they could be sites of leukotriene synthesis depending on the cell type and the state of activation [101, 102, 152, 192, 193].

In our study the appearance of CS-induced lipid bodies in the cytoplasm correlated with the $\mathrm{LTB}_{4}$ production under similar conditions. Additionally, antibody staining of 5-LO, FLAP and $\mathrm{LTA}_{4} \mathrm{H}$ revealed that it is exclusively localized within the lipid bodies (Fig. 14), showing that they were the site of CS-induced $\mathrm{LTB}_{4}$ production. Here, we coined the term "lipidosome" to distinguish LTB $_{4}$ synthesizing lipid bodies from other similar but unrelated cytoplasmic organelles of lipid storage. Lipidosome is not only the physical form but also a functional complex that allows the coupling of phagocytosis to $\mathrm{LTB}_{4}$ production. The lipidosome can compartmentalize the enzymatic machinery necessary for leukotriene production. 
Simultaneous staining with pHrodo dextran and BODIPY showed nonoverlapping but close association of phagosome and lipidosome, providing evidence that it is an early event initiated by phagocytosis (Fig. 15). Interestingly, phagocytosis of Urate crystals and E.Coli, which induced $\mathrm{LTB}_{4}$ production in a similar fashion, also triggered lipidosome activation. Whereas phagocytosis of other particles such as $\mathrm{ZnO}$ nano particles or non-toxic latex beads did not induce $\mathrm{LTB}_{4}$ production or the appearance of lipidosome (Fig. 16). Calcium ionophore A23187 induced $\mathrm{LTB}_{4}$ production independent of lipid body formation, suggesting that CS-induced lipidosome is a distinct phagocytosis-dependent pathway that is different from the conventional synthesis on nuclear membrane. Phagocytosis-induced $\mathrm{LTB}_{4}$ synthesis appears to be a specific process, as uptake of $\mathrm{ZnO}$ and latex beads did not induce lipid body formation. The mechanisms that trigger the synthesis of $\mathrm{LTB}_{4}$ in lipid bodies needs further understanding. The differences in the kinetics of appearance, composition and functional significance of lipidosome activation during the uptake different materials also needs further investigation.

siRNA knockdown studies allowed further examination of the phagosome maturation pathway to lipidosome activation. Clearly, knockdown of large number of genes involved in phagocytosis pathways reduced the levels of CS-induced $\mathrm{LTB}_{4}$ synthesis (Fig. 17). Caveolin-1, which is a structural protein commonly found on plasma membrane is often associated with the lipid bodies [194]. In our study knockdown of 
Caveolin-1 resulted in inhibition of $\mathrm{LTB}_{4}$ production. Consistent with the results using Baf-A1 and inflammasome KO, knockdown of Rab7a, LAMP1 and ASC did not affect $\mathrm{LTB}_{4}$ production or lipidosome formation (Fig. 18). In agreement with our inhibitor studies and known roles of certain Rab proteins [195], knockdown of Rab5c and JNK pathway completely abrogated $\mathrm{LTB}_{4}$ production and lipidosome formation. Proteomic studies of lipid bodies in adipocytes have shown high concentration of Rab18 and Rab40c along with ADRP [196, 197]. Rab18 is one of the better-characterized proteins associated with lipid bodies. Although its function is not entirely understood, the studies indicate that Rab18 could have a role in biogenesis of ER-derived lipid bodies [197, 198]. Surprisingly Rab18 was not found to be essential for the formation CS-induced lipidosome or $\mathrm{LTB}_{4}$ synthesis (Fig. 18). However, Rab40c was clearly required for lipidosome formation. Antibody staining with Rab40c also revealed that it is co-localised with BODIPY, suggesting that it is an important structural component of the lipidosome (Fig. 19). Further studies are needed to determine the biochemical composition and activation mechanisms of the CS-induced lipidosome. 

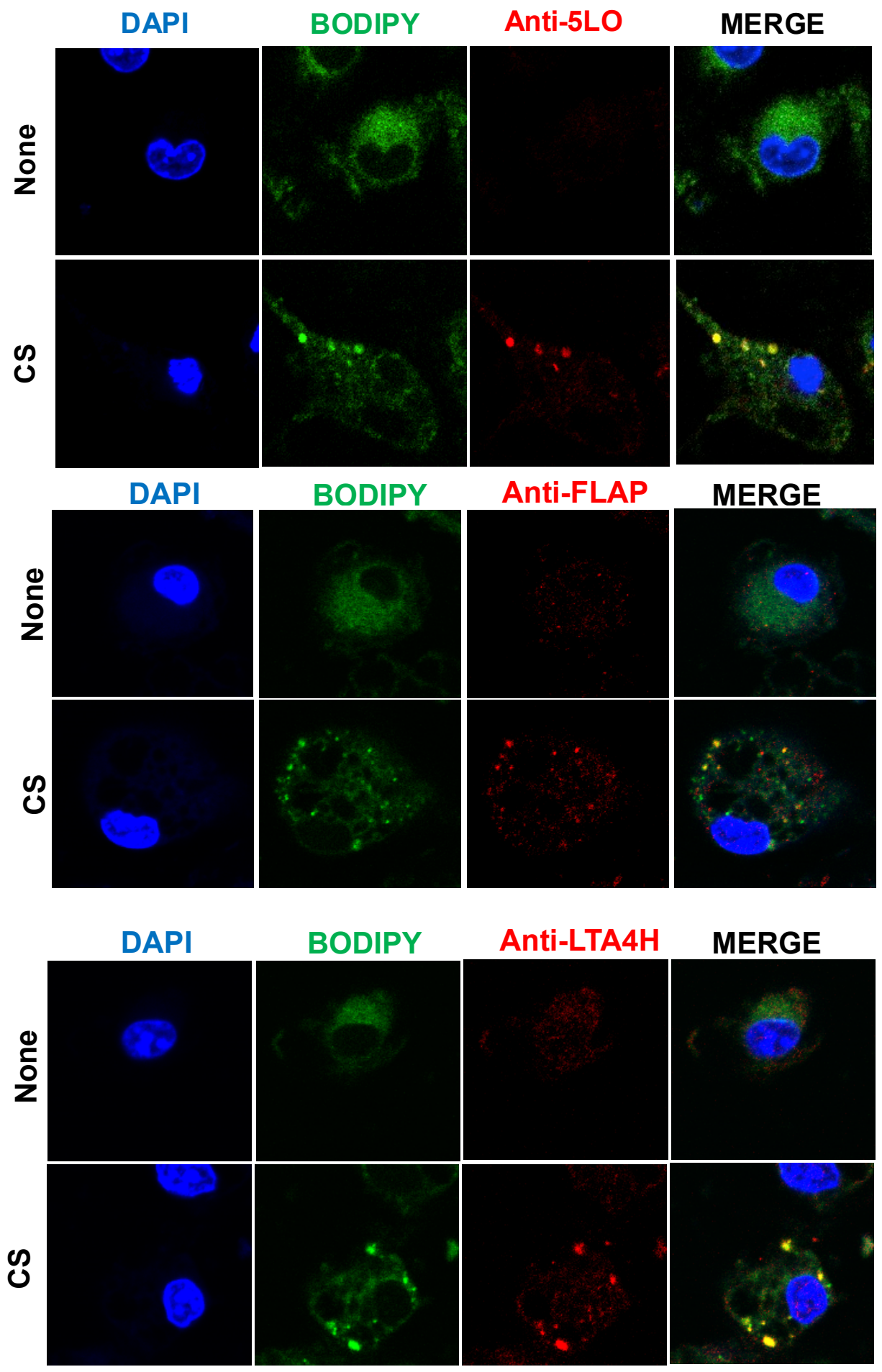
Figure 14. CS-induced LTB 4 production occurs in lipid bodies: LPS-primed BMDMs were stimulated with $35 \mu \mathrm{g} / \mathrm{cm}^{2} \mathrm{CS}$ for $3 \mathrm{~h}$. The cells were stained for 5LO, FLAP, or $\mathrm{LTA}_{4} \mathrm{H}$ (red) using specific antibodies and BODIPY (green) as described in the Materials and Methods. Images shown are representative from one of three independent experiments. 


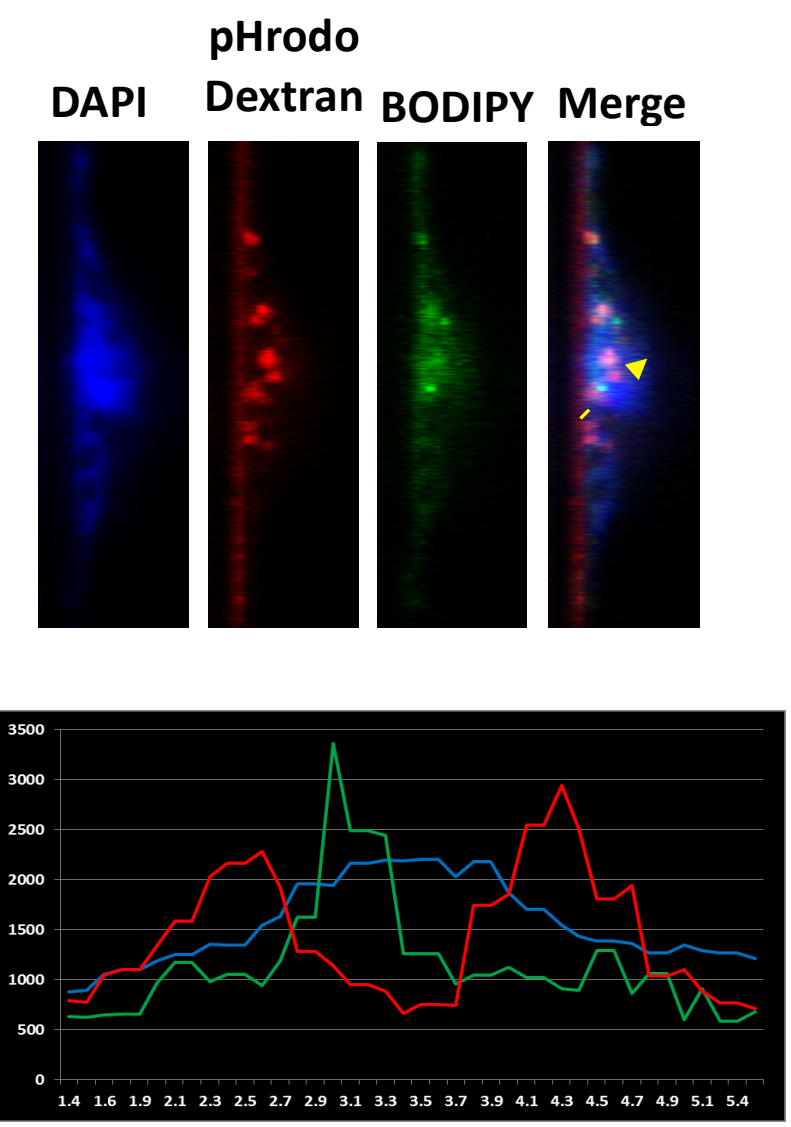

Figure 15. Lipid bodies are closely associated with phagosomes: LPS-primed BMDMs were loaded with pHrodo red dextran (red) and BODIPY (green) post CS stimulation. A slice of a z-stack showing appearance of lipid bodies and phagosomes. The intensity plot shows the proximity of non-overlapping green and red signals. The intensity plot shown is representative of ten separate measurements. 

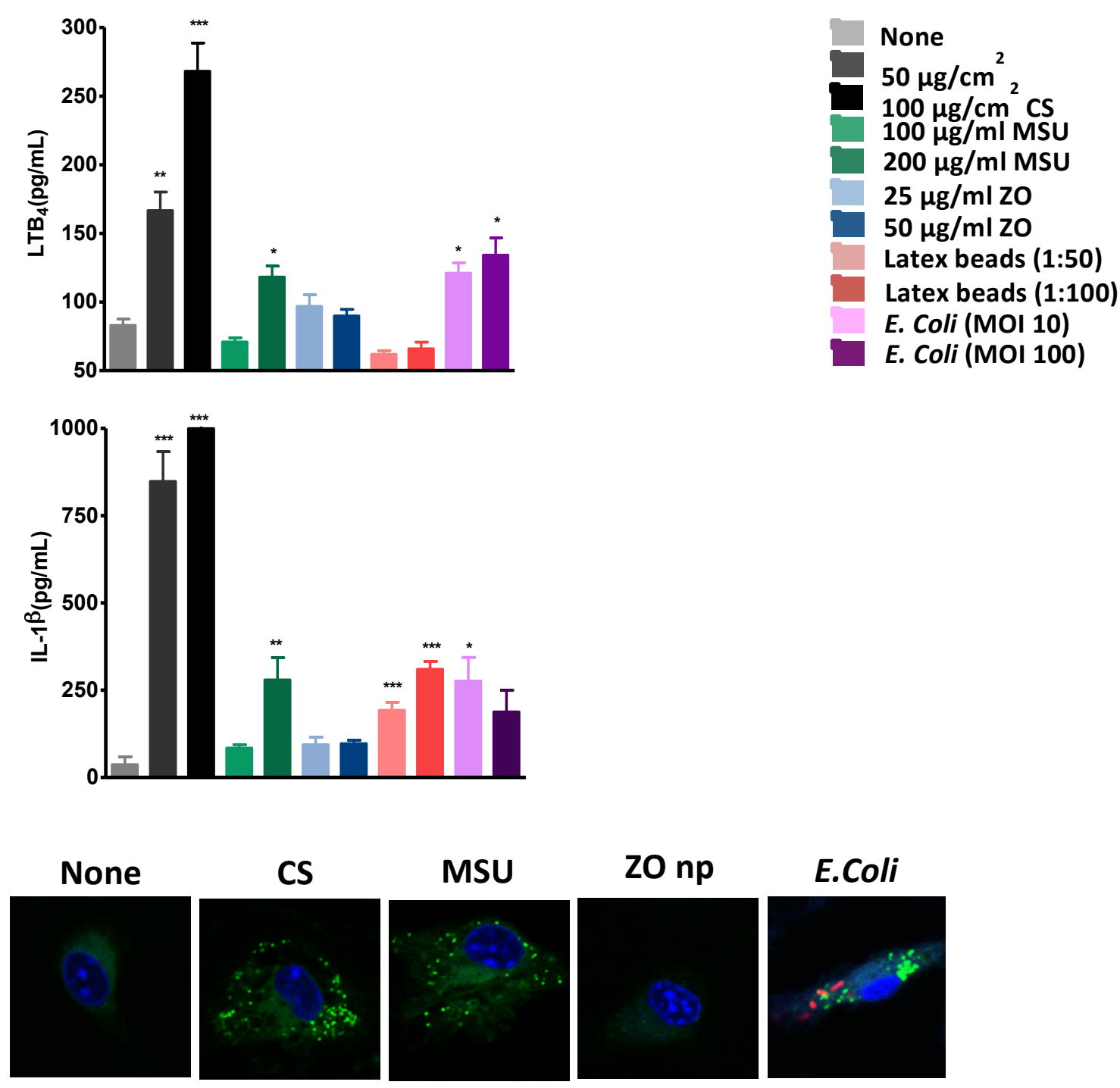
Figure 16. $\mathrm{LTB}_{4}$ production and lipid body formation with other phagocytic particles. LPS-primed BMDMs were stimulated with $100 \mu \mathrm{g} / \mathrm{cm}^{2} \mathrm{CS}, 100 \mu \mathrm{g} / \mathrm{ml}$ and 200 $\mu \mathrm{g} / \mathrm{ml} \mathrm{MSU}, 25 \mu \mathrm{g} / \mathrm{ml}$ and $50 \mu \mathrm{g} / \mathrm{ml}$ zinc oxide nano particles, fluorescent red latex beads and mCherry labeled E.Coli particles. (a) The supernatant was collected after $6 \mathrm{~h}$ and LTB $_{4}$ was measured using ELISA. (b) The cells were stained with BODIPY (green), DAPI (blue), cholera toxin (red) and particles (white). Representative experiment of $n=2$. Data are expressed as mean $\pm \mathrm{SE} .{ }^{*} \mathrm{p}<0.05,{ }^{*} \mathrm{p}<0.01,{ }^{* * *} \mathrm{p}<0.001$ non-parametric $\mathrm{t}$ test. 

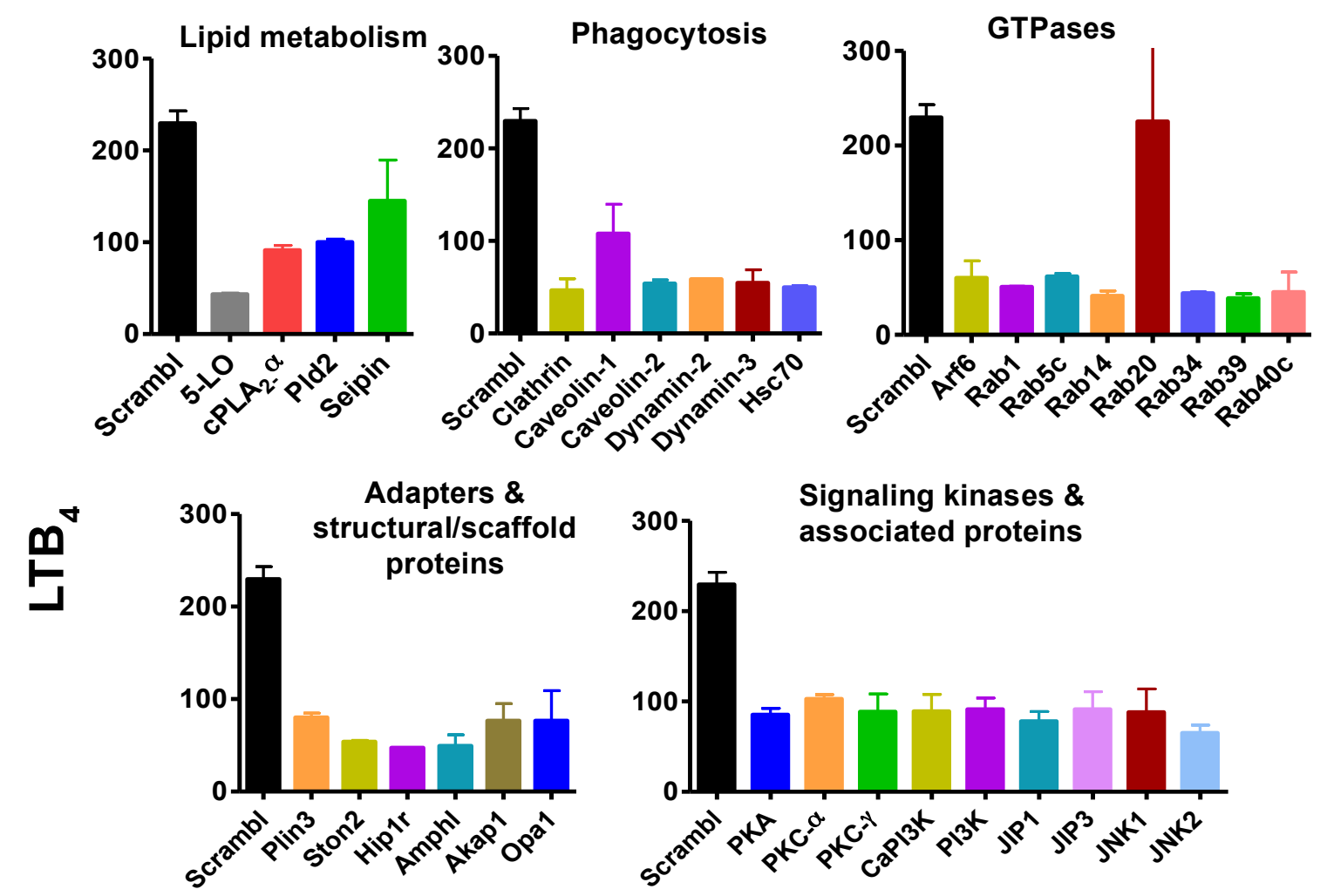

Figure 17. Molecular mediators of CS-induced LTB 4 production. RAW 264.7 cells were incubated with various siRNA as indicated for $48 \mathrm{~h}$. These cells were primed with LPS and stimulated with CS $\left(100 \mu \mathrm{g} / \mathrm{cm}^{2}\right)$ for $6 \mathrm{~h}$. After $6 \mathrm{~h}, \mathrm{LTB}_{4}$ in culture supernatants were measured. Data represent average inhibition of $\mathrm{LTB}_{4}$ production by at least two siRNA for each gene and are representative of at least two independent experiment. 
Table 2. Select siRNAs tested for their effects on lipidosome formation and LTB $_{4}$ production

\begin{tabular}{|r|l|l|c|}
\hline Sl.No & \multicolumn{1}{|c|}{$\begin{array}{c}\text { Gene } \\
\text { Symbol }\end{array}$} & \multicolumn{1}{|c|}{ Full Gene Name } & Gene ID \\
\hline 1 & Alox5 & Arachidonate 5-lipoxygenase & 11689 \\
\hline 2 & Rab5c & RAB5C, member RAS oncogene family & 19345 \\
\hline 3 & Pycard & ASC, inflammasome & 66824 \\
\hline 4 & Rab40c & Rab40c, member RAS oncogene family & 224624 \\
\hline 5 & Rab18 & RAB18, member RAS oncogene family & 19330 \\
\hline & & $\begin{array}{l}\text { mitogen activated protein kinase 8 } \\
\text { interacting protein 1 }\end{array}$ & 19099 \\
\hline 6 & Mapk8ip & 26419 \\
\hline 7 & Mapk8 & mitogen activated protein kinase 8 & \\
\hline
\end{tabular}



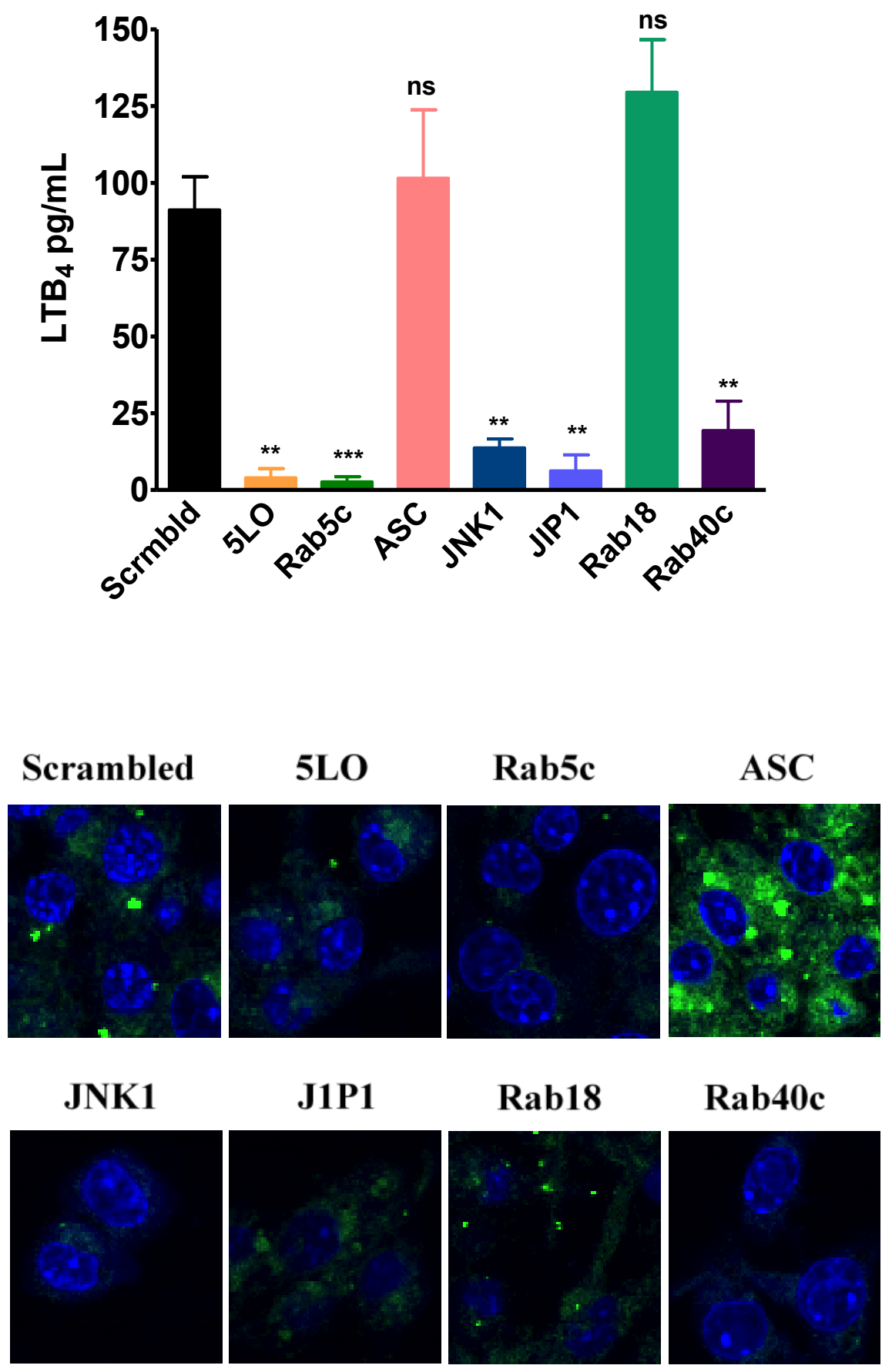
Figure 18. Molecular mediators of CS-induced lipidosome formation. RAW 264.7 cells were incubated with siRNAs as indicated, for $48 \mathrm{~h}$. Subsequently the cells were LPSprimed and stimulated with $100 \mu \mathrm{g} / \mathrm{cm}^{2} \mathrm{CS}$. $\mathrm{LTB}_{4}$ production after $6 \mathrm{~h}$ of CS-stimulation was measured using ELISA. The cells were stained for lipid bodies with BODIPY (green) and nucleus with DAPI (blue) 3h after CS stimulation. Representative experiment of $\mathrm{n}=3$. Data are expressed as mean \pm SE. $* * \mathrm{p}<0.01, * * * \mathrm{p}<0.001$ non-parametric $\mathrm{t}$-test. 


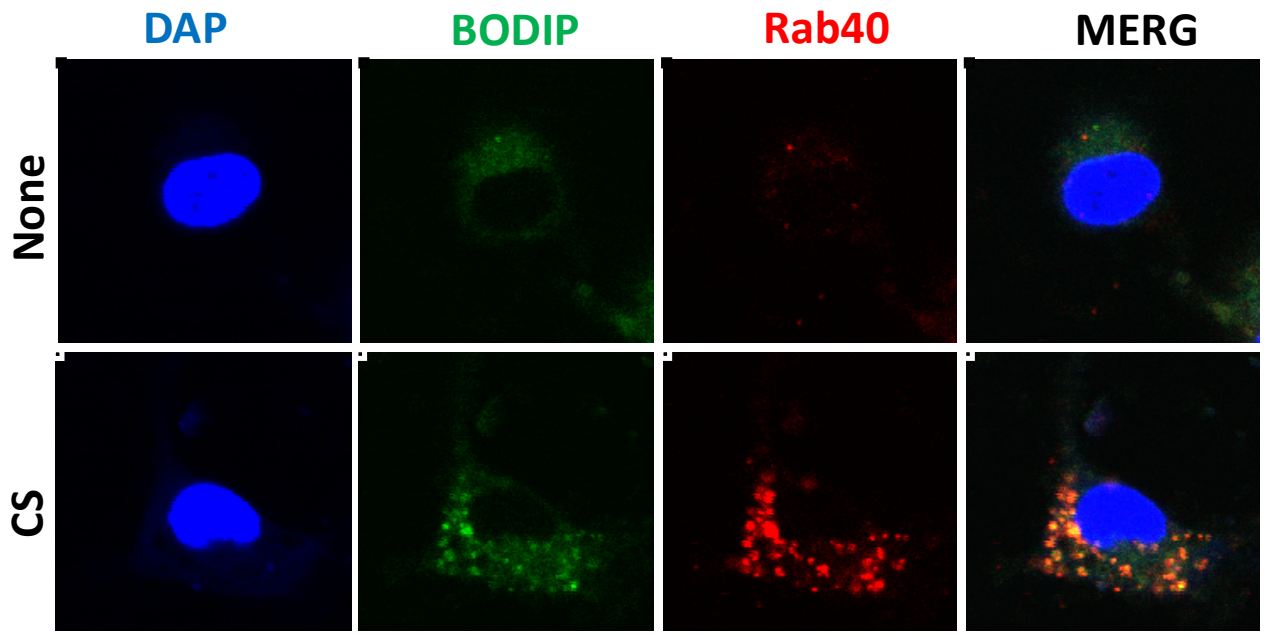

Figure 19. Rab40c is a structural component of lipidosome. After CS treatment, LPSprimed RAW 264.7 cells were stained for lipidosome (BODIPY, green). The cells were then fixed, permeabilized (saponin 0.01\%) and stained for Rab40c (red) and DAPI (blue). Representative images from one of the three experiments are shown. A minimum of five fields were captured for each sample in every experiment. 


\section{CHAPTER V}

\section{JNK ACTIVATION IS ESSENTIAL FOR CS-INDUCED LTB 4 AND IL-1 $\beta$ PRODUCTION}

\section{Introduction:}

Silica can cause a spike in the intracellular calcium levels, implicating that there is a possibility of intracellular signaling [199]. ERK1/2, JNK, and p38 MAP Kinases have roles in various signaling pathways activated by CS [199-201]. Silica nanoparticles have shown an upregulation of MEK-ERK1/2 signaling pathway, whereas p38 and JNK pathways were unaffected [202]. Conversely, silica was found to inhibit phosphorylation of ERK1/2 and p38 MAPK expression in dermal fibroblasts that resulted in increased type-1 collagen and decrease in collagen-degrading enzyme MMP-1, both contributing to increased fibrosis [203]. In another study with crystalline silica, Src tyrosine kinase was found to be important for CS-induced NF-אB activation [204]. Studies have also shown that Cox-2 expression is regulated both at the transcriptional and post-transcriptional level by members of the MAPK family [200, 205, 206]. Although MAP Kinases are 
crucial in various signaling pathways activated by CS, their role in activation of CSinduced $\mathrm{LTB}_{4}$ and IL-1 $\beta$ pathways is not well defined.

In chapters III and IV, we established that CS-induced $\mathrm{LTB}_{4}$ and IL-1 $\beta$ production are independently regulated. Understanding the role of signaling kinases in CS-induced lipidosome and inflammasome pathways would help us define these mechanisms better. This understanding might also provide useful insights into therapeutic strategies for silicosis or silica induced lung cancer.

Here, I investigate the role of MAPKs in CS-induced $\mathrm{LTB}_{4}$ and IL-1 $\beta$ production using specific pharmacological inhibitors. I used: AG126 that selectively inhibits the phosphorylation of ERK1 and ERK2, a potent p38 inhibitor SB202190, and BI-78D3, a competitive JNK inhibitor that inhibits binding of JNK to its interacting protein J1P1. Our preliminary results revealed that JNK pathway is important for both CS-induced $\mathrm{LTB}_{4}$ and IL-1 $\beta$ production. The role of JNK in CS-induced lipidosome formation and $\mathrm{LTB}_{4}$ production was further explored. JNK inhibitor, $\mathrm{BI}-78 \mathrm{D} 3$ was tested in an in-vivo air pouch model for CS-induced sterile inflammation. 


\section{Results:}

Activation of JNK pathway is essential for CS-induced $\mathrm{LTB}_{4}$ production: To investigate the involvement of MAP Kinases in CS induced $\mathrm{LTB}_{4}$ production, LPSprimed BMDMs were pre-treated with specific MAPK inhibitors prior to CS exposure. p38 inhibitor SB202190 $(10 \mu \mathrm{M})$ moderately inhibited $\mathrm{LTB}_{4}$ but not IL-1 $\beta$ production. MEK inhibitor AG-126 had no effect on production of CS-induced $\mathrm{LTB}_{4}$ or IL-1 $\beta$. JNK inhibitor BI-78D3 $(10 \mu \mathrm{M})$ significantly inhibited production of both $\mathrm{LTB}_{4}$ and IL-1 $\beta$ in BMDM (Fig. 20a-b). The inhibitory effect of BI-78D3 was confirmed in mast cells, mouse and human neutrophils (Fig. 20c). Real-time PCR analysis revealed that BI-78D3 significantly lowered the expression on CXCL1, 2, 3 and 5 neutrophil active chemokines (Fig. 21a). MTT assay revealed that treatment with BI-78D3 did not increase the cytotoxicity of BMDMs over the CS control (Fig. 21b). The JNK inhibitor also blocked Bafilomycin induced increase in $\mathrm{LTB}_{4}$ production in BMDM (data not shown). Together,

these results indicate that $\mathrm{JNK}$ activation is crucial for CS-induced $\mathrm{LTB}_{4}$ and IL-1 $\beta$ production.

Activation of JNK pathway is essential for lipidosome formation: To determine the requirement of JNK pathway in activation of lipidosome and inflammasome pathways, we used BODIPY and caspase-1 staining. LPS-primed BMDMs with/without pretreatment with pharmacological inhibitors were stimulated with CS for $3 \mathrm{~h}$, followed by staining with BODIPY. Inflammasome activation under similar conditions was measured 
by staining for active caspase-1. In the presence of BI-78D3, lipidosome and inflammasome were completely absent (Fig. 22). These results indicate that activation of lipidosome and inflammasome require JNK activation.

JNK signaling is required for CS-induced neutrophilic inflammation: Given that JNK inhibitor, BI-78D3, completely blocked the production of neutrophil chemokines $\mathrm{LTB}_{4}, \mathrm{IL}-1 \beta$ and CXC chemokines in macrophages, mast cells and neutrophils in our invitro studies, I wanted to test the efficacy of this compound in an in-vivo model. The air pouch model was used to study the effect of BI-78D3 on CS induced inflammation (Fig. 23). The air pouch formed provides a localized environment to study infiltration of immune cells in response to an inflammatory irritant $[207,208]$. This is also a convenient model to assess the anti-inflammatory efficacy of a test compound. Sterile air was injected into the back of the mouse and the air pouch was maintained for a week. BI78D3 $(10 \mathrm{mg} / \mathrm{kg})$ was injected into the air pouch an hour prior to CS injection (2 $\mathrm{mg} / \mathrm{mouse}$ ) into the air pouch. The air pouch was lavaged $6 \mathrm{~h}$ after CS administration with $3 \mathrm{ml}$ of cold PBS. Analysis of cellular infiltrates upon CS administration using cytospin and flow cytometry revealed that CS induced recruitment of leukocytes, mainly neutrophils and macrophages into the air pouch (Fig. 24a, b). Pre-treatment with BI-78D3 resulted in significant reduction in leukocytes especially neutrophils into the air pouch. These results indicate that BI-78D3 was effective in reducing CS-induced neutrophilic inflammation in-vivo by inhibiting the production of neutrophil chemokines in the air 
pouch.

\section{Discussion:}

Neutrophil mediated inflammation is the driving factor for progression of silicosis and CS-induced lung cancer. Activation of neutrophil chemoattractants $\mathrm{LTB}_{4}$ and IL-1 $\beta$ production is a hallmark of sterile inflammation $[45,55,56]$. Studies with ASC and NLRP3 KO mice showed decreased pulmonary inflammation and fibrosis after CS installation [2, 209]. Therefore, IL-1R antagonists and inflammasome inhibitors have been tested in various mouse models and in clinical trials for silicosis [45]. IL-1R antagonists showed moderate reduction in fibrosis and inflammation in some trials, however, its overall therapeutic benefit remains to be established. Similarly, although $\mathrm{LTB}_{4}$ has been implicated in various sterile-inflammatory diseases, $\mathrm{LTB}_{4}$ receptor antagonists and $\mathrm{LTA}_{4} \mathrm{H}$ inhibitors have not seen much success clinically due to the complexities involved in the pathway [210]. Therefore targeting the production both IL$1 \beta$ and $\mathrm{LTB}_{4}$ might be an effective strategy to control CS-induced neutrophilic inflammation.

Our in-vitro studies revealed that JNK activation was essential for CS-induced lipidosome formation and $\mathrm{LTB}_{4}$ production (Fig. 20, 22). Blocking JNK activation also blocked CS-induced IL-1 $\beta$ production (Fig. 20). Additionally, real-time data showed that the JNK inhibitor could lower the expression of neutrophil CXC chemokines CXCL2, 3 
and 5 (Fig. 21). Therefore, targeting $\mathrm{LTB}_{4}$, IL-1 $\beta$, and $\mathrm{CXC}$ chemokines production through JNK signaling could be an effective way of reducing CS-induced sterile inflammation. Hence, we tested the JNK inhibitor, BI-78D3 In-vivo and found that it blocked the recruitment of neutrophils into the air pouch and reduced CS-induced sterile inflammation (Fig. 24).

JNK pathway plays an important role in various cellular events and is implicated in diseases like diabetes, cancer, atherosclerosis and neurodegenerative diseases [211]. JNK activation has been associated with liver cancer [212, 213], glioma [214], leukemia [215], multiple myeloma [216] and lymphoma [217]. Studies have also found JNK signaling to play an important role in COPD associated mucus overproduction and tobacco smoke-induced lung tumor promotion [218, 219]. Strategies to target JNK signaling for cancer have resulted in the development of two broad categories of JNK inhibitors: ATP-competitive inhibitors and ATP-non-competitive inhibitors. The key issue with some of the commercially available JNK inhibitors targeting the ATP-binding site, is their potential "off target" effects as they display poor kinase specificity [220]. BI78D3 disrupts the interaction between $\mathrm{JNK}$ and its scaffold protein JNK interacting protein J1P1. In in-vitro studies, BI-78D3 was found to inhibit the phosphorylation of its substrate c-Jun but not ATF2 (which is a substrate of both JNK and p38) [221]. For this reason, BI-78D3 specifically inhibited JNK and J1P1 without causing cytotoxicity [221]. BI-78D3 has been tested in various animal studies for other indications. BI-78D3 was 
able to restore insulin sensitivity in a mouse model of type-2 diabetes [222]. BI-78D3 also blocked Con-A induced liver damage in mice [221].

One of the ways by which JNK could be inhibiting $\mathrm{LTB}_{4}$ synthesis is by directly targeting cPLA2 enzyme. Several reports suggest that JNK is required for cPLA2 activation [223, 224]. Additionally, both p38 and JNK MAPK activation is also reported to be essential for lipid droplet biogenesis by activation of cPLA 2 enzyme $[225,226]$. Our studies indicate that JNK activation is necessary for both $\mathrm{LTB}_{4}$ an IL-1 $\beta$ production. However, it is not clear from this study if an initial step required for activation of both the pathways is targeted by JNK inhibition. Okada et. al report that activation of TAK1-JNK pathway after lysosomal rupture is necessary for ASC oligomerization and complete activation of inflammasome [227]. Therefore, it is possible that JNK pathway could be regulating $\mathrm{LTB}_{4}$ and IL-1 $\beta$ production by two different mechanisms.

Our In-vitro data provides substantial evidence of the role of JNK pathway in CSinduced $\mathrm{LTB}_{4}, \mathrm{IL}-1 \beta$ and $\mathrm{CXC}$ chemokine production. Our preliminary in-vivo data suggests that BI-78D3 can effectively reduce CS-induced sterile inflammation. However, its efficacy in reducing silicosis and CS-induced lung cancer needs further evaluation. 
BMDM

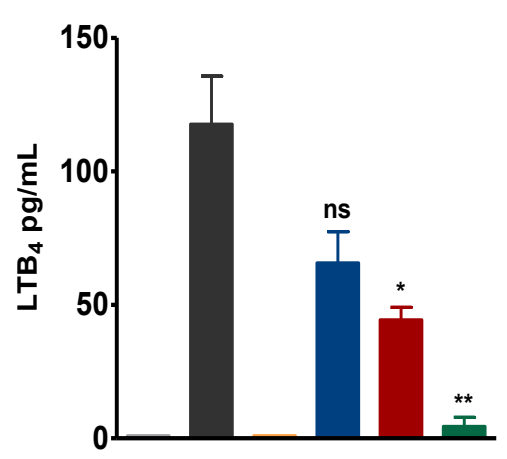

Mast Cells

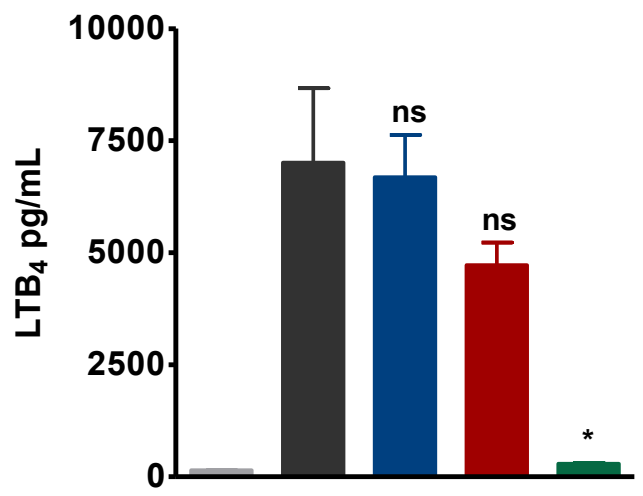

BMDM

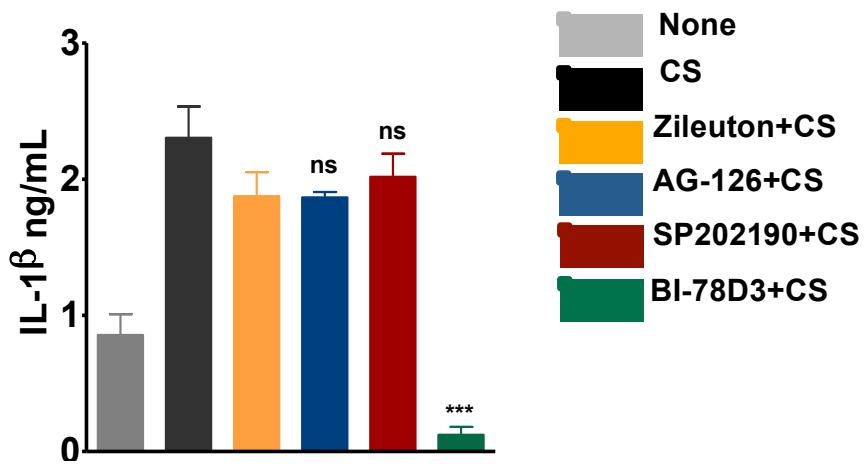

mNeutrophils

hNeutrophils

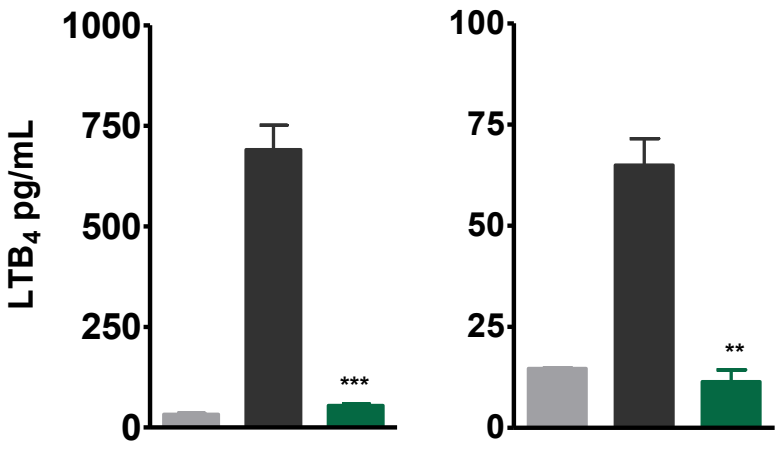


Figure 20. Activation of JNK pathway is essential for CS-induced $\mathrm{LTB}_{4}$ and IL-1 $\beta$ production. LPS-primed BMDMs were stimulated with $100 \mu \mathrm{g} / \mathrm{cm}^{2} \mathrm{CS}$ for $6 \mathrm{~h}$ in the presence or absence (control) of MAPK inhibitors: AG-126, SB-202190 and BI-78D3. Zileuton was used as a positive control for $\mathrm{LTB}_{4}$ inhibition. ELISA was done to asses (a) $\mathrm{LTB}_{4}$ levels and (b) IL-1 $\beta$ levels in the BMDM cell culture supernatants. ELISA was done to asses $\mathrm{LTB}_{4}$ levels in (c) mouse bone marrow-derived mast cells, mouse bone marrow-derived neutrophils and human neutrophils upon stimulation with $100 \mu \mathrm{g} / \mathrm{cm}^{2}$ CS in the presence MAPK inhibitors. 
a
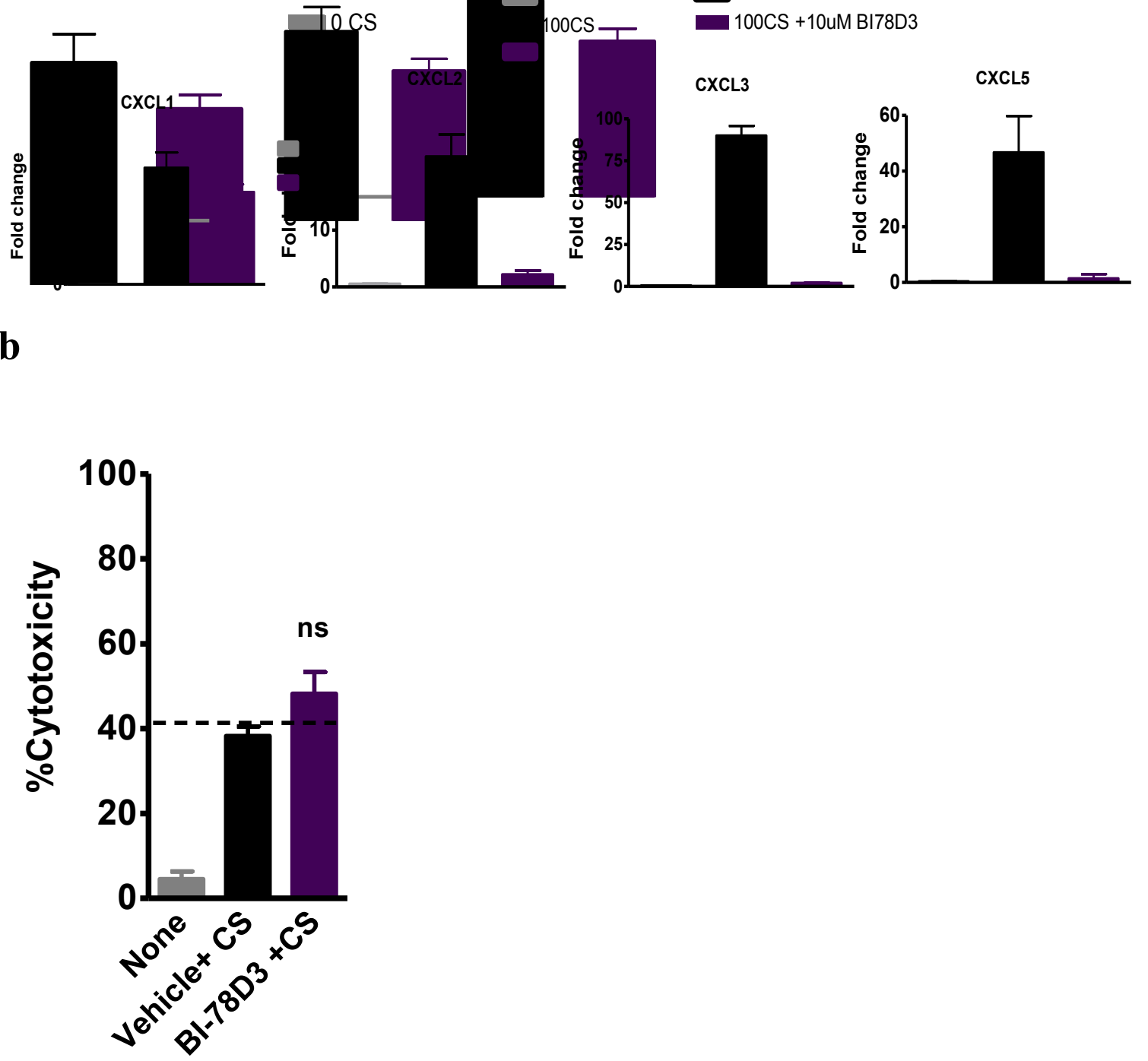
Figure 21. Effect of BI-78D3 on CXC chemokine expression and cytotoxicity. (a) Quantitative real time PCR of neutrophil-active chemokines was performed in the presence and absence of BI-78D3 in LPS-primed BMDM, 6h post exposure to CS. (b) Cytotoxic effects of BI-78D3 was measured by addition of 3-[4,5-dimethyltiazol-2-yl] 2,5-diphenyl-tetrazolium bromide (MTT) post CS-treatment. After 2h, absorbance was measured at $562 \mathrm{~nm}$ using a BioTek reader. Representative experiment of $n=3$. Data are expressed as mean $\pm \mathrm{SE}$. 


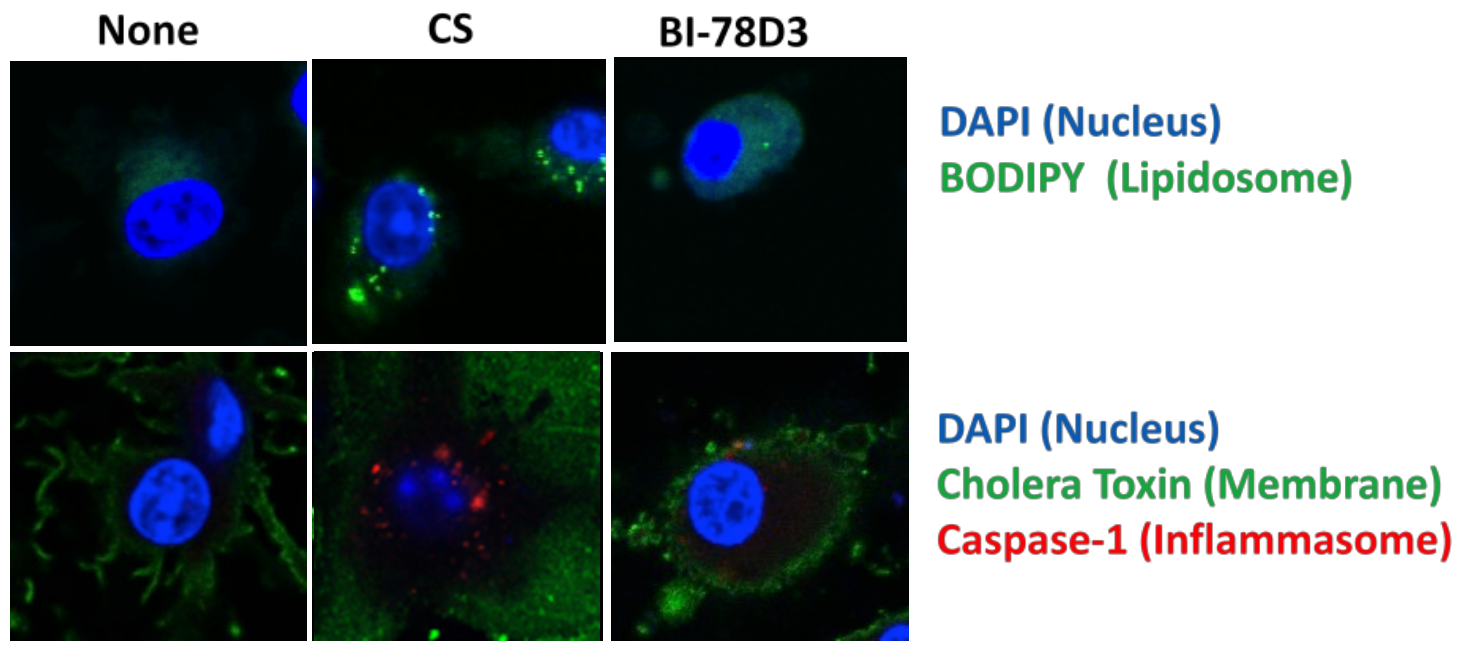

Figure 22. Activation of JNK pathway is essential for lipidosome activation: LPSprimed BMDMs were stimulated with $35 \mu \mathrm{g} / \mathrm{cm}^{2} \mathrm{CS}$ for $3 \mathrm{~h}$ in the presence or absence (control) of BI-78D3. The cells were loaded with BODIPY (green) for $60 \mathrm{~min}$. Subsequently, cells were fixed, permeabilized (saponin $0.01 \%$ ) and stained for nucleus using DAPI (blue) and analyzed by confocal microscopy to visualize lipid bodies (upper panel). The cells were fixed, permeabilized and stained for: Caspase-1 (red), cell membrane using Cholera toxin (green) and nucleus using DAPI (blue), post CS-treatment to visualize inflammasome activation (lower panel). 


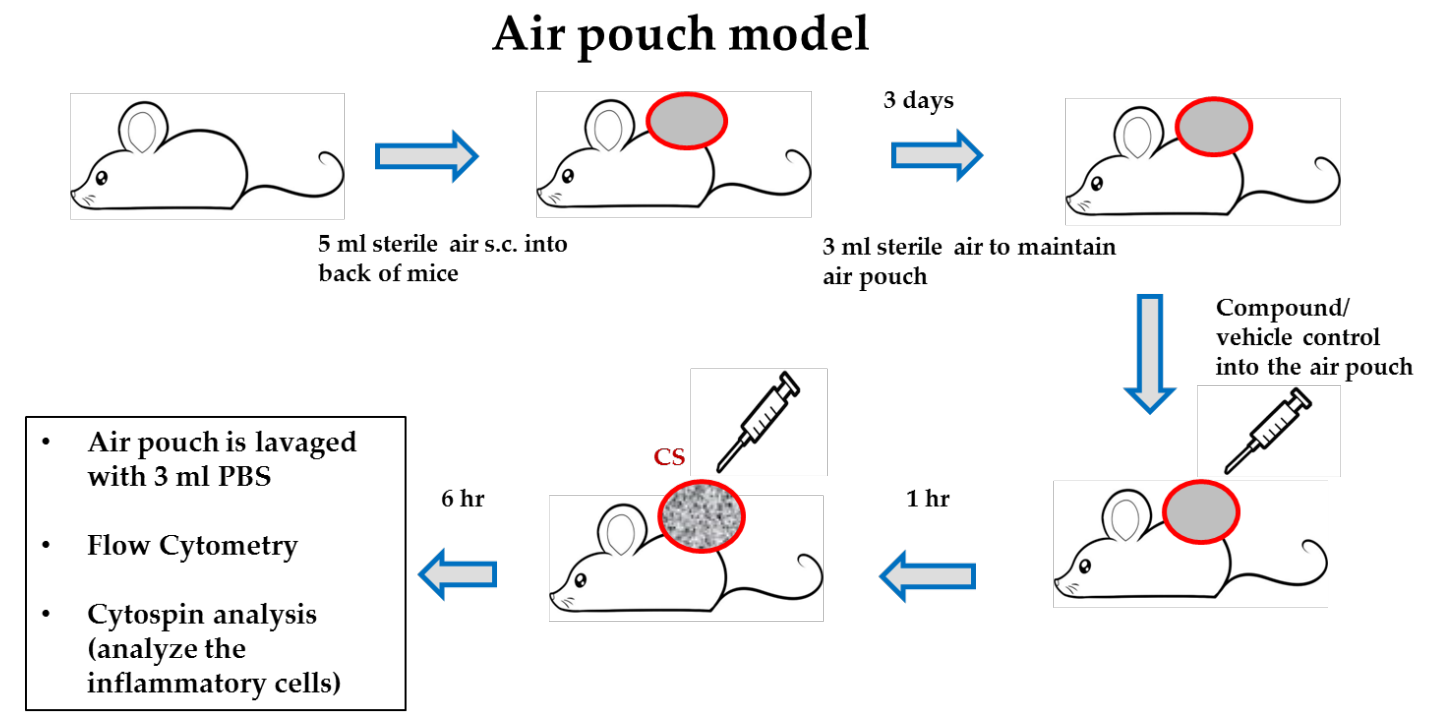

Figure 23. Experimental set-up of air pouch model: Sterile air is injected subcutaneously to the back of the mouse to form an air pouch. The air pouch is maintained for a week by injecting air on day 3. BI-78D3 is injected directly into the air pouch 1 hour prior to CS injection. After 6 hours the air pouch is lavaged with cold PBS and the cells are analysed using cytospin and flow cytometry. 


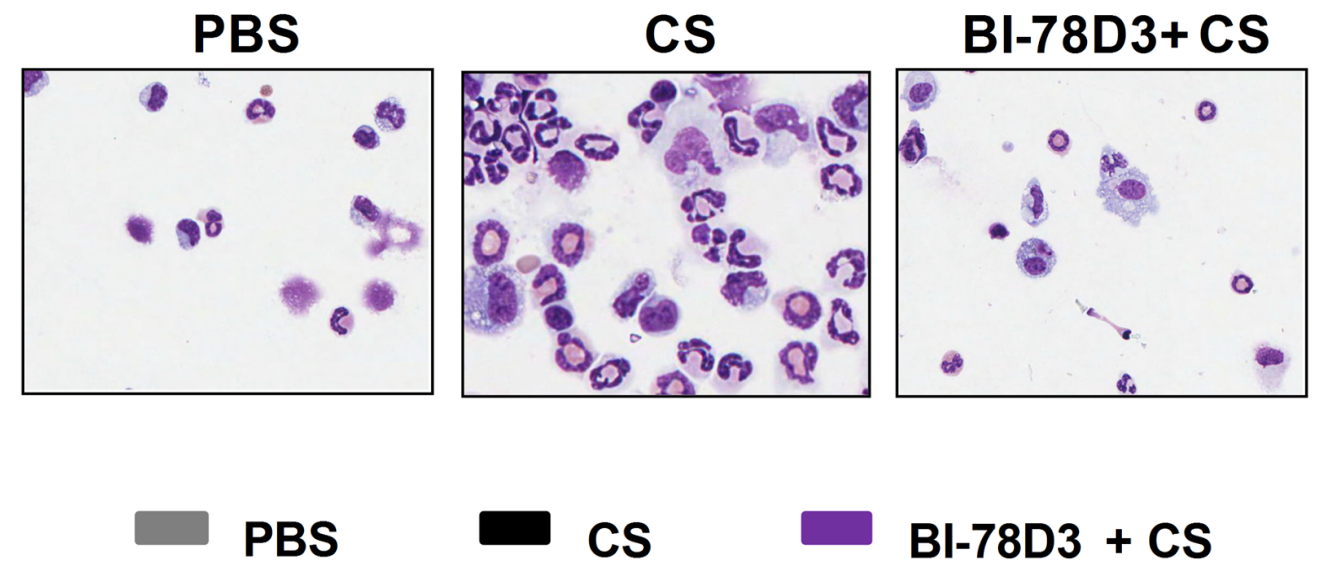

b

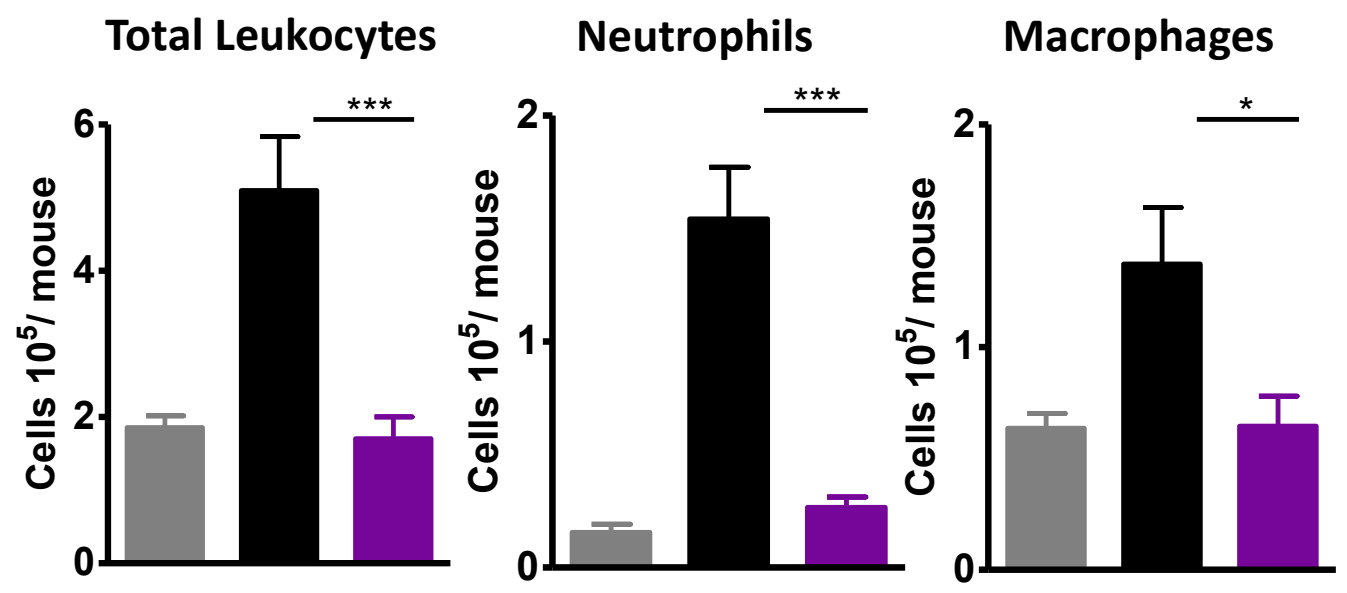


Figure 24. JNK signaling is required for CS-induced neutrophilic inflammation. Sterile air was injected subcutaneously to the back of the WT mice to form an air pouch. CS was injected into air pouch in the presence/absence of BI-78D3 and 6 hours later inflammation was assessed. (a) Leukocytes on cytospin slides and (b) total leukocytes, neutrophils and macrophages as identified by flow cytometry in the air pouch lavage fluid. Data are expressed as mean $\pm \mathrm{SE} .{ }^{*} \mathrm{p}<0.05, * * * \mathrm{p}<0.001$ non-parametric $\mathrm{t}$-test. Data are representative of at least nine mice per group. 


\section{CHAPTER VI}

\section{CONCLUSION}

Silicosis is an irreversible, progressive inflammatory disease caused by acute or chronic exposure to silica particles [13]. Despite preventive measures taken for decades, it continues to be a health concern worldwide [3]. Although the overall incidences have decreased substantially in the U.S over the last 30 years, silicosis cases that were earlier under-reported due to poor surveillance are now coming to light $[12,228]$.

Silica exposure increases the risk of tuberculosis and other mycobacterial, fungal, and bacterial lung infections, even without silicosis [17]. Silicosis could lead to autoimmune diseases such as scleroderma, sarcoidosis, rheumatoid arthritis and lung cancer [13]. So far, silicosis remains a preventable disease with no cure. Understanding the CS-induced pathways will provide key insights on the pathogenesis of silicosis and help in identifying the molecular targets that could halt its progression.

Neutrophil recruitment from blood to the extravascular sites of damage is a hallmark of sterile inflammation [38]. Among the molecular mediators, $\mathrm{LTB}_{4}$ plays a 
critical role. $\mathrm{LTB}_{4}$ is unique as it can amplify the local cell death signal to enhance neutrophil recruitment. Lammermann et. al. demonstrated that initial chemotaxis is followed by a second phase of neutrophil swarming from distant sites in a sterile skin injury model [38]. This could be attributed to phagocytosis of dead cells that enhances autocrine $\mathrm{LTB}_{4}$ production and signaling [38]. We find similarities in our study in the silicosis model where mast cell and macrophage- produced $\mathrm{LTB}_{4}$ leads to a sustained neutrophilic inflammation perpetuated by dead cells. In this study, we demonstrated that $\mathrm{LTB}_{4}$ production in these cells is closely linked to the phagocytosis maturation pathway. In fact, we found that several molecules like Dynamin, Clathrin and Rab GTPases Rab5 and Rab40 play a role in $\mathrm{LTB}_{4}$ production.

Inflammasome is a well-studied pathway in pathogenesis of silicosis [45]. Here, we showed that CS-induced $\mathrm{LTB}_{4}$ production is independent of the inflammasome pathway. We showed for the first time that CS-induced $\mathrm{LTB}_{4}$ synthesis mainly occurs in cytoplasmic lipid bodies. Lipid bodies, lipid rafts, oil bodies etc. are described in various studies [157]; however, some are not linked to inflammation. Peter Weller and colleagues described eicosanoid synthesis in lipid bodies which are similar to the lipid bodies in our study. We coined the term "lipidosome" to describe the functional unit of $\mathrm{LTB}_{4}$ synthesis that occurs in lipid bodies and to differentiate it from other lipid bodies not related to phagocytosis-dependent $\mathrm{LTB}_{4}$ synthesis. Careful analysis of time-lapse images showed that lipidosome activation occurs prior to inflammasome activation. 
We also demonstrated that JNK activation is essential for both lipidosome and inflammasome activation. JNK inhibitor BI-78D3 was effective in reducing CS-induced sterile inflammation in an air pouch model. Hence, targeting the JNK pathway may be good strategy for silicosis and silicosis associated lung cancer. Figure 25 summarizes the key findings of this dissertation in a diagram.

Overall, this study describes a unique phagocytosis and JNK activation-dependent pathway for CS-induced $\mathrm{LTB}_{4}$ production in lipidosome. More importantly, it highlights the underappreciated role of $\mathrm{LTB}_{4}$ in CS-induced sterile inflammation. Better understanding of the cellular mechanisms involving CS-induced $\mathrm{LTB}_{4}$ synthesis may provide valuable insights into therapeutic interventions of silica-associated disease. 


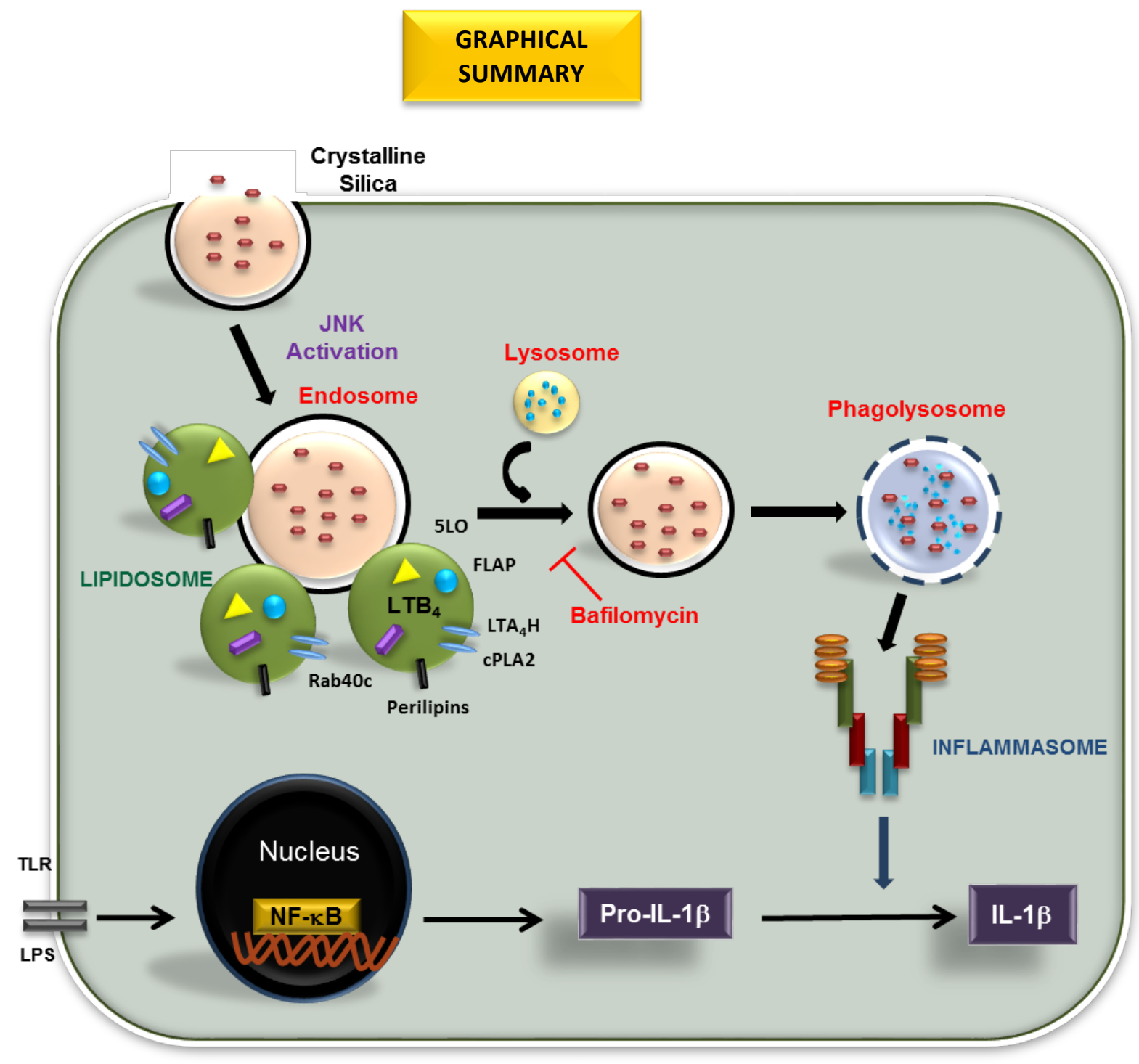

Figure 25. Graphical Summary. Cells take up silica by phagocytosis. During phagosome maturation process distinct lipid bodies appear in the cytosol that are the primary source of CS-induced $\mathrm{LTB}_{4}$ production. JNK activation is required for both $\mathrm{LTB}_{4}$ and IL-1 $\beta$ production. Lipidosome is formed independent of inflammasome 
activation. Enzymes required for $\mathrm{LTB}_{4}$ production, Rab40c are essential structural components of CS-induced lipidosome.

\section{FUTURE DIRECTIONS}

This dissertation describes a novel mechanism for CS-induced $\mathrm{LTB}_{4}$ production in cytoplasmic lipidosome that is JNK dependent and inflammasome independent. Although this study outlines the basic mechanism of CS-induced $\mathrm{LTB}_{4}$ synthesis, it raises several important questions that are worth exploring.

Our studies here indicate that uptake of CS induces $\mathrm{LTB}_{4}$ synthesis in cytoplasmic lipidosome. The fact that only specific phagocytic substances can trigger lipidosome indicates a potential signal that is recognized by the $\mathrm{LTB}_{4}$ pathway. The "triggers" that induce assembly and activation of lipidosome are not known. The differences in the mechanisms of phagocytosis-dependent $\mathrm{LTB}_{4}$ synthesis in lipidosome vs the known $\mathrm{LTB}_{4}$ synthesis in the nuclear envelope is worth exploring.

Future studies could be aimed at understanding the difference between CSinduced lipidosome and the lipid bodies generated by other phagocytic particles such as MSU or microbial pathogens. We do not know if lipidosome is activated in other sterile inflammatory conditions such as gout, atherosclerosis or arthritis. If so what are the similarities and differences between CS-induced and other lipidosome. Do they also require JNK activation? Can they be targeted in a similar way? The relevance and 
implications of lipidosome in other diseases where $\mathrm{LTB}_{4}$ is an important mediator needs further understanding.

Time-lapse images revealed that lipidosome activation occurs as early as $5 \mathrm{~min}$ after CS exposure. These are dynamic structures that are constantly generated as long as CS persists in the system. However, we do not know how long these persist and whether their activation would cease once the stimulus is removed. Kinetics with E.Coli would reveal important information about the stability and dynamics of lipidosome.

Majumdar et. al describe that $\mathrm{LTB}_{4}$ is packaged in multivesicular bodies and secreted as exosomes in neutrophils in response to fMLP [229]. In their study, they observed that these multivesicular bodies were tightly associated with the nuclear membrane. They also found 5-LO, $\mathrm{LTA}_{4} \mathrm{H}$ and FLAP enzymes within the exosomes. They describe that this exosomal $\mathrm{LTB}_{4}$ is able to regulate neutrophil chemotaxis in an autocrine and paracrine manner. Secretion of $\mathrm{LTB}_{4}$ in exosomes, encapsulated in a larger multivesicular body could lead to establishment of a stable gradient and signal relay during neutrophil chemotaxis. Despite having a distinct mode of formation, lipdosome could have similar functions and implications. Given that lipidosomes are activated in response to CS exposure, these could possibly be used as a biomarker for silicosis.

This study highlights the role of JNK pathway in CS-induced $\mathrm{LTB}_{4}$ and IL-1 $\beta$ production. We demonstrated the importance of JNK activation in the production of these 
mediators using inhibitor and siRNA knockdowns. However, the direct target of JNK in this pathway remains unknown. Future experiments could be aimed at understanding why JNK activation is crucial in CS-induced lipidosome and inflammasome pathways.

The importance of lipidosome pathway and its direct implications in the progression of silicosis needs to be established. Although BI-78D3 reduced CS-induced inflammation in an air pouch model, whether it can halt/slow the progression of silicosis remains to be answered. The efficacy of BI-78D3 on lung inflammation post CSinstallation needs to be tested.

In our previous study, we have shown that BLT1 knockout mice have significantly reduced tumor burden after CS exposure. Our study here has contributed to the understanding that both lipidosome and inflammasome activation play a crucial role in CS-induced sterile inflammation. The importance of lipidosome pathway in CSinduced lung tumor promotion could be studied in BLT1-NLRP3 double knockouts or in JNK1 knockout mice. Based on our preliminary results here, we expect to see a decrease in CS-induced lung inflammation and promotion of lung tumor with the JNK inhibitor BI-78D3. ${ }^{4}$

\footnotetext{
${ }^{4}$ FUNDING SUPPORT- This work was funded by NIH and Kentucky Lung Cancer Research Project
} 


\section{REFERENCES}

1. Hamilton, R.F., Jr., S.A. Thakur, and A. Holian, Silica binding and toxicity in alveolar macrophages. Free Radic Biol Med, 2008. 44(7): p. 1246-58.

2. Lopes-Pacheco, M., E. Bandeira, and M.M. Morales, Cell-Based Therapy for Silicosis. Stem Cells Int, 2016. 2016: p. 5091838.

3. Steenland, K. and E. Ward, Silica: a lung carcinogen. CA Cancer J Clin, 2014. 64(1): p. 639.

4. "Silicosis Fact Sheet". World Health Organization. May 2000. Archived from the original on 2007-05-10. Retrieved 2007-05-29.

5. Ministry of Health of the People's Republic of China . Chinese annual health statistical report in 2009. Beijing: Ministry of Health of the People's Republic of China; 2009.

6. World Health Organization Global Occupational Health Network. Elimination of silicosis. GOHNET Newsletter 12. Geneva: World Health Organization Global Occupational Health Network; 2007.

7. Zhang, M., et al., [Analyses on the characteristics and the trends of pneumoconiosis notified between 1997 and 2009, in China]. Zhonghua Lao Dong Wei Sheng Zhi Ye Bing Za Zhi, 2013. 31(5): p. 321-34.

8. Ministry of Health of China. National occupational diseases report for 2013. (2014).

9. http://www.appalachianhistory.net/2016/02/worst-industrial-tragedy-in-wvhistory.html.

10. Linch, K.D., Respirable concrete dust--silicosis hazard in the construction industry. Appl Occup Environ Hyg, 2002. 17(3): p. 209-21.

11. https://www.osha.gov/silica/factsheets/OSHA_FS-3683_Silica_Overview.html.

12. Blackley, D.J., C.N. Halldin, and A.S. Laney, Resurgence of a debilitating and entirely preventable respiratory disease among working coal miners. Am J Respir Crit Care Med, 2014. 190(6): p. 708-9.

13. Leung, C.C., I.T. Yu, and W. Chen, Silicosis. Lancet, 2012. 379(9830): p. 2008-18.

14. Mossman, B.T. and A. Churg, Mechanisms in the pathogenesis of asbestosis and silicosis. Am J Respir Crit Care Med, 1998. 157(5 Pt 1): p. 1666-80.

15. Leung, C.C., et al., Determinants of spirometric abnormalities among silicotic patients in Hong Kong. Occup Med (Lond), 2005. 55(6): p. 490-3.

16. Rushton, L., Chronic obstructive pulmonary disease and occupational exposure to silica. Rev Environ Health, 2007. 22(4): p. 255-72. 
17. Adverse effects of crystalline silica exposure. American Thoracic Society Committee of the Scientific Assembly on Environmental and Occupational Health. Am J Respir Crit Care Med, 1997. 155(2): p. 761-8.

18. Makol, A., M.J. Reilly, and K.D. Rosenman, Prevalence of connective tissue disease in silicosis (1985-2006)-a report from the state of Michigan surveillance system for silicosis. Am J Ind Med, 2011. 54(4): p. 255-62.

19. Kurihara, N. and O. Wada, Silicosis and smoking strongly increase lung cancer risk in silica-exposed workers. Ind Health, 2004. 42(3): p. 303-14.

20. Pelucchi, C., et al., Occupational silica exposure and lung cancer risk: a review of epidemiological studies 1996-2005. Ann Oncol, 2006. 17(7): p. 1039-50.

21. Lacasse, Y., et al., Dose-response meta-analysis of silica and lung cancer. Cancer Causes Control, 2009. 20(6): p. 925-33.

22. NIOSH Hazard Review. Health Effects of Occupational Exposure to Respirable Crystalline Silica.DHHS 2002-129. pp. 23.

23. Fernandez Alvarez, R., et al., Guidelines for the diagnosis and monitoring of silicosis. Arch Bronconeumol, 2015. 51(2): p. 86-93.

24. Langley, R.J., et al., Granuloma formation induced by low-dose chronic silica inhalation is associated with an anti-apoptotic response in Lewis rats. J Toxicol Environ Health A, 2010. 73(10): p. 669-83.

25. Jr, H.M.T., Environmental Lung Disease. 2010, Tracey Maxwell.

26. Huaux, F., New developments in the understanding of immunology in silicosis. Curr Opin Allergy Clin Immunol, 2007. 7(2): p. 168-73.

27. Chen, G.Y. and G. Nunez, Sterile inflammation: sensing and reacting to damage. Nat Rev Immunol, 2010. 10(12): p. 826-37.

28. Rock, K.L., et al., The sterile inflammatory response. Annu Rev Immunol, 2010. 28: p. 321-42.

29. Joshi, G.N. and D.A. Knecht, Silica phagocytosis causes apoptosis and necrosis by different temporal and molecular pathways in alveolar macrophages. Apoptosis, 2013. 18(3): p. 271-85.

30. Thibodeau, M.S., et al., Silica-induced apoptosis in mouse alveolar macrophages is initiated by lysosomal enzyme activity. Toxicol Sci, 2004. 80(1): p. 34-48.

31. Joshi, G.N., R.M. Gilberti, and D.A. Knecht, Single Cell Analysis of Phagocytosis, Phagosome Maturation, Phagolysosomal Leakage, and Cell Death Following Exposure of Macrophages to Silica Particles. Methods Mol Biol, 2017. 1519: p. 55-77.

32. Majno, G., M. La Gattuta, and T.E. Thompson, Cellular death and necrosis: chemical, physical and morphologic changes in rat liver. Virchows Arch Pathol Anat Physiol Klin Med, 1960. 333: p. 421-65.

33. Chen, C.J., et al., Identification of a key pathway required for the sterile inflammatory response triggered by dying cells. Nat Med, 2007. 13(7): p. 851-6.

34. Sullivan, D.E., et al., TNF-alpha induces TGF-beta1 expression in lung fibroblasts at the transcriptional level via AP-1 activation. J Cell Mol Med, 2009. 13(8B): p. 1866-76. 
35. Guo, J., et al., Neutralization of interleukin-1 beta attenuates silica-induced lung inflammation and fibrosis in C57BL/6 mice. Arch Toxicol, 2013. 87(11): p. 1963-1973.

36. Rabolli, V., et al., Lung fibrosis induced by crystalline silica particles is uncoupled from lung inflammation in NMRI mice. Toxicol Lett, 2011. 203(2): p. 127-34.

37. http://www.daviddarling.info/encyclopedia/P/pneumoconiosis.html.

38. Lammermann, T., et al., Neutrophil swarms require LTB4 and integrins at sites of cell death in vivo. Nature, 2013. 498(7454): p. 371-5.

39. Costantini, L.M., R.M. Gilberti, and D.A. Knecht, The phagocytosis and toxicity of amorphous silica. PLoS One, 2011. 6(2): p. e14647.

40. Hamilton, R.F., W.J. de Villiers, and A. Holian, Class A type Il scavenger receptor mediates silica-induced apoptosis in Chinese hamster ovary cell line. Toxicol Appl Pharmacol, 2000. 162(2): p. 100-6.

41. Iyer, R., et al., Silica-induced apoptosis mediated via scavenger receptor in human alveolar macrophages. Toxicol Appl Pharmacol, 1996. 141(1): p. 84-92.

42. Kobzik, L., Lung macrophage uptake of unopsonized environmental particulates. Role of scavenger-type receptors. J Immunol, 1995. 155(1): p. 367-76.

43. Taylor, P.R., et al., Macrophage receptors and immune recognition. Annu Rev Immunol, 2005. 23: p. 901-44.

44. Srivastava, K.D., et al., Crucial role of interleukin-1beta and nitric oxide synthase in silicainduced inflammation and apoptosis in mice. Am J Respir Crit Care Med, 2002. 165(4): p. 527-33.

45. Cassel, S.L., et al., The Nalp3 inflammasome is essential for the development of silicosis. Proc Natl Acad Sci U S A, 2008. 105(26): p. 9035-40.

46. Davis, G.S., L.M. Pfeiffer, and D.R. Hemenway, Persistent overexpression of interleukin1 beta and tumor necrosis factor-alpha in murine silicosis. J Environ Pathol Toxicol Oncol, 1998. 17(2): p. 99-114.

47. Sarih, M., et al., Silica induces apoptosis in macrophages and the release of interleukin-1 alpha and interleukin-1 beta. J Leukoc Biol, 1993. 54(5): p. 407-13.

48. Ledebur, H.C. and T.P. Parks, Transcriptional regulation of the intercellular adhesion molecule-1 gene by inflammatory cytokines in human endothelial cells. Essential roles of a variant NF-kappa B site and p65 homodimers. J Biol Chem, 1995. 270(2): p. 933-43.

49. Nario, R.C. and A.K. Hubbard, Silica exposure increases expression of pulmonary intercellular adhesion molecule-1 (ICAM-1) in C57BI/6 mice. J Toxicol Environ Health, 1996. 49(6): p. 599-617.

50. Jessop, F., et al., Autophagy deficiency in macrophages enhances NLRP3 inflammasome activity and chronic lung disease following silica exposure. Toxicol Appl Pharmacol, 2016. 309: p. 101-10.

51. Cullen, S.P., et al., Diverse Activators of the NLRP3 Inflammasome Promote IL-1beta Secretion by Triggering Necrosis. Cell Rep, 2015. 11(10): p. 1535-48.

52. Yin, Y., et al., Inflammasomes: sensors of metabolic stresses for vascular inflammation. Front Biosci (Landmark Ed), 2013. 18: p. 638-49. 
53. Storek, K.M. and D.M. Monack, Bacterial recognition pathways that lead to inflammasome activation. Immunol Rev, 2015. 265(1): p. 112-29.

54. Rathinam, V.A., S.K. Vanaja, and K.A. Fitzgerald, Regulation of inflammasome signaling. Nat Immunol, 2012. 13(4): p. 333-42.

55. Hornung, V., et al., Silica crystals and aluminum salts activate the NALP3 inflammasome through phagosomal destabilization. Nat Immunol, 2008. 9(8): p. 847-56.

56. Dostert, C., et al., Innate immune activation through Nalp3 inflammasome sensing of asbestos and silica. Science, 2008. 320(5876): p. 674-7.

57. Pollard, K.M., Silica, Silicosis, and Autoimmunity. Front Immunol, 2016. 7: p. 97.

58. Sandberg, W.J., et al., Comparison of non-crystalline silica nanoparticles in IL-1beta release from macrophages. Part Fibre Toxicol, 2012. 9: p. 32.

59. Moussion, C., N. Ortega, and J.P. Girard, The IL-1-like cytokine IL-33 is constitutively expressed in the nucleus of endothelial cells and epithelial cells in vivo: a novel 'alarmin'? PLoS One, 2008. 3(10): p. e3331.

60. Rabolli, V., et al., The alarmin IL-1alpha is a master cytokine in acute lung inflammation induced by silica micro- and nanoparticles. Part Fibre Toxicol, 2014. 11: p. 69.

61. Verri, W.A., Jr., et al., IL-33 induces neutrophil migration in rheumatoid arthritis and is a target of anti-TNF therapy. Ann Rheum Dis, 2010. 69(9): p. 1697-703.

62. Cayrol, C. and J.P. Girard, The IL-1-like cytokine IL-33 is inactivated after maturation by caspase-1. Proc Natl Acad Sci U S A, 2009. 106(22): p. 9021-6.

63. Boorsma, C.E., C. Draijer, and B.N. Melgert, Macrophage heterogeneity in respiratory diseases. Mediators Inflamm, 2013. 2013: p. 769214.

64. Endo, M., et al., Induction of arginase I and II in bleomycin-induced fibrosis of mouse lung. Am J Physiol Lung Cell Mol Physiol, 2003. 285(2): p. L313-21.

65. Misson, P., et al., Markers of macrophage differentiation in experimental silicosis. J Leukoc Biol, 2004. 76(5): p. 926-32.

66. Liu, H., et al., BBC3 in macrophages promoted pulmonary fibrosis development through inducing autophagy during silicosis. Cell Death Dis, 2017. 8(3): p. e2657.

67. Liu, H., et al., Macrophage-derived MCPIP1 mediates silica-induced pulmonary fibrosis via autophagy. Part Fibre Toxicol, 2016. 13(1): p. 55.

68. Herbert, D.R., et al., Alternative macrophage activation is essential for survival during schistosomiasis and downmodulates $T$ helper 1 responses and immunopathology. Immunity, 2004. 20(5): p. 623-35.

69. Cruz, F.F., et al., Dasatinib Reduces Lung Inflammation and Fibrosis in Acute Experimental Silicosis. PLoS One, 2016. 11(1): p. e0147005.

70. Wernersson, S. and G. Pejler, Mast cell secretory granules: armed for battle. Nat Rev Immunol, 2014. 14(7): p. 478-94.

71. Shaik-Dasthagirisaheb, Y.B. and P. Conti, The Role of Mast Cells in Alzheimer's Disease. Adv Clin Exp Med, 2016. 25(4): p. 781-7.

72. Kopinski, P., et al., [Cytoimmunologic changes in material obtained from bronchoalveolar lavage (BAL) in asymptomatic individuals chronically exposed to silica dust]. Pneumonol Alergol Pol, 2000. 68(3-4): p. 109-19. 
73. Hamada, H., et al., Mast cell basic fibroblast growth factor in silicosis. Am J Respir Crit Care Med, 2000. 161(6): p. 2026-34.

74. Brown, J.M., et al., Silica-directed mast cell activation is enhanced by scavenger receptors. American Journal of Respiratory Cell and Molecular Biology, 2007. 36(1): p. 43-52.

75. Suzuki, N., et al., Mast cells are essential for the full development of silica-induced pulmonary inflammation: a study with mast cell-deficient mice. Am J Respir Cell Mol Biol, 1993. 9(5): p. 475-83.

76. Satpathy, S.R., et al., Crystalline silica-induced leukotriene B4-dependent inflammation promotes lung tumour growth. Nat Commun, 2015. 6: p. 7064.

77. Tak, T., et al., What's your age again? Determination of human neutrophil half-lives revisited. J Leukoc Biol, 2013. 94(4): p. 595-601.

78. Leliefeld, P.H., L. Koenderman, and J. Pillay, How Neutrophils Shape Adaptive Immune Responses. Front Immunol, 2015. 6: p. 471.

79. Ermert, D., et al., Candida albicans escapes from mouse neutrophils. J Leukoc Biol, 2013. 94(2): p. 223-36.

80. Brinkmann, V., et al., Neutrophil extracellular traps kill bacteria. Science, 2004. 303(5663): p. 1532-5.

81. Huang, H., et al., Damage-associated molecular pattern-activated neutrophil extracellular trap exacerbates sterile inflammatory liver injury. Hepatology, 2015. 62(2): p. 600-14.

82. Fuchs, T.A., et al., Extracellular DNA traps promote thrombosis. Proc Natl Acad Sci U S A, 2010. 107(36): p. 15880-5.

83. Chevre, R., et al., High-resolution imaging of intravascular atherogenic inflammation in live mice. Circ Res, 2014. 114(5): p. 770-9.

84. Friedman, G.D., Klatsky, A. L. \& Siegelaub, A. B. The leukocyte count as a predictor of myocardial infarction. N. Engl. J. Med. 290, 1275-1278 (1974).

85. Zenaro, E., et al., Neutrophils promote Alzheimer's disease-like pathology and cognitive decline via LFA-1 integrin. Nat Med, 2015. 21(8): p. 880-6.

86. Ng, L.G., et al., Visualizing the neutrophil response to sterile tissue injury in mouse dermis reveals a three-phase cascade of events. J Invest Dermatol, 2011. 131(10): p. 2058-68.

87. Lugano, E.M., J.H. Dauber, and R.P. Daniele, Acute experimental silicosis. Lung morphology, histology, and macrophage chemotaxin secretion. Am J Pathol, 1982. 109(1): p. 27-36.

88. Bissonnette, E. and M. Rola-Pleszczynski, Pulmonary inflammation and fibrosis in a murine model of asbestosis and silicosis. Possible role of tumor necrosis factor. Inflammation, 1989. 13(3): p. 329-39.

89. Niculescu, T. and M. Cojocaru, Demonstration of the neutrophil granulocyte functional capacity in silicosis, using the NBT test. Rom J Intern Med, 1995. 33(1-2): p. 73-6.

90. Aparoy, P., K.K. Reddy, and P. Reddanna, Structure and ligand based drug design strategies in the development of novel 5- LOX inhibitors. Curr Med Chem, 2012. 19(22): p. 3763-78. 
91. Werz, O., et al., Activation of 5-lipoxygenase by cell stress is calcium independent in human polymorphonuclear leukocytes. Blood, 2002. 99(3): p. 1044-52.

92. Liu, M. and T. Yokomizo, The role of leukotrienes in allergic diseases. Allergol Int, 2015. 64(1): p. 17-26.

93. Yokomizo, T., et al., A G-protein-coupled receptor for leukotriene B4 that mediates chemotaxis. Nature, 1997. 387(6633): p. 620-4.

94. Del Prete, A., et al., Regulation of dendritic cell migration and adaptive immune response by leukotriene B4 receptors: a role for LTB4 in up-regulation of CCR7 expression and function. Blood, 2007. 109(2): p. 626-31.

95. Miyahara, N., et al., Leukotriene B4 receptor-1 is essential for allergen-mediated recruitment of CD8+T cells and airway hyperresponsiveness. J Immunol, 2005. 174(8): p. 4979-84.

96. Steinhilber, D., et al., 5-lipoxygenase: underappreciated role of a pro-inflammatory enzyme in tumorigenesis. Front Pharmacol, 2010. 1: p. 143.

97. Woods, J.W., et al., 5-Lipoxygenase is located in the euchromatin of the nucleus in resting human alveolar macrophages and translocates to the nuclear envelope upon cell activation. J Clin Invest, 1995. 95(5): p. 2035-46.

98. Peters-Golden, M. and R.W. McNish, Redistribution of 5-lipoxygenase and cytosolic phospholipase $A 2$ to the nuclear fraction upon macrophage activation. Biochem Biophys Res Commun, 1993. 196(1): p. 147-53.

99. Luo, M., et al., Nuclear localization of 5-lipoxygenase as a determinant of leukotriene B4 synthetic capacity. Proc Natl Acad Sci U S A, 2003. 100(21): p. 12165-70.

100. Bozza, P.T., et al., Lipid body function in eicosanoid synthesis: an update. Prostaglandins Leukot Essent Fatty Acids, 2011. 85(5): p. 205-13.

101. Vieira-de-Abreu, A., et al., Allergic challenge-elicited lipid bodies compartmentalize in vivo leukotriene C4 synthesis within eosinophils. Am J Respir Cell Mol Biol, 2005. 33(3): p. 254-61.

102. Bozza, P.T., K.G. Magalhaes, and P.F. Weller, Leukocyte lipid bodies - Biogenesis and functions in inflammation. Biochim Biophys Acta, 2009. 1791(6): p. 540-51.

103. Yu, W., et al., Co-compartmentalization of MAP kinases and cytosolic phospholipase A2 at cytoplasmic arachidonate-rich lipid bodies. Am J Pathol, 1998. 152(3): p. 759-69.

104. Moreira, L.S., et al., Cytosolic phospholipase A2-driven PGE2 synthesis within unsaturated fatty acids-induced lipid bodies of epithelial cells. Biochim Biophys Acta, 2009. 1791(3): p. 156-65.

105. Accioly, M.T., et al., Lipid bodies are reservoirs of cyclooxygenase-2 and sites of prostaglandin-E2 synthesis in colon cancer cells. Cancer Res, 2008. 68(6): p. 1732-40.

106. Scarfo, L.M., P.F. Weller, and H.W. Farber, Induction of endothelial cell cytoplasmic lipid bodies during hypoxia. Am J Physiol Heart Circ Physiol, 2001. 280(1): p. H294-301.

107. Plotkowski, M.C., et al., Lipid body mobilization in the ExoU-induced release of inflammatory mediators by airway epithelial cells. Microb Pathog, 2008. 45(1): p. 30-7.

108. Dvorak, A.M., et al., Ultrastructural immunogold localization of prostaglandin endoperoxide synthase (cyclooxygenase) to non-membrane-bound cytoplasmic lipid 
bodies in human lung mast cells, alveolar macrophages, type II pneumocytes, and neutrophils. J Histochem Cytochem, 1992. 40(6): p. 759-69.

109. Montuschi, P., Role of Leukotrienes and Leukotriene Modifiers in Asthma. Pharmaceuticals (Basel), 2010. 3(6): p. 1792-1811.

110. Mathis, S., V.R. Jala, and B. Haribabu, Role of leukotriene B4 receptors in rheumatoid arthritis. Autoimmun Rev, 2007. 7(1): p. 12-7.

111. Subbarao, K., et al., Role of leukotriene B4 receptors in the development of atherosclerosis: potential mechanisms. Arterioscler Thromb Vasc Biol, 2004. 24(2): p. 369-75.

112. Liao, T., et al., Blockade of the interaction of leukotriene b4 with its receptor prevents development of autoimmune uveitis. Invest Ophthalmol Vis Sci, 2006. 47(4): p. 1543-9.

113. Kim, N.D., et al., A unique requirement for the leukotriene $B 4$ receptor $B L T 1$ for neutrophil recruitment in inflammatory arthritis. J Exp Med, 2006. 203(4): p. 829-35.

114. Knab, L.M., P.J. Grippo, and D.J. Bentrem, Involvement of eicosanoids in the pathogenesis of pancreatic cancer: the roles of cyclooxygenase-2 and 5-lipoxygenase. World J Gastroenterol, 2014. 20(31): p. 10729-39.

115. White, K.L., et al., Ovarian cancer risk associated with inherited inflammation-related variants. Cancer Res, 2012. 72(5): p. 1064-9.

116. Goodman, J.E., et al., Arachidonate lipoxygenase (ALOX) and cyclooxygenase (COX) polymorphisms and colon cancer risk. Carcinogenesis, 2004. 25(12): p. 2467-72.

117. Kleinstein, S.E., et al., Genetic variation in the lipoxygenase pathway and risk of colorectal neoplasia. Genes Chromosomes Cancer, 2013. 52(5): p. 437-49.

118. Goodman, G.B., et al., Acute silicosis responding to corticosteroid therapy. Chest, 1992. 101(2): p. 366-70.

119. Sharma, S.K., J.N. Pande, and K. Verma, Effect of prednisolone treatment in chronic silicosis. Am Rev Respir Dis, 1991. 143(4 Pt 1): p. 814-21.

120. Di Giuseppe, M., et al., Systemic inhibition of NF-kappaB activation protects from silicosis. PLoS One, 2009. 4(5): p. e5689.

121. Lassance, R.M., et al., Intratracheal instillation of bone marrow-derived cell in an experimental model of silicosis. Respir Physiol Neurobiol, 2009. 169(3): p. 227-33.

122. Morales, M.M., et al., Pilot safety study of intrabronchial instillation of bone marrowderived mononuclear cells in patients with silicosis. BMC Pulm Med, 2015. 15: p. 66.

123. Liu, W.W., et al., Treatment of silicosis with hepatocyte growth factor-modified autologous bone marrow stromal cells: a non-randomized study with follow-up. Genet Mol Res, 2015. 14(3): p. 10672-81.

124. International Agency for Research on Cancer. World cancer report, 2014. Lyon, France: World Health Organization, International Agency for Research on Cancer; 2014. http://publications.iarc.fr/Non-Series-Publications/World-Cancer-Reports/WorldCancer-Report-2014.

125. Siegel RL, Miller KD, Jemal A. Cancer Statistics, 2016. CA: A Cancer Journal for Clinicians. 2016; 66:7-30. 
126. Brown, T., Silica exposure, smoking, silicosis and lung cancer--complex interactions. Occup Med (Lond), 2009. 59(2): p. 89-95.

127. Poinen-Rughooputh, S., et al., Occupational exposure to silica dust and risk of lung cancer: an updated meta-analysis of epidemiological studies. BMC Public Health, 2016. 16(1): p. 1137.

128. Colotta, F., et al., Cancer-related inflammation, the seventh hallmark of cancer: links to genetic instability. Carcinogenesis, 2009. 30(7): p. 1073-81.

129. Hanahan, D. and R.A. Weinberg, Hallmarks of cancer: the next generation. Cell, 2011. 144(5): p. 646-74.

130. Cavallo, F., et al., 2011: the immune hallmarks of cancer. Cancer Immunol Immunother, 2011. 60(3): p. 319-26.

131. Coussens, L.M. and Z. Werb, Inflammation and cancer. Nature, 2002. 420(6917): p. 8607.

132. Houghton, A.M., et al., Neutrophil elastase-mediated degradation of IRS-1 accelerates lung tumor growth. Nat Med, 2010. 16(2): p. 219-23.

133. Fridlender, Z.G. and S.M. Albelda, Tumor-associated neutrophils: friend or foe? Carcinogenesis, 2012. 33(5): p. 949-55.

134. Fridlender, Z.G., et al., Polarization of tumor-associated neutrophil phenotype by TGFbeta: "N1" versus "N2" TAN. Cancer Cell, 2009. 16(3): p. 183-94.

135. Eruslanov, E.B., et al., Tumor-associated neutrophils stimulate $T$ cell responses in earlystage human lung cancer. J Clin Invest, 2014. 124(12): p. 5466-80.

136. Gregory, A.D. and A.M. Houghton, Tumor-associated neutrophils: new targets for cancer therapy. Cancer Res, 2011. 71(7): p. 2411-6.

137. Kao, S.C., et al., High blood neutrophil-to-lymphocyte ratio is an indicator of poor prognosis in malignant mesothelioma patients undergoing systemic therapy. Clin Cancer Res, 2010. 16(23): p. 5805-13.

138. Linton, A., et al., Inflammation in malignant mesothelioma - friend or foe? Ann Cardiothorac Surg, 2012. 1(4): p. 516-22.

139. Chen, N., et al., Prognostic significance of neutrophil-to-lymphocyte ratio in patients with malignant pleural mesothelioma: a meta-analysis. Oncotarget, 2017. 8(34): p. 5746057469.

140. Pelclova, D., et al., Leukotrienes in exhaled breath condensate and fractional exhaled nitric oxide in workers exposed to TiO2 nanoparticles. J Breath Res, 2016. 10(3): p. 036004.

141. Huotari, J. and A. Helenius, Endosome maturation. EMBO J, 2011. 30(17): p. 3481-500.

142. Bergsbaken, T., S.L. Fink, and B.T. Cookson, Pyroptosis: host cell death and inflammation. Nat Rev Microbiol, 2009. 7(2): p. 99-109.

143. Vande Walle, L. and M. Lamkanfi, Pyroptosis. Curr Biol, 2016. 26(13): p. R568-72.

144. Labbé K., S.M., The Inflammasomes. Progress in Inflammation Research. Pyroptosis: A Caspase-1-Dependent Programmed Cell Death and a Barrier to Infection. 2011: Springer, Basel. 
145. Yoshimori, T., et al., Bafilomycin A1, a specific inhibitor of vacuolar-type H(+)-ATPase, inhibits acidification and protein degradation in lysosomes of cultured cells. J Biol Chem, 1991. 266(26): p. 17707-12.

146. Gilberti, R.M., G.N. Joshi, and D.A. Knecht, The phagocytosis of crystalline silica particles by macrophages. Am J Respir Cell Mol Biol, 2008. 39(5): p. 619-27.

147. Beamer, C.A. and A. Holian, Scavenger receptor class A type I/II (CD204) null mice fail to develop fibrosis following silica exposure. Am J Physiol Lung Cell Mol Physiol, 2005. 289(2): p. L186-95.

148. Hamilton, R.F., Jr., et al., MARCO mediates silica uptake and toxicity in alveolar macrophages from C57BL/6 mice. J Biol Chem, 2006. 281(45): p. 34218-26.

149. Rejman, J., et al., Size-dependent internalization of particles via the pathways of clathrinand caveolae-mediated endocytosis. Biochem J, 2004. 377(Pt 1): p. 159-69.

150. Rejman, J., A. Bragonzi, and M. Conese, Role of clathrin- and caveolae-mediated endocytosis in gene transfer mediated by lipo- and polyplexes. Mol Ther, 2005. 12(3): p. 468-74.

151. Jessop, F., et al., Phagolysosome acidification is required for silica and engineered nanoparticle-induced lysosome membrane permeabilization and resultant NLRP3 inflammasome activity. Toxicol Appl Pharmacol, 2017. 318: p. 58-68.

152. Bozza, P.T., R.C. Melo, and C. Bandeira-Melo, Leukocyte lipid bodies regulation and function: contribution to allergy and host defense. Pharmacol Ther, 2007. 113(1): p. 3049.

153. Tauchi-Sato, K., et al., The surface of lipid droplets is a phospholipid monolayer with a unique Fatty Acid composition. J Biol Chem, 2002. 277(46): p. 44507-12.

154. Guo, Y., et al., Lipid droplets at a glance. J Cell Sci, 2009. 122(Pt 6): p. 749-52.

155. Thiam, A.R., R.V. Farese, Jr., and T.C. Walther, The biophysics and cell biology of lipid droplets. Nat Rev Mol Cell Biol, 2013. 14(12): p. 775-86.

156. Bartz, R., et al., Lipidomics reveals that adiposomes store ether lipids and mediate phospholipid traffic. J Lipid Res, 2007. 48(4): p. 837-47.

157. Walther, T.C. and R.V. Farese, Jr., Lipid droplets and cellular lipid metabolism. Annu Rev Biochem, 2012. 81: p. 687-714.

158. Tzen, J.T. and A.H. Huang, Surface structure and properties of plant seed oil bodies. J Cell Biol, 1992. 117(2): p. 327-35.

159. Konige, M., H. Wang, and C. Sztalryd, Role of adipose specific lipid droplet proteins in maintaining whole body energy homeostasis. Biochim Biophys Acta, 2014. 1842(3): p. 393-401.

160. Le Lay, S. and I. Dugail, Connecting lipid droplet biology and the metabolic syndrome. Prog Lipid Res, 2009. 48(3-4): p. 191-5.

161. Weller, P.F., Leukocyte Lipid Bodies - Structure and Function as "Eicosasomes". Trans Am Clin Climatol Assoc, 2016. 127: p. 328-340.

162. Onal, G., et al., Lipid Droplets in Health and Disease. Lipids Health Dis, 2017. 16(1): p. 128. 
163. Czaja, M.J., Function of Autophagy in Nonalcoholic Fatty Liver Disease. Dig Dis Sci, 2016. 61(5): p. 1304-13.

164. Ost, A., et al., Attenuated mTOR signaling and enhanced autophagy in adipocytes from obese patients with type 2 diabetes. Mol Med, 2010. 16(7-8): p. 235-46.

165. Hubler, M.J. and A.J. Kennedy, Role of lipids in the metabolism and activation of immune cells. J Nutr Biochem, 2016. 34: p. 1-7.

166. Xu, X., et al., Obesity activates a program of lysosomal-dependent lipid metabolism in adipose tissue macrophages independently of classic activation. Cell Metab, 2013. 18(6): p. 816-30.

167. Larigauderie, G., et al., Adipophilin enhances lipid accumulation and prevents lipid efflux from THP-1 macrophages: potential role in atherogenesis. Arterioscler Thromb Vasc Biol, 2004. 24(3): p. 504-10.

168. Wilfling, F., et al., Lipid droplet biogenesis. Curr Opin Cell Biol, 2014. 29: p. 39-45.

169. Gao, Q. and J.M. Goodman, The lipid droplet-a well-connected organelle. Front Cell Dev Biol, 2015. 3: p. 49.

170. Fujimoto, T. and R.G. Parton, Not just fat: the structure and function of the lipid droplet. Cold Spring Harb Perspect Biol, 2011. 3(3).

171. van Manen, H.J., et al., Single-cell Raman and fluorescence microscopy reveal the association of lipid bodies with phagosomes in leukocytes. Proc Natl Acad Sci U S A, 2005. 102(29): p. 10159-64.

172. Murphy, D.J. and J. Vance, Mechanisms of lipid-body formation. Trends Biochem Sci, 1999. 24(3): p. 109-15.

173. Tan, R., et al., Small GTPase Rab40c associates with lipid droplets and modulates the biogenesis of lipid droplets. PLoS One, 2013. 8(4): p. e63213.

174. Liu, P., et al., Rab-regulated interaction of early endosomes with lipid droplets. Biochim Biophys Acta, 2007. 1773(6): p. 784-93.

175. Sollner, T.H., Lipid droplets highjack SNAREs. Nat Cell Biol, 2007. 9(11): p. 1219-20.

176. Bickel, P.E., J.T. Tansey, and M.A. Welte, PAT proteins, an ancient family of lipid droplet proteins that regulate cellular lipid stores. Biochim Biophys Acta, 2009. 1791(6): p. 41940.

177. Wolins, N.E., et al., Adipocyte protein S3-12 coats nascent lipid droplets. J Biol Chem, 2003. 278(39): p. 37713-21.

178. Wolins, N.E., et al., OXPAT/PAT-1 is a PPAR-induced lipid droplet protein that promotes fatty acid utilization. Diabetes, 2006. 55(12): p. 3418-28.

179. Kimmel, A.R., et al., Adoption of PERILIPIN as a unifying nomenclature for the mammalian PAT-family of intracellular lipid storage droplet proteins. J Lipid Res, 2010. 51(3): p. 468-71.

180. Wolins, N.E., D.L. Brasaemle, and P.E. Bickel, A proposed model of fat packaging by exchangeable lipid droplet proteins. FEBS Lett, 2006. 580(23): p. 5484-91.

181. Skinner, J.R., et al., Diacylglycerol enrichment of endoplasmic reticulum or lipid droplets recruits perilipin 3/TIP47 during lipid storage and mobilization. J Biol Chem, 2009.

284(45): p. 30941-8. 
182. Bozza, P.T., et al., Pathways for eosinophil lipid body induction: differing signal transduction in cells from normal and hypereosinophilic subjects. J Leukoc Biol, 1998. 64(4): p. 563-9.

183. Bozza, P.T., et al., Mechanisms of platelet-activating factor-induced lipid body formation: requisite roles for 5-lipoxygenase and de novo protein synthesis in the compartmentalization of neutrophil lipids. J Exp Med, 1996. 183(4): p. 1515-25.

184. Wilfling, F., et al., Triacylglycerol synthesis enzymes mediate lipid droplet growth by relocalizing from the ER to lipid droplets. Dev Cell, 2013. 24(4): p. 384-99.

185. Khandelia, H., et al., Triglyceride blisters in lipid bilayers: implications for lipid droplet biogenesis and the mobile lipid signal in cancer cell membranes. PLoS One, 2010. 5(9): p. e12811.

186. Mandal, A.K., et al., The nuclear membrane organization of leukotriene synthesis. Proc Natl Acad Sci U S A, 2008. 105(51): p. 20434-9.

187. Kulkarni, S., et al., Molecular basis of the specific subcellular localization of the C2-like domain of 5-lipoxygenase. J Biol Chem, 2002. 277(15): p. 13167-74.

188. Pacheco, P., et al., Monocyte chemoattractant protein-1/CC chemokine ligand 2 controls microtubule-driven biogenesis and leukotriene B4-synthesizing function of macrophage lipid bodies elicited by innate immune response. J Immunol, 2007. 179(12): p. 8500-8.

189. Weller, P.F. and A.M. Dvorak, Arachidonic acid incorporation by cytoplasmic lipid bodies of human eosinophils. Blood, 1985. 65(5): p. 1269-74.

190. Arrese, E.L., F.Z. Saudale, and J.L. Soulages, Lipid Droplets as Signaling Platforms Linking Metabolic and Cellular Functions. Lipid Insights, 2014. 7: p. 7-16.

191. Melo, R.C. and A.M. Dvorak, Lipid body-phagosome interaction in macrophages during infectious diseases: host defense or pathogen survival strategy? PLoS Pathog, 2012. 8(7): p. e1002729.

192. Bozza, P.T. and J.P. Viola, Lipid droplets in inflammation and cancer. Prostaglandins Leukot Essent Fatty Acids, 2010. 82(4-6): p. 243-50.

193. Weinstein, J., Synovial fluid leukocytosis associated with intracellular lipid inclusions. Arch Intern Med, 1980. 140(4): p. 560-1.

194. Robenek, M.J., et al., Lipids partition caveolin-1 from ER membranes into lipid droplets: updating the model of lipid droplet biogenesis. FASEB J, 2004. 18(7): p. 866-8.

195. Kiss, R.S. and T. Nilsson, Rab proteins implicated in lipid storage and mobilization. J Biomed Res, 2014. 28(3): p. 169-77.

196. Ozeki, S., et al., Rab18 localizes to lipid droplets and induces their close apposition to the endoplasmic reticulum-derived membrane. J Cell Sci, 2005. 118(Pt 12): p. 2601-11.

197. Martin, S. and R.G. Parton, Characterization of Rab18, a lipid droplet-associated small GTPase. Methods Enzymol, 2008. 438: p. 109-29.

198. Martin, S., et al., Regulated localization of Rab18 to lipid droplets: effects of lipolytic stimulation and inhibition of lipid droplet catabolism. J Biol Chem, 2005. 280(51): p. 42325-35. 
199. Holian, A., K. Kelley, and R.F. Hamilton, Jr., Mechanisms associated with human alveolar macrophage stimulation by particulates. Environ Health Perspect, 1994. 102 Suppl 10: p. 69-74.

200. Tomaru, M. and M. Matsuoka, The role of mitogen-activated protein kinases in crystalline silica-induced cyclooxygenase-2 expression in A549 human lung epithelial cells. Toxicol Mech Methods, 2011. 21(7): p. 513-9.

201. Li, X., et al., Silica-induced TNF-alpha and TGF-beta1 expression in RAW264.7 cells are dependent on Src-ERK/AP-1 pathways. Toxicol Mech Methods, 2009. 19(1): p. 51-8.

202. Kim, K.J., et al., Silica nanoparticles increase human adipose tissue-derived stem cell proliferation through ERK1/2 activation. Int J Nanomedicine, 2015. 10: p. 2261-72.

203. Li, Y., et al., MAP kinase mediates silica-induced fibrotic nodule formation and collagen accumulation in fibroblasts. J Cell Physiol, 2012. 227(1): p. 328-38.

204. Kang, J.L., et al., Src tyrosine kinases mediate crystalline silica-induced NF-kappaB activation through tyrosine phosphorylation of IkappaB-alpha and p65 NF-kappaB in RAW 264.7 macrophages. Toxicol Sci, 2006. 90(2): p. 470-7.

205. Kang, Y.J., et al., Regulation of intracellular cyclooxygenase levels by gene transcription and protein degradation. Prog Lipid Res, 2007. 46(2): p. 108-25.

206. Chun, K.S. and Y.J. Surh, Signal transduction pathways regulating cyclooxygenase-2 expression: potential molecular targets for chemoprevention. Biochem Pharmacol, 2004. 68(6): p. 1089-100.

207. Martin, S.W., et al., The six-day-old rat air pouch model of inflammation: characterization of the inflammatory response to carrageenan. J Pharmacol Toxicol Methods, 1994. 32(3): p. 139-47.

208. Romano, M., et al., Carrageenan-induced acute inflammation in the mouse air pouch synovial model. Role of tumour necrosis factor. Mediators Inflamm, 1997. 6(1): p. 32-8.

209. Cavalli, G., et al., Treating pulmonary silicosis by blocking interleukin 1. Am J Respir Crit Care Med, 2015. 191(5): p. 596-8.

210. Bhatt, L., et al., Recent advances in clinical development of leukotriene B4 pathway drugs. Semin Immunol, 2017. 33: p. 65-73.

211. Manning, A.M. and R.J. Davis, Targeting JNK for therapeutic benefit: from junk to gold? Nat Rev Drug Discov, 2003. 2(7): p. 554-65.

212. Seki, E., D.A. Brenner, and M. Karin, A liver full of JNK: signaling in regulation of cell function and disease pathogenesis, and clinical approaches. Gastroenterology, 2012. 143(2): p. 307-20.

213. Sakurai, T., et al., Loss of hepatic NF-kappa B activity enhances chemical hepatocarcinogenesis through sustained c-Jun $N$-terminal kinase 1 activation. Proc Natl Acad Sci U S A, 2006. 103(28): p. 10544-51.

214. Li, J.Y., et al., Constitutive activation of c-Jun N-terminal kinase correlates with histologic grade and EGFR expression in diffuse gliomas. J Neurooncol, 2008. 88(1): p. 11-7.

215. Cui, J., et al., Basal c-Jun NH2-terminal protein kinase activity is essential for survival and proliferation of T-cell acute lymphoblastic leukemia cells. Mol Cancer Ther, 2009. 8(12): p. 3214-22. 
216. Hideshima, T., et al., Biologic sequelae of c-Jun NH(2)-terminal kinase (JNK) activation in multiple myeloma cell lines. Oncogene, 2003. 22(54): p. 8797-801.

217. Hess, P., et al., Survival signaling mediated by c-Jun NH(2)-terminal kinase in transformed B lymphoblasts. Nat Genet, 2002. 32(1): p. 201-5.

218. Takahashi, H., et al., Tobacco smoke promotes lung tumorigenesis by triggering IKKbetaand JNK1-dependent inflammation. Cancer Cell, 2010. 17(1): p. 89-97.

219. Mercer, B.A. and J.M. D'Armiento, Emerging role of MAP kinase pathways as therapeutic targets in COPD. Int J Chron Obstruct Pulmon Dis, 2006. 1(2): p. 137-50.

220. Flight, M.H., Getting rid of JNK. Nature Reviews Drug Discovery, 2008. 7: p. 975.

221. Stebbins, J.L., et al., Identification of a new JNK inhibitor targeting the JNK-JIP interaction site. Proc Natl Acad Sci U S A, 2008. 105(43): p. 16809-13.

222. Kaneto, H., et al., Possible novel therapy for diabetes with cell-permeable JNK-inhibitory peptide. Nat Med, 2004. 10(10): p. 1128-32.

223. Casas, J., et al., Requirement of JNK-mediated phosphorylation for translocation of group IVA phospholipase A2 to phagosomes in human macrophages. J Immunol, 2009. 183(4): p. 2767-74.

224. Van Putten, V., et al., Induction of cytosolic phospholipase A2 by oncogenic Ras is mediated through the JNK and ERK pathways in rat epithelial cells. J Biol Chem, 2001. 276(2): p. 1226-32.

225. Guijas, C., et al., Simultaneous activation of $p 38$ and JNK by arachidonic acid stimulates the cytosolic phospholipase A2-dependent synthesis of lipid droplets in human monocytes. J Lipid Res, 2012. 53(11): p. 2343-54.

226. Gubern, A., et al., JNK and ceramide kinase govern the biogenesis of lipid droplets through activation of group IVA phospholipase A2. J Biol Chem, 2009. 284(47): p. 3235969.

227. Okada, M., et al., The lysosome rupture-activated TAK1-JNK pathway regulates NLRP3 inflammasome activation. J Biol Chem, 2014. 289(47): p. 32926-36.

228. Blackley, D.J., et al., Resurgence of Progressive Massive Fibrosis in Coal Miners - Eastern Kentucky, 2016. MMWR Morb Mortal Wkly Rep, 2016. 65(49): p. 1385-1389.

229. Majumdar, R., A. Tavakoli Tameh, and C.A. Parent, Exosomes Mediate LTB4 Release during Neutrophil Chemotaxis. PLoS Biol, 2016. 14(1): p. e1002336. 
APPENDIX

ABBREVIATIONS

1. $\mathrm{CS}$

2. LTB4

3. IL

4. 5-LO

5. FLAP

6. $\mathrm{LTA}_{4} \mathrm{H}$

7. NLRP3

8. JNK

9. OSHA

10. NIOSH

11. $\mathrm{PMF}$

12. ROS

13. TGF $\beta$

14. $\mathrm{TNF} \alpha$

15. SR

16. MARCO

17. LDL

18. MSU
Crystalline Silica

Leukotriene B4

Interleukin

5-Lipoxygenase

5-Lipoxygenase Activating Protein

Leukotriene A4 Hydrolase

NOD-Like Receptor family Pyrin domain containing 3

c-Jun N-terminal Kinases

Occupational Safety and Health Administration

National Institute for Occupational Safety and Health

Progressive Massive Fibrosis

Reactive Oxygen Species

Transforming Growth Factor beta

Tumor Necrosis Factor alpha

Scavenger Receptor

Macrophage Receptor with Collagenous structure

Low-Density Lipoprotein

Mono-Sodium Urate crystals 
19. TLR

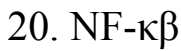

21. PRR

22. PAMP

23. DAMP

24. NOS

25. bFGF

26. IFN

27. NET

28. c-pLA2

29. AA

30. COX

31. LOX

32. EPOX

33. LT

34. CysLT

35. NSAID

36. COPD

37. IARC

38. TAN

39. NLR
Toll-Like Receptors

Nuclear Factor kappa beta

Pattern Recognition Receptor

Pathogen-Associated Molecular Pattern

Damage-Associated Molecular Pattern

Nitric Oxide Synthase

Basic Fibroblast Growth Factor

Interferon

Neutrophil Extracellular Traps

cytosolic Phospholipase 2

Arachidonic Acid

Cyclooxygenase

Lipoxygenase

Epoxygenase

Leukotrienes

Cysteinyl Leukotrienes

Non-Steroidal Anti-Inflammatory Drugs

Chronic Obstructive Pulmonary Disease

International Agency for Research on Cancer

Tumor-Associated Neutrophils

Neutrophil-Lymphocyte ratio 
40. IACUC

41. WT

42. DMEM

43. FBS

44. LPS

45. BMDM

46. BODIPY

sindacene

47. DAPI

48. BSA

49. PBS

50. EE

51. LE

52. ADRP

53. $\mathrm{CPZ}$

54. MAPK
Institutional Animal Care and Use Committee

Wild Type

Dulbeco's Modified Eagle Medium

Fetal Bovine Serum

Lipopolysaccharide

Bone Marrow Derived Macrophages

4,4-difluoro-1,3,5,7,8-pentamethyl-4-bora-3a,4a-diaza-

4',6-Diamidino-2-Phenylindole, Dihydrochloride

Bovine Serum Albumin

Phosphate Buffered Saline

Early Endosomes

Late Endosomes

Adipose differentiation related protein

Chlorpromazine

Mitogen-Activated Protein Kinase 


\title{
CURRICULUM VITAE
}

\author{
Bindu Hegde
}

binduhegde@gmail.com

$502-292-7404$

\section{EDUCATION}

Ph.D. in Microbiology and Immunology, University of Louisville, USA

2012-Present

MS in Medical Biotechnology, Manipal University, India

2006-2008

BS in Biotechnology, Manipal University, India

2003-2006

\section{RESEARCH EXPERIENCE}

\section{University of Louisville, School of Medicine. (August 2012 to present)}

PhD candidate, Microbiology and Immunology Department, Louisville, KY, USA.

"Leukotriene B4 Induced Sterile Inflammation by Crystalline Silica"

- Performed ex-vivo studies to understand the cellular mechanisms activated in crystalline silica-induced sterile inflammation

- Tested the efficacy of select inhibitors in silica-induced sterile inflammation model

- Trained and supervised summer trainees in basic cell culture and immunology techniques

- Studies led to the discovery of an inflammasome independent "lipidosome" pathway, that drives crystalline silica mediated $\mathrm{LTB}_{4}$ production

\section{Piramal Life Sciences Ltd. (August 2008 to June 2012)}

Research Associate, High Throughput Screening, Mumbai, India

- Screened a library consisting of $\sim 50,000$ natural products and synthetic compounds for antiinflammatory activity

- Performed extensive studies using physiologically relevant cells like hPBMCs and synovial cells to elucidate the mechanism of action of the potential lead anti-inflammatory agents 
- Standardized cell based and enzymatic assays for screening of compounds on antiinflammatory targets

- Gained experience in handling automated workstation (Tecan Freedom EVO), script designing and database management

- Trained and supervised new inductees in conducting experiments and in the use of various laboratory instruments

- Planned purchase of laboratory consumables and equipment

- Gained proficiency in working independently as well as in a team

$-$

Piramal Life Sciences Ltd. (October 2007 - June 2008)

Project Trainee, High Throughput Screening, Mumbai, India

"Transcriptional Analysis of Human Monocytes in Response to Specific Anti-inflammatory Agents"

- Screened a library of natural products for their anti-inflammatory activity by evaluating inhibition of TNF- $\alpha$, IL- 6 and IL-2 using ELISA

- Elucidated the molecular mechanism involved in the immunosuppressive effect of an active lead compound using qRT-PCR

$-$

\section{Manipal Life Sciences Centre (February 2006- June 2006)}

Project Trainee, Manipal Life Sciences Centre, Manipal, India

"Cytogenetic and molecular analysis of congenital cataract"

- Screened for mutations in the amplified region of the crystallin genes using PCR

- Carried out karyotyping of blood samples to detect chromosomal abnormalities in cataract patients

- Performed pedigree analysis using information about familial history of the patients to understand the pattern of inheritance of the disease

- Studies led to the discovery of a novel human mutation in the gamma-D crystallin gene responsible for juvenile autosomal dominant cataract 


\section{SPECIALISED SKILLS}

\begin{tabular}{|c|c|c|}
\hline $\begin{array}{l}\text { Immunology Techniques } \\
\text { - } \quad \text { ELISA } \\
\text { - } \quad \text { Multicolor flow cytometry } \\
\text { - Immunohistochemistry } \\
\text { - } \quad \text { Confocal microscopy }\end{array}$ & $\begin{array}{l}\text { Molecular Biology Techniques } \\
\text { - } \quad \text { QRT-PCR } \\
\text { - } \text { SDS-PAGE and Western } \\
\text { blotting } \\
\text { - } \quad \text { Karyotyping and various } \\
\text { banding techniques } \\
\text { - Cloning and transfection }\end{array}$ & $\begin{array}{l}\text { In-vivo Techniques } \\
\text { - Mouse colony } \\
\text { maintenance } \\
\text { - Experience with } \\
\text { lung cancer model, } \\
\text { orthotopic tumor } \\
\text { model }\end{array}$ \\
\hline $\begin{array}{l}\text { Cell Biology Techniques } \\
\text { - Mammalian cell culture } \\
\text { - Subset isolation of } \\
\text { leukocytes from peripheral } \\
\text { blood } \\
\text { - } \quad \text { Isolation of cells from } \\
\text { synovial tissue } \\
\text { - Cytotoxicity assays, } \\
\text { Proliferation assays }\end{array}$ & $\begin{array}{l}\text { Software tools } \\
\text { - } \quad \text { Bioinformatics tools like } \\
\text { BLAST } \\
\text { - } \text { Primer designing } \\
\text { - } \text { Graph-Pad Prism } \\
\text { - } \quad \text { FlowJo } \\
\text { - } \text { Automated workstation } \\
\text { (Tecan Freedom EVO) script } \\
\text { designing }\end{array}$ & $\begin{array}{l}\text { - Tumor } \\
\text { measurements }\end{array}$ \\
\hline
\end{tabular}

\section{PATENT APPLICATIONS}

\section{WO/2016/020724. Sphaeranthus indicus composition as IL-17 inhibitor and uses thereof:}

The present invention relates to herbal composition comprising an extract of the flowering and fruiting heads of the plant Sphaeranthus indicus as interleukin-17 (IL-17) inhibitor. Further, the invention relates to the use of the said herbal composition for the treatment of disorders mediated by IL-17.

\section{PUBLICATIONS}

- Hegde B, Bodduluri SR, Satpathy SR, Alghsham RS, Jala VR, Uriarte SM, Chen D, Lawrenz MB, Haribabu B. Inflammasome independent leukotriene-B4 production drives crystalline silica induced sterile inflammation. J Immunol. 2018 Apr 2. pii: ji1701504. doi: 10.4049/jimmunol.1701504. [Epub ahead of print] 
- Kulkarni-Almeida A, Shah M, Jadhav M, Hegde B, Trivedi J, Mishra PD, Mahajan GB, Dadarkar S, Gupte R, Dagia N. A semi-synthetic natural product blocks collagen induced arthritis by preferentially suppressing the production of IL-6. Int Immunopharmacol. 2016 Apr;33:63-9. doi: 10.1016/j.intimp.2016.01.001. Epub 2016 Feb 9. PubMed PMID: 26869203.

- Satpathy SR, Jala VR, Bodduluri SR, Krishnan E, Hegde B, Hoyle GW, Fraig M, Luster AD, Haribabu B. Crystalline silica-induced leukotriene B4-dependent inflammation promotes lung tumour growth. Nat Commun. 2015 Apr 29;6:7064. doi: 10.1038/ncomms8064. PubMed PMID: 25923988; PubMed Central PMCID: PMC4418220.

- Saklani A, Hegde B, Mishra P, Singh R, Mendon M, Chakrabarty D, Kamath DV, Lobo A, Mishra PD, Dagia NM, Padigaru M, Kulkarni-Almeida AA. NF-KB dependent antiinflammatory activity of chlorojanerin isolated from Saussurea heteromalla. Phytomedicine. 2012 Aug 15;19(11):988-97. doi: 10.1016/j.phymed.2012.05.016. Epub 2012 Jul 3. PubMed PMID: 22762939.

- Hegde B, Vadnal P, Sanghavi J, Korde V, Kulkarni-Almeida AA, Dagia NM. Vitamin E is a MIF Inhibitor. Biochem Biophys Res Commun. 2012 Feb 10;418(2):384-9. doi: 10.1016/j.bbrc.2012.01.031. Epub 2012 Jan 18. PubMed PMID: 22281490.

\section{MANUSCRIPTS UNDER PREPARATION}

- Singh R, Chandrashekharappa S, Bodduluri SR, Baby BV, Hegde B, Kotla GN, Hiwale AA, Saiyed T, Patel P, Kumar MV, Langille MGI, Douglas GM, Dryden GW, Alatassi $H$, Zhang $H$, Haribabu B, Vemula PK, Jala VR. Microbial metabolite. Urolithin A enhances gut barrier function through AhR pathway. Nat Commun.

- Alghsham RS, Bodduluri SR, Satpathy SR, Hegde B, Jala VR, Sunkara M, Haribabu B. Activation of distinct inflammatory pathways by Zinc oxide Nanowires. Journal of Particle and fiber toxicology.

- Burlison JA, Hedge B, Jala VR, Haribabu B, Trent JO. The Discovery and Structure-Activity Relationship Studies of 3-(1-(2-Fluorobenzyl)-1H-indol-3-yl)-N-(pyridin-3-ylmethyl) propanamide, a BLT1 Agonist for the Treatment of Cancer. 


\section{POSTER PRESENTATIONS}

- Hegde B, Satpathy SR., et. al. Inflammasome Independent $\mathrm{LTB}_{4}$ Production Drives Crystalline Silica Induced Sterile Inflammation. AAI2017, Washington D.C., USA, May2017

- Hegde B, Satpathy $S R$, et. al. Inflammasome Independent $\mathrm{LTB}_{4}$ Production Drives Crystalline Silica Induced Sterile Inflammation. Research! Louisville2016, Louisville, USA, September 2016

- Hegde B, Satpathy SR, et. al. Role of Phagocytosis Pathway in Crystalline Silica Induced LeukotrieneB4 Production. Research! Louisville2015, Louisville, USA, October 2015

- Hegde B, Vadnal P, et. al. Vitamin E is a Potent MIF Inhibitor. 5th Congress of the Federation of Immunological Societies of Asia-Oceania, Delhi, March 2012

- Hegde B, Saklani A, et. al. Chlorojanerin - an interesting natural compound from Sausurrea heteromalla with anti-inflammatory activity. SBCI Conference, IISC, Bangalore, India, December 2010

- Hegde B, Dias C A, et. Al. Th17 cell inhibition by lapatinib - implications for the treatment of inflammatory diseases. SBCI Conference, IISc, Bangalore, India, December 2010

\section{CERTIFICATIONS}

- Introduction to the Principles and Practice of Clinical Research (IPPCR) by NIH, April. 2016

- Scientific Writing by Stanford Online, Sept. 2015

- Health in Numbers: Quantitative Methods in Clinical \& Public Health Research by HarvardX, Feb. 2013

- Fundamentals of Clinical Trials by HarvardX, Feb. 2013

\section{AWARDS AND RECOGNITION}

- 2017 AAI Trainee Poster Award (May 2017)

- GSC travel scholarship (April 2017)

- Served as a Graduate Student Ambassador for the School of Interdisciplinary and Graduate Studies, University of Louisville 2016-2017

- Integrated Program in Biomedical Sciences Fellowship - 2012-2014

- Award for dedication and excellence exhibited for scientific support at Piramal Life Sciences Ltd, Mumbai (Nov 2010) 